\title{
Proceedings of the British Thoracic Society
}

The 1985 summer meeting of the British Thoracic Society was held on 3-5 July at the University of York

\begin{abstract}
Asthma and indoor mould exposure
ML BURR, J MULLINS, TG MERRET, NCH STOTT MRC Epidemiology Unit, Cardiff; Sully Hospital, Penarth; RAST Allergy Unit, Benenden; Ely Surgery, Cardiff Asthmatics aged 15-60 years, currently receiving treatment, were identified from a register maintained by a group practice in Cardiff. Seventy-two patients were identified and may be taken to represent the spectrum of treated asthma in the community. Each patient was matched with a control, of the same age and sex, registered with the same general practitioners. Patients and controls were investigated for evidence of allergy to moulds and other allergens. Nineteen of the asthmatics $(26 \%)$ and nine of the controls $(12.5 \%)$ reported visible mould on the inside walls of their homes. The commonest moulds found in the asthmatics' houses were Penicillium (13 asthmatics), Cladosporium (12), Stemphyllium (5), and Cephalosporium (4); seven other moulds were also found. Eight asthmatics and one control had a positive skin test reaction (weal $3 \mathrm{~mm}$ or more) to one of five moulds. IgE antibodies to common moulds were found (with RAST assay) much more frequently in the asthmatics than in the controls, often to the same moulds that were found in the corresponding houses. Exposure to visible indoor mould may be a contributory factor to the disease in a proportion of asthmatics.
\end{abstract}

What are the symptoms of asthma and their importance?

CMB higgs, P JONES, AR TANSER, G LASZlo Chest Unit, Royal United Hospital, Bath In outpatient studies of asthma it is usual to record a standard set of symptoms cough $(C)$, wheeze $(W)$, tightness $(T)$, breathlessness $(B) \pm$ nocturnal waking $(\mathrm{N})$, limitation of daily activity (A). But are these the symptoms of asthma, are they what patients use to judge the severity of their asthma, and does each symptom increase as asthma worsens? Fifty-six patients with asthma ( 31 male), aged 18-74 years, were asked, "What symptoms do you experience with your asthma?" and "Which do you use to judge the severity of your asthma?" They were then asked specifically whether they experienced and used for assessment $C, W, T, B$, and chest/back pain $(P)$. The occurence of symptoms was $B$
$95 \%$, W $88 \%$, T $86 \%$, C $48 \%$, P $36 \%$, A $16 \%$, N $13 \%$ plus others (panic $11 \%$, sputum 7\%). The symptoms used to judge asthma were B 75\%, T 70\%, W 52\%, C 30\%, P $30 \%$, A $16 \%, \mathrm{~N} 13 \%$ plus others (loss of inhaler response $5 \%$, fast pulse rate $4 \%$ ). Some volunteered that as asthma worsened $\mathrm{C}$ disappeared, others that $\mathrm{W}$ disappeared. Apart from $B$ at least half of other symptoms were not volunteered before specified questioning. Asthma symptoms and asthma judgment are not consistent but highly individual. This has implications for asthma symptom scoring. Pain should be regarded as a common symptom of asthma.

\section{Management of asthma in schools}

RA HILl, JR BRITTON, AE TATTERSFIELD City Hospital, Nottingham A postal questionnaire was sent to 291 primary and comprehensive schools in Nottingham to evaluate the management of asthma in schools and teachers' attitudes to the disorder and its treatment. A $90 \%$ response was elicited. The percentage of children known to have asthma by the schools ranged from nil to $12 \%$ (mean $3.5 \%$ ) for primary and from $1 \%$ to $6 \%(2.9 \%)$ for comprehensive schools. The main source of information for schools was informal notification from parents on a child's admission, although $26 \%$ of primary schools employed a parental questionnaire and $72 \%$ of comprehensive schools used previous school records. Information was less certain when children were diagnosed later. Supervision rested largely with teachers in primary schools, and more often with the school nurse in comprehensive schools. Children were required to hand in their inhalers and to have their administration supervised in $66 \%$ of primary and $10 \%$ of comprehensive schools. Children kept their inhalers at all times in $10 \%$ of primary and $53 \%$ of comprehensive schools, while the remainder permitted selected children to hold and adminster their own inhalers. Only $10 \%$ of schools employed teachers with any training about asthma or other illnesses, and this usually from voluntary courses. Concern was expressed by teachers over their ignorance about asthma and its treatment, and $89 \%$ of schools considered further information desirable. 
How differently from their European colleagues do British chest specialists manage asthma?

P VERMEIRE, E JANSSENS, W DE BACKER, W WITTESAELE, TJH CLARK University of Antwerp (UIA), Belgium, and Guy's Hospital Medical School, London One hundred and thirty-three British non-paediatric chest specialists participated in a survey of the diagnosis and treatment of asthma. Their answers were compared with those of 584 "adult" specialists from 15 other European countries and with a "mean European answer," weighted for the respective populations served by these specialists. On several issues British specialists are at the extremes of the wide range of answers. For diagnostic work up they are among the most frequent users of reversibility testing, daily record cards for PEFR, and trial courses of steroids; they also measure most frequently lung function at each visit by the patient. In contrast, they are the lowest users of provocation tests and specific IgE. As first line for maintenance treatment in adults they reported the highest use of inhaled steroids and the lowest of oral $\beta$ agonists and theophylline. For sodium cromoglycate they are only slightly below, and for inhaled $\beta$ agonists slightly above, the "mean European answer." They are, however, among those using the highest doses of inhaled $\beta$ agonists and steroids, only preceded by their Scandinavian colleagues. In allergic asthma they are the lowest users of desensitisation. For treatment of asthmatic children they had similar positions in the range of responses. Sixty British paediatricians, also participating in the survey, used less inhaled steroids and more oral $\beta$ agonists and theophylline and their doses of inhaled $\beta$ agonists and steroids were also considerably lower. The wide differences in responses between European specialists should prompt more comparative studies relating asthma management to objective performance indicators such as mortality or hospital admission rates.

An expert system to improve the diagnosis and treatment of asthma

ST HOLGATE, JR BROOKS, JP KEARNEY, TW HIGENBOTTOM. JE STARK, JP DEMPSEY, RM SMITH Southampton General Hospital, Allen and Hanburys Ltd, Addenbrookes Hospital, Cambridge, and Marconi Instruments, Dunfirmline Enhanced non-specific bronchial reactivity is a central feature of asthma that may be quantified from the clinical history. We have applied this clinical assessment to the design of an educational aid to improve the diagnosis and treatment of asthma. The system (ADEPT) combines a personal IBM computer and a laser video disc facility, with a touch screen interface. When a consultation is requested, the doctor is asked questions designed to identify and then quantify bronchial hyperreactivity. Further questions elaborate on contributory factors, current treatment, the results of physical examination, and measurements of airflow limitation. On completion, a diagnostic profile is produced on the state of airways non-specific reactivity (with and without current treatment), an analysis of the physical examination findings and pulmonary function and, based on these, suggestions for therapy. The program may be interrupted at any stage for an instantaneous video disc sequence to explain the rationale of a question (EXPLAIN), to revise an answer (REVIEW), or to seek assistance with operation (HELP). The system is designed not to replace a doctor but to improve his diagnostic skills and awareness that symptoms of bronchial hyperreactivity are useful clues for the initial diagnosis and subsequent assessment of asthma in its various forms.

\section{Paradoxical vocal cord motion in asthma}

MT NOLAN, N GIBNEY, N BRENNAN, MX FITZGERALD Medical Professorial Department, St Vincent's Hospital, Dublin Paradoxical vocal cord motion (PVCM) has previously been described as a benign psychosomatic condition, predominantly affecting females, characterised by appreciable inspiratory stridor frequently misdiagnosed as asthma, and responding to voice training and psychotherapy. We describe four patients with asthma who developed appreciable stridor during attacks and who had bronchoscopic evidence of PVCM with considerable paradoxical adduction of the vocal cords on inspiration. Flow-volume curves revealed reduced inspiratory flow rates associated with sharp inspiratory cut off in two patients. All four patients were female health care workers (mean age 29 (range 24-33). Evidence for coincidental asthma included history of episodic wheeze and dyspnoea, a fall in mean percentage predicted $\mathrm{FEV}_{1}$ during attacks from $76 \%$ to $40 \%$, considerable diurnal variation in PEFR, positive skin prick test responses, and arterial hypoxaemia during attacks in three patients $\left(\mathrm{PaO}_{2} 8.45,5.18\right.$, and $6.1 \mathrm{kPa}$ respectively). Three of our patients have been poorly controlled despite maximum oral and inhaled bronchodilator therapy, including high dose prednisolone (40 mg/day), have required frequent hospital admissions, and have experienced serious steroid toxicity. Upper airways obstruction caused by PVCM appeared to contribute substantially to the severity of the attacks in our patients, but did not respond to voice training or psychotherapy. A permanent tracheostomy was required in one patient because of refractory stridor and asthma, resulting in dramatic reduction in the frequency and severity of attacks and eventual cessation of steroid therapy. Thus in our experience PVCM is not a benign condition, particularly in patients with asthma.

\section{Diagnosis of acute bronchitis and asthma in general practice}

SP RUFFLES, JG AYRES Department of Respiratory Medicine, East Birmingham Hospital, Birmingham One hundred and six general practitioners (GPs) contribute to the weekly returns system of the Royal College of General Practitioners which system can follow trends in common respiratory disorders. Questionnaires were sent to the GPs so that we could assess diagnostic trends and consistency of diagnosis nationally and in Northern, Central, and Southern urban and rural areas. Eighty questionnaires were returned. The various criteria were rated essential (1), important (2), relevant (3) and irrelevant (4). The table shows the percentages for criteria rated (1) or (2). 


\begin{tabular}{lcc}
\hline Criterion & $\begin{array}{c}\text { Acute } \\
\text { bronchitis }(A B)\end{array}$ & Asthma $(A)$ \\
\hline Low PEFR/wheeze on examination & 49 & 96 \\
History of wheeze & 38 & 86 \\
Previous similar attack & - & 76 \\
History of chest disease & 51 & - \\
Cough & 83 & 46 \\
Smoker & 52 & 5 \\
\hline
\end{tabular}

The results showed no regional variation. No recognisable pattern of diagnostic criteria emerged. In particular there was no greater appreciation of cough as a symptom of $\mathbf{A}$ by GPs who favoured wheeze and low PEFR in AB ( $p>0.1)$. Smokers with a history of chest disease are likely to be labelled $A B$ but this may reflect inclusion of chronic bronchitis. $A$ and $A B$ need to be differentiated diagnostically and a clearer definition of acute bronchitis is needed to achieve this.

Effects of number and tar content of cigarettes smoked on decline in $\mathrm{FEV}_{1}$ over ten years in middle aged men

A WATSON, H JOYCE, F HOLLAND, NB PRIDE Department of Medicine, Hammersmith Hospital, London We examined the decline in height corrected $\mathrm{FEV}_{1}$ in middle aged men over 10 years in 42 never smokers (NS), 40 established exsmokers (XS) and 65 regular cigarette smokers (S). Annual mean (SEM) $\Delta \mathrm{FEV}_{1}$ was $4.67(0.62)$ in NS, $5.71(0.72)$ in $\mathrm{XS}$ and $8.55(0.76) \mathrm{ml}^{\mathrm{y}}-1 \mathrm{~m}^{-3}$ in $\mathrm{S}$; all groups showed large variation in $\triangle \mathrm{FEV}_{1}$ between individuals. Mean (SEM) $\triangle F_{1}$ was related to average daily number of cigarettes smoked over the 10 year period $(\leqslant 15 /$ day 7.06 (1.49), 16-25/day $8.00(1.23),>25 /$ day 9.43 (1.19)). Smokers of $>15$ cigarettes/day who smoked lower tar brands $(n=19$, mean 31.0 cigarettes/day, mean tar 12.1 $\mathrm{mg} /$ cigarette) had $\triangle \mathrm{FEV}_{1}$ of 8.39 (1.36) while men smoking middle tar brands $(n=35$, mean 28.9 cigarettes/day, mean tar $17.7 \mathrm{mg} /$ cigarette) had $\triangle F E_{1}$ of 9.10 (1.12). Lower tar smokers showed lower plasma cotinine (277 (28) vs $320(33) \mathrm{ng} / \mathrm{ml}$ ) and fractional expired carbon monoxide (14.8 (1.3) vs $15.9(1.3) \mathrm{ppm})$ than middle tar smokers, but these differences were smaller than expected from the nominal nicotine and $\mathrm{CO}$ yields. Though we found some relation between smoking dose and annual $\triangle \mathrm{FEV}_{1}$ and a modest slowing of $\triangle \mathrm{FEV}_{1}$ in smokers of low yield cigarettes, closer definition of smoking 'dose' only slightly reduced the wide variability in $\triangle F^{\prime} V_{1}$ between male smokers.

Respiratory syncytial virus, parainfluenza viruses 1 and 2 , winter acute bronchitis and autumnal asthma in general practice in the United Kingdom 1976-1984

J AYRES, ND NOAH Department of Chest Medicine, East Birmingham Hospital, Birmingham, and Communicable Disease Surveillance Unit, Colindale, London Acute bronchitis is a common condition causing much lost time from school/work. The weekly returns system (WRS) of the Royal College of General Practitioners shows that acute bronchitis/bronchiolitis (AB/B) attack rates trough in August, rising sharply therafter to peak in January
(1976-1983) (Ayres J, Thorax 1984;39:687). Virus isolation reports from the CDSC for the same period reveal that respiratory syncytial virus (RSV) and parainfluenza viruses 1 and 2 (PIV) show closely matching seasonal variations, RSV peaking in February for each year except 1982, and PIV in October in alternate years. This is more precise for the 0-4 age group for 1982-4 (the only years with the age banded data available) and reflects the earlier RSV peak of 1982. Autumn peaks in acute attacks of asthma (WRS) are most marked up to age 14 and coincide temporally with the autumn rise in $\mathrm{AB} / \mathrm{B}$, suggesting that in some cases asthma attacks may be RSV or PIV induced. There was no disease related peaking for influenza $A$ or $B$, rhinoviruses or adenoviruses 1 to 7 . These data support the link between childhood bronchiolitis and RSV and suggest that RSV and PIV may be important in autumnal asthma attacks and acute bronchitis.

Respiratory symptoms, lung function and bronchial reactivity after pertussis in infancy

IDA JOHNSTON, S PATEL, HR ANDERSON, HP LAMBERT, D INGRAM, JO WARNER The Middlesex, St George's and Brompton Hospitals, London In an earlier field survey, children with a history of pertussis were more likely to have had other chest illnesses, and to have current chest symptoms, but did not differ from controls in spirometry. We have done more detailed laboratory lung function tests, allergy prick skin tests and histamine bronchial challenges on 36 subjects admitted to hospital with pertussis in infancy and 36 controls (mean age both groups $9.9 \mathrm{y}$ ), all enlisted from the original survey. Cases were more likely to have a family history of wheeze $(25 \%$ vs $6 \%, p=0.04)$ and to have had respiratory symptoms in the past year, e.g. "Yes" to "Ever wheezy?" (17\% vs 3\% p=0.05). Cases were more likely than controls to have positive allergy skin tests but there was no difference in the histamine $\mathrm{PC}_{20}$ (concentration of histamine to produce a $20 \%$ fall in $\mathrm{FEV}_{1}$ ) between the two groups. Likewise, no differences were found in any index of lung function derived as a percentage of value predicted for height from spirometry, flow-volume curves and single breath nitrogen washout analysis. We conclude that a history of pertussis in infancy is associated with increased current respiratory symptoms but does not cause any detectable deficit in lung function or increased bronchial reactivity in later childhood.

Are the tuberculosis notification rates for the Indian subcontinent population in England declining as fast as the 1983 survey suggests?

AJ NUNN, SP BYFIELD, KM CITRON, JH DARBYSHIRE, W FOX, MJ HUMPHRIES, VH SPRINGETT MRC Tuberculosis and Chest Diseases Unit, London Annual tuberculosis notification rates for the different ethnic groups in England have been calculated for $1978 / 79$ and 1983 from the findings of the MRC surveys of notifications in England and Wales using population figures from two national sample surveys. The highest rates occurred in the Indian and the Pakistani and Bangladeshi ethnic groups, but they had halved between the surveys, representing annual declines of $15 \%$ and $16 \%$, 
respectively, compared with $7.0 \%$ for the White ethnic group. There are several population factors which affect the rate of decline in the Indian subcontinent ethnic groups. These groups together made up less than $3 \%$ of the total population and the population estimates were based on $0.5 \%$ sample surveys. Allowing for possible discrepancies in these estimates reduces the annual decline to $11 \%$ for the Indian and $13 \%$ for the Pakistani and Bangladeshi ethnic group. Standardising for age and sex differences between the $1978 / 79$ and 1983 Indian subcontinent populations has very little effect on the declines in rate. In contrast, standardising for the year of first entry to the UK substantially reduces the decline in rates between the surveys for the Indian subcontinent population, the annual rate of decline being only $8 \%$, much closer to that of the White group than it appears from the crude estimates.

\section{Community acquired legionnaires, disease - a review of 79 cases in Nottingham}

MA WoOdheAd, JT MACFARLANe City Hospital, Nottingham In previous studies of legionnaires disease (LD) nosocomial cases have predominated. All cases of LD identified in Nottingham between 1972 and 1984 have been reviewed retrospectively. Community acquired infection accounted for 79 cases ( 50 male, 29 female), which are the subject of this study. (Four nosocomial infections were also identified but are not considered.) The mean age was 53 years (range $25-83)$. Seven patients $(10 \%)$ had recently returned from abroad. Twenty-eight patients $(35 \%)$ had underlying chronic disease, of whom two were on current immunosuppressive therapy. The commonest symptom was cough in $73 \%$ of cases followed by expectoration $(41 \%)$, chest pain $(36 \%)$, dyspnoea $(35 \%)$, confusion $(35 \%)$, other neurological symptoms $(33 \%)$, vomiting $(32 \%)$, headache $(27 \%)$ and diarrhoea $(22 \%)$. Respiratory symptoms were absent in $22 \%$. Fever $\left(\geqslant 37.5^{\circ} \mathrm{C}\right)$ occurred in $90 \%$ and was $\geqslant 40^{\circ} \mathrm{C}$ in $24 \%$. Relative bradycardia occurred in only $18 \%$. Crepitations were heard in $86 \%$ but only $22 \%$ had classical signs of consolidation. Thirteen patients died $(17 \%)$. Twenty-one patients $(27 \%)$ were admitted to an intensive care unit, of whom 20 were ventilated and nine died. This confirms the diverse symptomatology of LD and emphasises that the outcome is not as bad as was once thought.

\section{Lung abscess and empyema}

JE NEILD, SJ EYKYN, I PHILLIPS Departments of Medicine and Microbiology, St Thomas's Hospital Medical School (UMDS), London Fifty patients (19 abscess, 31 empyema) who presented to St Thomas's Hospital between 1976 and 1985 were studied prospectively. Those with cavitating staphylococcal or klebsiella pneumonia, tuberculous empyema or empyema following intrathoracic surgery were excluded; but the nine patients subsequently found to have underlying lung pathology were included. No specific clinical features indicated underlying pathology. Most patients gave a history of unconsciousness (alcoholism, general anaesthesia, epilepsy), inhalation (vomiting, bulbar dysfunction), poor dentition or immunosuppression. Abscesses were evenly distributed throughout the lungs and there was no correlation between either site of lesion or size of cavity and recovery. In 16 of those with an abscess, bacteriological specimens were obtained at bronchoscopy or percutaneous transthoracic aspiration. Aerobes were cultured in $36 \%$ of cases, aerobes and anaerobes in $56 \%$ and anaerobes alone in only $8 \%$. The commonest aerobe was Str milleri and commonest anaerobes the anaerobic cocci, black pigmented bacteroides and fusobacteria. $B$ fragilis was not isolated. $43.6 \%$ of the aerobes and $15.6 \%$ of the anaerobes were resistant to penicillin and this should no longer be the antibiotic of choice. Empyemas were drained surgically. Patients with lung abscesses were treated with intensive physiotherapy and usually a combination of amoxycillin and metronidazole; in those with no underlying pathology, fever settled within 10 days and cavities disappeared by 6 weeks.

Increasing incidence of Branhamella catarrhalis bronchopulmonary infection: is ampicillin or trimethoprim responsible?

DT MCLEOD, F AHMAD, S CAPEWELL, MJ CROUGHAN, MA CALDER, A SEATON City Hospital, Edinburgh An increase in bronchopulmonary infection due to Branhamella catarrhalis, usually a nasopharyngeal commensal, has previously been reported (McLeod DT et al, Br Med J 1983;287:1446-47). The reason for this increase is unclear though a change in antibiotic prescribing practice was suspected. In a prospective study $B$ catarrhalis was isolated from the sputum of 63 patients with bronchopulmonary infection: 49 isolates in pure culture, 14 with other pathogens. Forty-four of the 63 isolates $(70 \%)$ produced $\beta$ lactamase, 26 of these being community acquired. As a result $41 \%$ were treated inappropriately with ampicillin and did not respond. Of 36 patients infected in the community, 26 required hospital admission. The remaining 27 patients were infected in hospital. Most patients had chronic lung diseases or carcinoma of the bronchus, but three healthy non-smoking patients developed bronchitis. B catarrhalis contributed to the death of five patients. A survey of the referring general practitioners revealed that ampicillin/amoxycillin was the drug of choice of $75 \%$ of practitioners. Trimethoprim was used in $90 \%$ of the practices. Ampicillin pressure may be responsible for increasing the proportion of strains producing $\beta$ lactamase. Widespread use of trimethoprim, to which $B$ catarrhalis is resistant, may alter the nasopharyngeal flora resulting in an increase in this bacterium.

\section{Cilia from sites of purulent infection beat more slowly in} vitro

R WILSON, PJ COLE Host Defence Unit, Department of Medicine, Cardiothoracic Institute, Brompton Hospital, London Purulent sputum sol with elastase activity slows normal ciliary beat frequency (CBF) in vitro (Smallman et 
al, Thorax 1984;39:663) and bacterial products also compromise ciliary function (Wilson et al, Thorax $1985 ; 40: 125)$. We have compared the in vitro CBF measured by a photometric technique (Rutland J, Cole PJ, Lancet $1980 ; 2: 564)$ of nasal cilia, obtained by brushing the inferior turbinate with a cytology brush, in normal controls, bronchiectasis without nasal symptoms, patients with mucopurulent sinusitis (MPS) alone and patients with MPS and bronchiectasis. Nasal mucociliary clearance (NMCC) was also measured by a modified saccharin method.

\begin{tabular}{|c|c|c|}
\hline & $N M C C$ (min) mean $(S D)$ & $C B F(H z)$ mean $(S D)$ \\
\hline $\begin{array}{l}\text { Normal controls }(n=10) \\
\text { Bronchiectasis alone } \\
(n=10) \\
\text { MPS alone }(n=8) \\
\text { MPS and bronchiectasis } \\
(n=10)\end{array}$ & $\begin{array}{l}12(5) \\
21(13) \\
31(15)\left(4 / 8=>60^{\prime}\right) \\
47 \quad\left(8 / 10=>60^{\prime}\right)\end{array}$ & $\begin{array}{l}14.3(0.9) \\
13.6(1.3) \\
12.4(1.7)^{*} \\
11.6(1.2)^{* *}\end{array}$ \\
\hline
\end{tabular}

${ }^{*} \mathrm{p}=<0.01$ between MPS alone and normal controls; ${ }^{* *} p=<0.001$ between bronchiectasis with MPS and bronchiectasis alone (Student's $t$ test). We conclude from the results (Table) that cilia obtained from the site of purulent secretions beat more slowly in vitro and that the nasal cilia of bronchiectatic patients lacking chronic MPS beat normally.

Pigment production is a probable mechanism by which Pseudomonas aeruginosa colonises the human respiratory tract

R WILSON, T PITT, D ROBERTS, PJ COLE, Host Defence Unit, Department of Medicine, Cardiothoracic Institute, Brompton Hospital, London Culture filtrates of Pseudomonas aeruginosa slow the beating of normal human nasal cilia, which can be measured by a photometric technique in vitro (Wilson et al, Thorax 1985;40:125). Ciliary slowing activity failed to correlate with protease or haemolytic activity, or with other pseudomonas enzymes (lipase, lecithinase, DNAase) measured by plate techniques. Other pseudomonas virulence factors (exotoxin A, lipopolysaccharide, alginic acid) did not slow cilia. However, the activity did correlate $(r=0.97)$ with pigment in the filtrate (absorbance $400 \mathrm{~nm}$ ). Gel filtration of lyophilised filtrate yielded a single peak of cilioinhibitory activity corresponding to the pigment fraction. Serial samples removed at intervals from a 4-day culture of pseudomonas (then centrifuged and filtered $(0.2 \mu \mathrm{M})$ ) slowed cilia increasingly and correlated $(r=0.94)$ with the spectrophotometric development of pigment. Pyocyanin (pseudomonas pigment), extracted from an active strain with chloroform then crystallised with petroleum ether, slowed cilia in a dose-dependent manner; $250 \mu \mathrm{g} / \mathrm{ml}$ (complete ciliostasis), $16 \mu \mathrm{g} / \mathrm{ml}$ (64\% ciliary slowing), 4 $\mu \mathrm{g} / \mathrm{ml}$ (35\% ciliary slowing). This ciliary slowing factor might be expected to slow mucociliary clearance in vivo. Ability to produce it would provide the bacterium with obvious advantages early in an infection, allowing it to multiply and establish itself within the lung.
What is the meaning of bronchographic abnormalities seen in patients chronically producing purulent sputum?

J COOKE, D CURRIE, A MORGAN, I KERR, D DELANY, B STRICKLAND, PJ COLE Department of Radiology, Brompton Hospital, and Host Defence Unit, Department of Medicine, Cardiothoracic Institute, Brompton Hospital, London Bronchography is generally accepted as the definitive investigation for the diagnosis of bronchiectasis. Twenty-seven patients chronically producing sputum were investigated by bronchography. Fifty-one lungs (456 segments) were examined and the films read separately and in "blind", randomised fashion by two pulmonary radiologists. Presence or absence of proximal and distal dilatation of bronchi, non-tapering, lack of demonstration of side branches, and presence of mucus (luminal filling defects) were noted in each segment and a "diagnostic interpretation" was made in each segment. Both radiologists agreed to the presence of the following number of segmental abnormalities, in parenthesis being the number of additional segments interpreted as abnormal by one radiologist alone. Proximal dilatation 61 (68), distal dilatation 64 (50), non-tapering 109 (60), lack of demonstrable side branches 129 (65), mucus 268 (69). Bronchiectasis was agreed as present in 94 segments by both radiologists but felt to be present in 26 additional segments by one radiologist alone. We conclude that reporting of individual bronchographic abnormalities and diagnostic interpretation as bronchiectasis are subjective.

\section{Assessment of the accuracy and sensitivity of computerised tomography (CT) in the diagnosis of bronchiectasis}

J COOKE, D CURRIE, A MORGAN, I KERR, D DELANY, B STRICKLAND, PJ COLE Department of Radiology, Brompton Hospital, and Host Defence Unit, Department of Medicine, Cardiothoracic Institute, Brompton Hospital, London Our study was prompted by two conflicting reports of the accuracy of CT in diagnosing bronchiectasis. Osman J et al (Thorax 1984;39:688) stated the usefulness of CT; however, Müller NL et al (AJR 1984;43:971-976) found CT unreliable in patients with cylindrical and varicose bronchiectasis. Twenty-seven patients chronically producing sputum, in whom bronchography was clinically indicated, were investigated by CT before the bronchogram. Fifty-one lungs (456 segments) were examined, and films were read separately in "blind" randomised fashion by two pulmonary radiologists. Presence or absence of proximal and distal dilatation, proximal and distal bronchial wall thickening and parenchymal disease were noted in each segment and a diagnostic interpretation made. For analysis, segments were arbitrarily defined as having a particular abnormality or diagnostic interpretation only if recorded as such by both radiologists. The CT scan was interpreted as showing bronchiectasis in 63 of 94 bronchographically bronhiectatic segments (67\% sensitivity). It was interpreted as showing bronchiectasis in 16 of 338 bronchographically normal segments (2\% “false positives"). It was interpreted as normal in 18 of 94 bronchographically bronchiectatic 
segments ( $19 \%$ "false negatives"). We conclude that CT is inaccurate and insensitive as a method for diagnosing bronchiectasis.

\section{British Paediatric Association cystic fibrosis study}

JA DODGE, DM GEDDES, J GOODALL, JM LITTLEWOOD, MB MEARNS, G RUSSELl Brompton Hospital, London All members of the British Paediatric Association were circulated with a questionnaire enquiring about CF patients under their care. Almost all paediatricians and about $30 \%$ of thoracic physicians completed the questionnaire. Information has been received about more than 4500 patients. Ascertainment may be less complete for adult patients but preliminary data suggest an $80 \%$ survival to 13 years and $50 \%$ survival to 20 years. Mortality is higher in females. It is estimated that approximately 1000 additional patients will enter the adult (16 years or more) age group during the next five years. The survey will continue over the next 3 years to allow calculations of age at diagnosis, life expectancy and differential mortality. The working party has also considered data from other countries. It concludes that there is a need for properly established and funded referral centres for CF although patterns of care will need to vary in different parts of the countries.

\section{Efficacy of BCG vacination in England and Wales in 1983}

I SUTHERLAND, VH SPRINGETT Medical Research Council Biostatistics Unit, Cambridge In collaboration with the MRC Notification Survey and with the co-operation of very many chest physicians and school health authorities, the effectiveness of BCG in preventing tuberculosis in ages 15-24 years in England and Wales in 1983 has been determined by the same method as in the BTA survey for 1978 (Brit J Dis Chest 1980;74:215) and the BTA survey for 1973 (Tubercle 1975;56:129). The notification rate (3.32 per $100000)$ in those vaccinated in the schools' scheme was compared with the estimated rate (13.12 per 100000$)$ in those who were tuberculin negative and not vaccinated in the scheme. The protective effectiveness of BCG at ages 15-24 years in 1983 was estimated as $75 \%$, compared with $72 \%$ in 1978, and with $80 \%$ in the cohort in the MRC tuberculosis vaccines trial 24 years previously. The protective efficacy for the white ethnic group in 1983 was $76 \%$, closely similar to that for the whole population. The findings of the three latest surveys, with other information, showed that the tuberculosis notification rate among those not vaccinated in the schools' scheme is decreasing by about 9\% each year. Despite the continuing efficacy of the vaccine, the absolute numbers of notifications prevented by BCG in England and Wales each year (about 580 in 1983) are thus decreasing equally steeply. These findings are being used to assess the consequences of continuing or stopping the schools' BCG scheme.

\section{BTS pneumonia study: Design and outcome}

B FARR for the BTS Research Committee A prospective study was conducted in 27 hospitals throughout Great Britain with the following aims: 1) to study the outcome of acute community acquired primary pneumonia in adults requiring admission, 2) to determine factors predictive of outcome, and 3) to assess the value of diagnostic tests in establishing microbial aetiology. All patients between 15 and 74 years with acute primary pneumonia confirmed radiographically to be at least segmental or present in more than one lobe were to be included. Five hundred and eleven patients were enrolled between $15 / 11 / 82$ and $31 / 12 / 83$. Thirty were excluded because of bronchial obstruction, active tuberculosis, carcinomatosis, or absence of pneumonia; 28 patients failed to return for assessment of outcome. Four hundred and fifty-three patients $(\mathbf{8 8 . 7 \%})$ completed the study and were available for analysis. Mean age was 48.4 years $(S D=17.8) .274(60.5) \%$ ) were male; 294 $(64.9 \%)$ had smoked cigarettes; and $260(57.4 \%)$ had a preexisting illness (chronic bronchitis 24.7\%; asthma $12.4 \%$; other pulmonary $18.0 \%$; cardiovascular $10.8 \%$; neurological 5.1\%). Two hundred and three (44.8\%) had received antibiotics before admission. Major symptoms included cough $(87.9 \%)$, dyspnoea $(70.9 \%)$, sputum $(68.7 \%)$, and chest pain $(63.6 \%)$. Two hundred and ninetyseven $(65.6 \%)$ had a temperature of at least $38^{\circ} \mathrm{C}$ during the first 48 hours of admission. Median duration of fever was 3 days. Microbial aetiology was successfully determined for 305 patients $(67.3 \%)$. Twenty-six patients $(5.7 \%)$ died of pneumonia. Mean length of hospital stay for survivors was 10.8 days. Two hundred and eighty-six $(63.1 \%)$ returned for follow-up at 6 weeks ( \pm 9 days); in this group 196 of 284 had returned to work or normal activity, 225 of 272 were considered fit for work or normal activity by the physician, and 158 of 284 had radiological resolution.

\section{BTS pneumonia study: Microbiological results}

S PUGH for the BTS Research Committee On admission patients had the following microbiological investigations: Gram's stain and sputum culture; blood cultures; countercurrent immunoelectrophoresis (CIE) of sputum, urine and serum for pneumococcal antigen; complement fixation tests for antibodies to respiratory antigens; immunofluorescent tests for legionella antibodies and mycoplasma IgM and IgG antibodies. Serological tests were repeated 6 weeks after admission. An aetiology was found in 305/453 patients (67\%). Agents were Streptococcus pneumoniae 154 (34\%), Mycoplasma pneumoniae 81 $(18 \%)$, influenza A virus 32 (7\%), Haemophilus influenzae $24(5 \%)$, Chlamydia psittaci $13(3 \%)$, Legionella pneumophila 9 (2\%), Staphylococcus aureus 7 (2\%), Coxiella burnetti $5(1 \%)$, others $36(8 \%)$. Fifty-six patients had dual aetiologies. Sputum CIE (102/272 (37\%) positive) and urine CIE (54/317 (17\%) positive) were the most sensitive tests for pneumococcal infection and serum CIE $(12 / 384(3 \%)$ positive) the least sensitive. Sputum and blood cultures grew pneumococci in $35 / 420(8 \%)$ and $37 / 427(9 \%)$ of cases respectively. Completeness of laboratory testing had a significant $(p<0.001)$ effect on diagnosis. An aetiology was found in $78 \%$ of patients who had all tests performed but only in $61 \%$ of patients in whom testing was incomplete. Antibiotic treatment before 
admission decreased the diagnostic rate for pneumococcal infections, $47 \%$ of all patients studied had received antibiotics, compared with $24 \%$ for patients with a diagnosis of pneumococcal infection. Most patients with mycoplasma infection $(\mathbf{8 7 \%})$ had received antibiotics.

\section{BTS Pneumonia study: Mortality}

JT MACFARLANE for the BTS Research Committee Twenty-six of $453(5.7 \%)$ adults died of pneumonia. Pathogens implicated included Streptococcus pneumoniae (7), Mycoplasma pneumoniae (4), $S$ aureus with influenza A virus (3), Gram negative bacteria (2), Haemophilus influenzae (2) and $H$ parainfluenzae (1). No aetiology was found in 7 patients. Some mixed infections occurred. The overall mortality for the commoner pathogens was $4.9 \%$ for $M$ pneumoniae, $4.6 \%$ for $S$ pneumoniae and $43 \%$ for $S$ aureus. Illness had been present for 7 days (mean) before hospital admission and one third had received antibiotics. After admission all fatal cases received antibiotics; $46 \%$ received treatment for heart failure, $38 \%$ corticosteroids and $11 \%$ anticoagulants. Thirteen patients were given $\geqslant 3$ different antibiotics and four $\geqslant 5$ different antibiotics. Only 7 clinicians recorded that inital laboratory results had guided antibiotic therapy. Although $92 \%$ had oxygen therapy, only $31 \%$ (8) received assisted ventilation (IPPV). Patients who died and who did and did not receive IPPV were similar as regards age, previous respiratory illness, extent of pneumonia and arterial blood gases. However, only $11 \%$ who died and were not ventilated had previously been well compared with half who died after IPPV. In all, 22 study patients received IPPV and $64 \%$ (14) survived, confirming that IPPV was valuable treatment. Patients who died from pneumococcal, staphylococcal (with influenza A virus) or mycoplasma pneumonia had not received appropriate antibiotics before hospital admission. All cases of mycoplasma and influenza infection coincided with periods of national epidemics, suggesting that doctors should be kept clearly informed of the current pattern of respiratory infections in the country.

BTS pneumonia study: Clinical features and $x$-ray and laboratory data available soon after admission which affect prognosis

BDW HARRISON for the BTS Research Committee Death and length of hospital stay, delayed return to work, delayed fitness for work in the doctor's opinion and delayed resolution of the chest radiograph, all assessed six weeks after admission, were the outcome variables studied. In the history, increasing age, work status, non-respiratory past medical illness, confusion, dyspnoea and drug treatment for pre-existing medical condition were significantly associated with death. Three points in the history each suggested a good prognosis: regular alcohol consumption, chest pain and vomiting. There was no association between smoking, chronic bronchitis or past respiratory illness and death. On examination confusion, tachypnoea, tachycardia, and systolic and diastolic hypotension were significantly associated with death. Of immediately available investigation results, leucopenia, leucocytosis, hypoxia, acidosis, raised blood urea and hypoalbuminaemia were significantly associated with death. After multivariate analysis, age, tachypnoea, diastolic hypotension and raised blood urea remained independently significant predictors of death. Regular alcohol intake, chest pain and vomiting remained favourably associated with survival. Similar associations were found for the other outcome variables studied.

\section{Asthma in Avon schoolchildren}

F CARSWELL, M BREWIN, AO HUGHES, M BURR, AM CARSWELL Department of Child Health, Bristol University, Royal Hospital for Sick Children, St Michael's Hill, Bristol Hospital populations have been extensively studied in asthma but such information may not be representative of asthma in the community. We have devised and applied a questionnaire for the diagnosis of asthma in children outside hospital. We surveyed all 1657 pupils attending five large but otherwise randomly selected primary schools in Avon Country. 87.4\% returned the questionnaire within one week. One hundred and eighty questionnaires (including 74 from asthmatics) were independently diagnosed by a paediatrician, a general practitioner and an epidemiologist. There was good concordance and the results of exercise and skin testing also agreed. Seventy-four of 95 'definite' asthmatics and 16 of the 30 'equivocal' subjects together with age, sex and class room matched controls were followed up with daily recording of symptoms and peak expiratory flow rates (PEF) over four weeks of school attendance. There was significant association between falls in PEF and asthma symptoms and the PEF was more variable in the asthmatics than the controls. Only $52 \%$ of the families knew their child had asthma. $53 \%$ were not receiving any treatment and only $21 \%$ were on regular prophylaxis. $46 \%$ of asthmatics had symptoms on the majority of days and $13 \%$ had PEF $<70 \%$ predicted on at least $20 \%$ of results. Our parent completed questionnaire has proved to be a sensitive and specific tool for the diagnosis of asthma in the community. The results suggest that there is still considerable undertreatment of asthmatics in the community.

The change in non-specific reactivity during the pollen season in a rural population sample

JR BRITTON, PGJ BURNEY, S CHINN, AO PAPACOSTA, D PEARSON, AE TATTERSFIELD City Hospital, Nottingham, and St Thomas's Hospital, London Increased non-specific bronchial reactivity has been shown to occur in pollen sensitive subjects (Sotomayor et al, Am Rev Respir Dis $1984 ; 130: 56-58)$ during the grass pollen season when exacerbations of asthma are well recognised. We now report on the change in bronchial reactivity during the pollen season in a sample from a large community population surveyed for asthma prevalence. Ninety-nine subjects whose histamine reactivity and skin sensitivity to common allergens were measured in March 1984 were 
rechallenged with histamine in June 1984 (Yan et al, Thorax 1983;38:760-765) giving up to $4 \mu \mathrm{mol}$ histamine with extrapolation to $8 \mu \mathrm{mol}$. There was a small estimated mean fall in $\mathrm{PD}_{20} \mathrm{FEV}_{1}$ of $-0.84( \pm 0.21, \mathrm{SE})$ doubling doses of histamine in the 66 subjects with a measurable $P D_{20}$ $(p<0.001)$. Change in reactivity did not correlate with change in baseline $F E V_{1}$ or with March $\mathrm{PD}_{20}$, nor was it associated with pre-season skin weal diameter to mixed grass pollens (Bencard) or to D Pteronyssinus or cat fur. There was a correlation with histamine skin sensitivity and a history of wheezing in the pollen season $(p<0.05)$. Thus skin test response to grass pollen and non-specific bronchial reactivity are poor predictors of a change in reactivity in the grass pollen season.

Respiratory symptoms, atopy and bronchial reactivity a random young population sample

WOCM COOKSON, AW MUSK, G RYAN The Osler Chest Unit, Churchill Hospital, Headington, Oxford and the Department of Respiratory Medicine, Sir Charles Gairdner Hospital, Perth, Western Australia The study describes the distribution of non-specific bronchial reactivity and its relationship to atopy and to respiratory symptoms in a normal young population. One hundred and five individuals (19 female) answered a modified MRC respiratory questionnaire, were skin prick tested with 19 common antigens, and underwent measurement of nonspecific bronchial reactivity to methacholine (NSBR) before starting work with a grain company. The mean age was 20 years. Eleven percent had a past history of asthma, $24 \%$ admitted the symptom of wheeze, and $57 \%$ were atopic (one or more skin prick responses greater than or equal to 3 $\mathrm{mm}$ weal). The mean $\mathrm{FEV}_{1}$ was $112 \%$ of predicted. The distribution of NSBR appeared unimodal. There was a strong positive association between the presence of the atopic state and a high level of bronchial reactivity to methacholine: all eight subjects with high NSBR and 20 of 29 subjects with moderate NSBR were atopic, but only 32 of the 68 subjects with low or unmeasurable NSBR were atopic $(\mathrm{p}<0.01)$. Stepwise regression analysis found atopy and NSBR to predict the symptom of wheeze independently. The reason for this association between atopy and NSBR may be of importance in understanding the pathogenisis of asthma.

\section{Respiratory symptoms, bronchial reactivity and asthma}

AK MORTAGY, JBL hOWELl, We WATERS Medicine 1 and Community Medicine, Southampton General Hospital Existing definitions of asthma are no more than descriptions of the clinical presentation of reversible airflow obstruction and do not provide operational criteria for the diagnosis. In an epidemiological survey of the prevalence of a range of respiratory symptoms and measurements in a population, we have identified individuals with a close association of one or more of three symptoms - bronchial irritability (BI), nocturnal dyspnoea (ND) and morning tightness for more than one hour (MT > lhour) - and bronchial hyperreactivity (BHR). In
$27 \%$ of this group GPs had diagnosed asthma, and in $\mathbf{8 \%}$ other chest disorders. The clinical status of the remainder is uncertain. The appropriateness of using this cluster (i.e. symptomatic and objective evidence of BHR as criteria for 'asthma') is not established. We have given this association of 'Sensitivity to Histamine And BI' the acronym SHABI syndrome. We conclude that the SHABI syndrome is a diagnostic category definable by symptoms and/or measurement which should alert to the possibility of benefit from treatment with bronchodilators, cromoglycate and/or corticosteroids.

\section{A general practice survey of bronchial reactivity}

J BENNETT, M TOOLEY, MF D'SOUZA, RJ DAVIES Academic Unit of Respiratory Medicine, St Bartholomew's Hospital, and The Canbury Medical Centre, Kingston-uponThames In order to define the distribution of bronchial hyperreactivity (BHR) in the community and its correlation with respiratory symptoms, atopy and age, we have studied a randomly selected sample of 200 individuals (aged 18 to 75 , mean age 43 years) from the list of a general practice in Kingston, Surrey. Bronchial provocation testing was performed using doubling concentrations of methacholine administered via the DeVilbiss 646 nebuliser. Respiratory function was measured using a Vitalograph bellows spirometer. A detailed respiratory and smoking history was taken using a computer administeed questionnaire and skin prick testing with six common inhalant allergens was performed. Of the 200 individuals, 177 (88.5\%) underwent bronchial provocation testing. Reasons for not performing provocation testing were: impaired lung function $(3.5 \%)$, pregnancy $(2 \%)$, ischaemic heart disease $(4 \%)$ and refusal $(2 \%)$. Thirty-two $(18 \%)$ of those challenged exhibited BHR, defined as a methacholine concentration producing a $20 \%$ fall in $\mathrm{FEV}_{1}\left(\mathrm{PC}_{20}\right)$ equal to $2 \mathrm{mg} \mathrm{ml}^{-1}$ or less. Of these $6(3.3 \%)$ had severe BHR PC $20\left(<0.125 \mathrm{mg} \mathrm{ml}^{-1}\right), 7$ (3.9\%) had moderate BHR $\left(\mathrm{PC}_{20}>0.125<0.5 \mathrm{mg} \mathrm{ml}^{-1}\right)$ and $19(10.7 \%)$ had mild BHR $\left(\mathrm{PC}_{20}>0.5 \mathrm{mg} \mathrm{ml}^{-1}<2 \mathrm{mg}\right.$ $\left.\mathrm{ml}^{-1}\right)$. Bronchial hyperreactivity correlated with symptoms of wheeze $(p<0.001)$ and atopy $(p<0.01)$, but not with cough or shortness of breath. BHR was significantly commoner in women $(p<0.01)$ and significantly less prevalent in individuals aged $30-40(p<0.01)$. There was no correlation with cigarette smoking or symptoms of chronic bronchitis. Eight individuals with mild or moderate BHR had no respiratory symptoms. All individuals with severe BHR were symptomatic.

The use of serum thiocyanate estimations to validate smoking histories and to identify passive smokers

AS ROBERTSON, PS BURGE, BL COCKRILl Solihull Hospital, Solihull, West Midlands A doctor administered smoking questionnaire was obtained from randomly selected office workers. Current and previous smoking habits were determined including exposure to passive smoking at home and at work. To validate this smoking history serum thiocyanate $\left(\mathrm{SCN}^{-}\right)$was estimated using the ferric nitrate method. The difference between mean thiocyanate levels in 
non-smokers (NS) and smokers (S) was highly significant (mean (SD) NS= 46.4 (23.1); $S=103.1$ (51.2); $<<0.001$ ). There was no significant difference between non-smokers and smbkers of $\leqslant 5$ cigarettes/day $(\mathrm{NS}=46.4(23.1) ; \leqslant 5$ cigarettes $/$ day $=56.1(27.5)$ ) but with increasing cigarette consumption, mean levels rose significantly (see table).

\begin{tabular}{c|c|c|c|c}
\hline Cigs/day & No & Mean SCN & SD & $\begin{array}{c}\text { p values: comparison } \\
\text { with } \leqslant 5 \text { cigs }\end{array}$ \\
\hline$\leqslant 5$ & 9 & 56.1 & 27.5 & - \\
$6-15$ & 18 & 100.8 & 44.4 & $<0.001$ \\
$16-25$ & 11 & 121.6 & 48 & $<0.01$ \\
$>25$ & 5 & 155.4 & 52.1 & $<0.01$ \\
\hline
\end{tabular}

Non-smokers exposed to passive smoking at home and/or work had levels which were not significantly different from non-passively exposed non-smokers. In our hands serum thiocyanate identifies heavy smokers but could not distinguish between non-smokers, light smokers and passive smokers.

Does plasma nicotine raise the white blood cell count in smokers?

RG TAYLOR, G WOODMAN, SW CLARKE Department of Thoracic Medicine, Royal Free Hospital and School of Medicine, London The peripheral blood total white cell count (WBC) is $\mathbf{2 0 - 2 5 \%}$ higher in smokers than in nonsmokers, and tends to be higher in those who smoke and inhale more. We have examined how smoking might raise the WBC by testing if the WBC is related to the level of endexpired carbon monoxide (CO) or of plasma nicotine in 10 healthy young white male non-smokers and 12 smokers, none of whom had a reduced $F E V_{1}$ or any cause except smoking for a raised WBC. End-expired $\mathrm{CO}$ was measured with an Ecolyzer after a mid-afternoon half-hour rest when smoking was forbidden. The plasma nicotine (smokers only) and WBC levels were measured in venous blood taken immediately afterwards. The mean (SD) WBC was 7.37 (1.39) in smokers and $6.73(1.17) \times 109 / 1$ in non-smokers. In smokers, there was no relation between WBC and cigarette consumption on the test day $\left(r_{s}=0.33, p>0.3\right)$ or on usual days $\left(r_{s}=0.09\right)$. The median (range) plasma nicotine level was $11.2(0.1-36.8) \mathrm{ng} / \mathrm{ml}$ in smokers, and there was a significant correlation between the WBC and plasma nicotine levels $\left(r_{s}=0.58, p<0.05\right)$, but not between endexpired $C O$ and $W B C$ in smokers $\left(r_{s}=0.43, p>0.1\right)$ or nonsmokers $\left(r_{s}=0.03\right)$. This study reveals a significant association between the WBC in smokers and an individual constituent of cigarette smoke. However, it does not distinguish whether nicotine itself raises the WBC or whether it acts as a marker for other smoke constituents.

Rapid diagnosis of sputum negative miliary tuberculosis using the flexible fibreoptic bronchoscope

PA WILlCOX, SR BENATAR, PD POTGIETER, ED BATEMAN Department of Medicine, University of Cape Town and Groote Schuur Hospital, Observatory, Cape, South Africa In miliary tuberculosis, sputum is often negative on direct smear and delays in diagnosis are common. Previous reports on the use of the flexible fibreoptic bronchoscope in securing a prompt diagnosis in this situation have been scanty, and restricted to small numbers of patients. We report 40 patients with sputum smear negative miliary tuberculosis who were subjected to bronchoscopy (42), bronchial brushing and transbronchial biopsy. The overall diagnostic yield was $81 \%$. Bronchial brushings yielded Mycobacterium tuberculosis in 23/41 bronchoscopies $(56 \%), 14$ on direct smear and a further nine on culture only. Transbronchial biopsies were diagnostic in $28 / 41$ procedures $(68 \%), 27$ by positive histology and one case exclusively by culture of the biopsy specimen. A rapid diagnosis was established in the majority of positive cases $(32 / 34$, i.e. $94 \%$ ), either by positive direct smear of brushings only (5), histology only (18) or by both positive direct smear and histology (9). Only one case was exclusively diagnosed by culture of brushings and another by culture of brushings and biopsy specimen. Fibreoptic bronchoscopy is, therefore, a valuable technique for rapidly establishing the diagnosis of miliary tuberculosis.

Long term follow up of a clinical trial of six month and four month regimens of chemotherapy in the treatment of pulmonary tuberculosis

SK TEO, TH TAN for the Singapore Tuberculosis Service and the British Medical Research Council Chinese, Malay and Indian patients in Singapore with newly diagnosed sputum smear positive pulmonary tuberculosis received 2 months of daily streptomycin, isoniazid, rifampicin, and pyrazinamide, followed by daily isoniazid and rifampicin either with or without pyrazinamide, allocated at random. Both regimens were given for a total duration of either six or four months by random allocation. All 330 patients with drug sensitive strains pretreatment had a favourable bacteriological response during chemotherapy, and only two $(1 \%)$ of 158 in the two six month series compared with $15(10 \%)$ of 156 in the four month series relapsed bacteriologically up to 30 months after the start of chemotherapy. A long term follow up was subsequently conducted, the patients being seen five to eight years after admission to the study. Only one of the 138 patients assessed in the six month series relapsed after 30 months, compared with five of the 130 in the four month series. None of the 27 patients with bacilli resistant to isoniazid, streptomycin, or both drugs pretreatment assessable at long term follow up relapsed after $\mathbf{3 0}$ months. The long term follow up shows that the excellent early results achieved by the six month regimens have been maintained.

\section{Bone tuberculosis in Leicestershire}

GJ FANCOURT, P EBDEN, TF STOYLE, P GARNER Glenfield General Hospital, Leicester We have conducted a survey of notification of bone tuberculosis in Leicester during 1978-1983 (inclusive). Sixty-nine case notes confirmed tuberculosis (mean age 40.2 years, 39 male, 54 Asian); mean length of symptoms was $\mathbf{8 . 4}$ months, the commonest being pain and swelling. The diagnosis (further delayed for 
3.1 months) was established by evidence of bone involvement plus one of the following: positive Heaf test (54/56), positive culture at bony sites $(43 / 45)$, or suggestive histology (30/34). There were no resistant organisms. Chemotherapy (mean duration $\mathbf{1 6 . 2}$ months) was well tolerated. The spine was the site most often involved (37 patients, 34 Asians) with abscess formation common (17 patients). Four who presented with spinal cord compression received a mean of eight months bed rest; three required decompression and one died. No patient developed neurological signs on treatment. Fourteen others received an average of $\mathbf{2 . 3}$ months bed rest. In this predominantly Asian immigrant population, spinal tuberculosis is common, but does not progress to cord compression on treatment. For those without cord compression, the course and outcome was similar whether or not they were treated with bed rest.

\section{Bone tuberculosis in Brent}

PJ LUCE, WS TAOR, MW MCNICOL Central Middlesex Hospital and Willesden Chest Clinic In the last 20 years 268 patients with bone tuberculosis have been treated in Brent. We report on 181 patients seen in the last 10 years, of whom 160 were Asian. There were 96 men (average age 36 years) and 85 women (average age 38 years). Diagnosis was made on clinical and radiological grounds. Tuberculin testing and measurement of ESR were not helpful. The chest radiograph was abnormal in $28 / 98$. Histological or bacteriological proof were not routinely sought, but biopsies were positive in $70 / 79$ patients, and microbiology in 54/104. Patients were supervised in a combined clinic. Chemotherapy was given for one year (currently isoniazid, rifampicin with initial pyrazinamide). Surgery and immobilisation were not routinely practised. Abscesses were sometimes drained, biopsies done, and spinal lesions operated on for major neurological complications. A total of 93 surgical procedures were undertaken. The spine was the single commonest site, being involved in 80 patients, of whom 22 had disease at other sites, and 27 had paravertebral abscesses. The dorsal spine was the most often involved (48 patients). Forty-five patients had anterior disease, and 15 posterior disease. Eleven patients had involvement of more than one part of the vertebra. There was neurological involvement in 22 patients; surgery was required in nine. Follow up data on 106 patients seen for more than 2 years after diagnosis showed cure and good or excellent functional results in 105 . Bone healing appears to be better without surgery.

The detection and management of tuberculosis in common hostel dwellers

AJ FRANCE, S CAPEWELL, M ANDERSON, AG LEITCH Chest Unit, City Hospital, Greenbank Drive, Edinburgh 10 Tuberculosis remains common in the vagrants, alcoholics and others using the common hostels (lodging houses) in many of our big cities. Hostel dwellers in Edinburgh have been regularly screened for pulmonary tuberculosis (PTB) since 1957. Sixty-eight cases of PTB were notified during the seven years 1976-1982: $42(65 \%)$ were detected by 4687 hostel survey radiographs, a detection rate of $896 / 10^{5}$, and a further 26 presented with symptoms. Disease was more advanced in the symptomatic hostellers by both radiological and bacteriological criteria with twice as many being sputum smear positive $(58 \%$ vs $26 \%, p<0.05$ ). Full clinical details were available for 65 of the 68. Four were diagnosed at post mortem examination and two had chemotherapy stopped because the disease was considered inactive. Of the remaining 59 eligible for treatment, $47(80 \%)$ received a complete course of adequate chemotherapy: 16 as hospital in-patients, 26 first in hospital and then under out-patient supervision and five simply as supervised out-patients. None relapsed. Twelve $(20 \%)$ of the 59 defaulted from supervision after a mean treatment period of 2.4 months.A centralised regular $x$-ray screening programme remains valuable in the detection of tuberculosis in hostel dwellers. Supervised out-patient chemotherapy is surprisingly successful in the treatment of these "problem patients".

Positive tuberculin tests: The influence of age and previous BCG vaccination

AJ france, S CAPEWell, ag Leitch Chest Unit, City Hospital, Greenbank Drive, Edinburgh Heaf tests were performed in $\mathbf{8 3 5}$ adults and children seen during one year in a Tuberculosis Contact Clinic in Edinburgh. All subjects with a past history of tuberculosis, or who subsequently developed evidence of tuberculosis infection and 63 Asians were excluded to leave $\mathbf{7 4 9}$ 'healthy' adults and children broadly representative of the local caucasian population. All Heaf tests in 178 children without BCG vaccination were negative or Grade 1 whereas $16(73 \%)$ of the 22 children with a history of previous BCG vaccination were weakly positive, Grade I or II. Two hundred and seventy adults without previous BCG vaccination showed an increasing incidence of strongly positive Heaf tests (Grade III or IV) with age, reaching a peak of 55\% in the 45-65 age group; beyond the age of 65 this fell to $37 \%$. 281 adults with previous BCG vaccination showed significantly more Heaf Grades I and II, less negatives and less strong positives than the unvaccinated group $(p<0.01)$. A strongly positive Heaf test (III-IV) is a frequent finding in a healthy adult and has little discriminatory value in the diagnosis of active tuberculosis in Edinburgh, and by implication elsewhere in the United Kingdom. Positive tuberculin tests should be viewed in the context of the tuberculin profile of the local population.

The effect of combined versus single anti-tuberculosis drugs on in vitro sensitivity patterns of $M$ malmoense and $M$ xenopi

J BANKS, PA JENKINS Chest Unit, Llandough Hospital, Penarth, and Mycobacterium Reference Unit, University Hospital of Wales Non-tuberculous mycobacteria often show in vitro resistance to first line anti-tuberculous drugs. Despite this there is frequently a poor correlation between sensitivity result and clinical response in many patients infected with these organisms and combination chemotherapy using standard drugs is often effective. We 
have studied the effect of combining two drugs in the culture media on the in vitro sensitivity patterns of eight strains of $M$ malmoense and seven strains of $M$ xenopi. Sensitivity patterns were tested against ethambutol, rifampicin, streptomycin and isoniazid. Most strains showed borderline or complete resistance to single drugs but the combination of rifampicin with ethambutol succeeded in reducing the minimum inhibitory concentration (MIC) for each drug to the lowest concentration used, for all strains of $M$ malmoense and five of the seven strains of $M$ xenopi. With the exception of the ethambutol/isoniazid combination the MICs for other drugs were lower when used in combination than when used alone. The results suggest that in vitro sensitivity testing against drugs in combination may correlate better with clinical response in patients with these infections and might provide more useful information to the clinician planning treatment regimens.

Heterotransplantation of human bronchial tumours to immunosuppressed mice: a useful model for assessing anticancer drugs

RJ FERGUSSON, J CARMICHAEL, LE ANDERSON, JF SMYTH Imperial Cancer Research Fund Medical Oncology Unit, Western General Hospital, Edinburgh A laboratory test which could assess the sensitivity of an individual patient's tumour to various chemotherapeutic agents using small numbers of cells cultured in vitro has long been considered an attractive concept. Attempts so far to achieve such a system have met with little success. However it is now possible to grow human bronchogenic tumours in immune deprived mice, and use these tumours for drug testing. We have established a number of bronchial carcinoma xenografts in CBA mice rendered immunodeficient by neonatal thymectomy followed three weeks later by whole body irradiation (720 rads) after a priming dose of cytosine arabinoside. Growth rates of individual tumours are fairly constant and the histological and chromosomal characteristics of the original tumour are maintained through multiple serial passages over many months. By using tumour growth delay as the principal end point, we have used this model system to assess the response of histologically different lung tumours to various chemotherapeutic agents and in particular to evaluate newer anticancer treatments hitherto untried in patients with bronchial carcinoma.

\section{Immunostaining of bronchial carcinomas using a panel of} monoclonal antibodies

FM MOSS, LG BOBROW, M SHEPPARD, M GRIFFITHS, D ROWE, PCL BEVERLEY, B ADDIS, RL SOUHAMI Imperial Cancer Research Fund, Department of Pathology, Department of Oncology, Faculty of Clinical Sciences, University College London, and Brompton Hospital, London A panel of seven monoclonal antibodies has been used to stain $\mathbf{4 0}$ bronchial carcinomas of different histological types. Three of these antibodies recognise epitopes on cytokeratins, three recognise other epithelially associated antigens and one recognises an antigen found on neuroectodermal tissue. Immunoperoxidase was used as the detection system. Seventeen of 18 small cell lung carcinomas (SCLC) reacted with all the antibodies tested. There was variation both in the number of cells staining and in the intensity of staining. The most consistent staining was with the antibody recognising the neural antigen. Non-small cell carcinomas (NSCLC) showed a similar staining pattern with the epithelial antibodies. Squamous carcinomas and adenocarcinomas did not react with the neural antibody. However 4/6 large cell carcinomas reacted strongly with this reagent. The expression of epithelial antigens by SCLC provides further evidence that it is a true epithelial tumour. The observation that some large cell carcinomas share a neural antigen with SCLC which is not expressed by other NSCLC suggests that large cell and SCLC share a common pathway of differentation. The variation in phenotype within and between tumours has implications for immunotargetting and for the detection and removal of tumour cells from bone marrow.

Epidermal growth factor and its receptor in normal and malignant lung tissue

D VEALE, C MARSH, T ASHCROFT, AL HARRIS, GJ GIBSON Regional Cardiothoracic Centre, Freeman Hospital, Newcastle upon Tyne Epidermal growth factor (EGF) is a growth promoting agent found in normal human plasma and tissues which is known to stimulate proliferation of cultured cells (Osborne et al, Cancer Res 1980;40:2361-66). Its mode of action is similar to that of some oncogene products, and the aminoacid sequence of the V-erb-B oncogene protein closely resembles a truncated EGF receptor (EGFr) (Downward et al, Nature 1984;307:521-27). Cultured tumour cell lines exposed to EGF have been shown to respond by synthesising DNA and undergoing cell division. Studies in breast cancer have demonstrated a relationship between numbers of EGFr and presence of metastases. (Sainsbury et al, Lancet 1985;1:364-66). We have examined 29 lung cancers and 14 non-malignant lung specimens for the presence of EGFr and EGF by the immunoperoxidase method. Slides were graded for positive staining by two independent observers, on a scale from 0 to +++ (Table).

\begin{tabular}{c|cc|cc}
\hline Score & \multicolumn{2}{|c|}{ Tumour $N=29$} & \multicolumn{2}{c}{ Lung $N=14$} \\
\hline & EGF & EGFr & EGF & EGFr \\
\hline+++ & 6 & 5 & 1 & 0 \\
++ & 8 & 11 & 0 & 3 \\
+ & 10 & 10 & 7 & 7 \\
0 & 5 & 3 & 6 & 4 \\
\hline
\end{tabular}

Thus we conclude that staining for EGF and EGFr is more marked in lung cancer than in normal lung tissue. 
The accuracy of cytological diagnosis from percutaneous lung needle biopsy in pulmonary neoplasms

AA ROBINSON, CDR FLOWER, v BARKER Papworth Hospital, Papworth Everard, Cambridge The accuracy of cytological typing of pulmonary neoplasms from material obtained by percutaneous lung needle biopsy was compared to the eventual pathological diagnosis made at operative resection or necropsy. A previous report suggested that needle biopsy, though effective for diagnosing malignancy, less accurately predicted the eventual pathology than either bronchoscopic biopsy and aspiration or sputum cytology (Payne CR et al, Thorax 1979;34:294-299). Over nine years (1976-84) 730 percutaneous lung needle biopsies were performed on 683 patients with intrapulmonary masses, each providing material for cytological interpretation. 491 showed evidence of malignancy. A false positive diagnosis occurred in three patients $(0.6 \%)$. Twenty-eight specimens from 24 patients who were subsequently shown to have malignancy were interpreted as showing no cytological evidence of malignancy, giving a false negative rate of $11.7 \%$. Histological material was available in 147 patients. Cytology correctly predicted the final histology in 65 of 97 patients $(67 \%)$ with squamous carcinoma, 17 of 20 patients $(85 \%)$ with adenocarcinoma, and eight of 11 patients $(73 \%)$ with other tumours. In 19 patients with cytologically undifferentiated tumours, seven were squamous, six adenocarcinomas, five other malignant tumours and one undifferentiated carcinoma. Therefore in 91 of 147 biopsies $(62 \%)$ cytological interpretation correctly predicted the histological diagnosis, a finding similar to that of Rudd et al (Thorax 1982;37:462-465).

Adverse reactions and quality of life during combination chemotherafy compared with selective palliative treatment for small cell lung cancer

NM BLEEHEN, PM FAYERS, DJ GIRLING, RJ STEPHENS for the MRC Lung Cancer Working Party Multi-drug cytotoxic chemotherapy for small cell lung cancer has a high level of toxicity, and not all clinicians consider that its immediate use is justified. A total of $\mathbf{1 5 6}$ patients in a multi-centre study were therefore allocated at random to ECMV (etoposide, cyclophosphamide, methotrexate and vincristine) or ST (selective treatment, in which radiotherapy and/or single drug chemotherapy with cyclophosphamide were given as required to relieve symptoms). In the ECMV series compared with the ST series, survival was prolonged $(p<0.0001$, log-rank test), median survivals being 33 and 17 weeks, but reported adverse reactions (ignoring alopecia) were commoner $\mathbf{( 7 7 \%}$ vs $35 \%)$. The commonest reactions were vomiting (37\% vs $10 \%)$ and haematological reactions $(33 \%$ vs $10 \%)$, the latter predominantly leucopenia $(23 \%$ vs $8 \%)$, defined as WBC $<3000 / \mathrm{mm}^{3}$. Peripheral neuropathy occurred in $8 \%$ of the ECMV but in none of the ST patients. Quality of life was assessed using a diary card completed daily by the patient. Compliance in its use varied greatly from centre to centre. During the first 12 weeks, vomiting on one or more occasions was reported in $6 \%$ of patient-days in the ECMV compared with $2 \%$ in the ST series. Level of activity was normal for $27 \%$ and $36 \%$ of patient-days respectively.
Differences between the two series with respect to mood, degree of anxiety, and general condition were small.

Controlled trial of maintenance (M) vs no maintenance (NoM) chemotherapy in the treatment of small cell lung cancer

NM BLEEHEN, PM FAYERS, DJ GIRLING, RJ STEPHENS for the MRC Lung Cancer Working Party A total of 544 patients was entered into a study in which 505 with small cell lung cancer and good performances status were assessable. They were all prescribed an initial six courses of etoposide 120 $\mathrm{mg} / \mathrm{m}^{2}$, cyclophosphamide $1 \mathrm{~g} / \mathrm{m}^{2}$, methotrexate 35 $\mathrm{mg} / \mathrm{m}^{2}$, and vincristine $1.3 \mathrm{mg} / \mathrm{m}^{2}(\max 2 \mathrm{mg})$ intravenously on day 1 , plus etoposide $240 \mathrm{mg} / \mathrm{m}^{2}$ by mouth on days 2 and 3 , at 3 weekly intervals. Patients with limited disease received radiotherapy, $40 \mathrm{~Gy}$ in 15 fractions in 3 weeks, of the primary site between courses 2 and 3 . Response rates three weeks after the second course were complete in $10 \%$ and partial in $72 \%$. Treatment was well tolerated. At the end of the initial courses, patients in complete or partial response (total 266) were randomised to maintenance (six more courses of the same drugs) or no maintenance chemotherapy. There was no survival advantage to either series.

\begin{tabular}{lccc}
\hline & Total & \multicolumn{2}{c}{ Randomised patients } \\
& patients & $M$ & NoM \\
\hline Total & 505 & 132 & 134 \\
Limited disease & 379 & 99 & 99 \\
Extensive disease & 126 & 33 & 35 \\
Median survival (wks)** & $39(35-42) * *$ & $57(50-63)^{* *}$ & $50(46-56)^{* *}$ \\
\% alive at 1 year* & $32(27-37 * *$ & $56(47-65)^{* * *}$ & $46(37-55)^{* *}$ \\
\% alive at 2 years* & $8(4-12) * *$ & $11(2-20)^{* * *}$ & $15(5-25)^{* *}$ \\
\hline *Actuarial & $* 95 \%$ confidence limits & & \\
\hline
\end{tabular}

Can tumour volume be estimated accurately from the plain chest radiograph?

JJ GILMARTIN, A MOHAMEDANI, T ASHCROFT, GJ GIBSON Regional Cardiothoracic Centre and Department of Pathology, Freeman Hospital, Newcastle upon Tyne Knowledge of the volume of a lung tumour is of value to the clinician in assessing both the rate of growth and the response to therapy. To determine the accuracy of radiographic estimates of tumour volume we compared measurements taken from routine chest radiographs with the actual volume of the tumour measured after excision. Twenty-two lung specimens obtained at thoracotomy each containing a primary bronchial tumour were fixed in formol saline by bronchial perfusion. The tumour was dissected out and weighed, and its volume measured by water displacement. A second observer independently measured the 3 maximum radii ( $a, b$ and $c$ ) of the tumour from pre-operative standard $6^{\prime} \mathrm{PA}$ and lateral chest radiographs which were taken without markers for measurements. The radiographic volume was calculated from the formula for an ellipsoid $(V=4 / 3 \pi \mathrm{abc})$, and corrected for $x$-ray magnification assuming a magnification factor of 1.1. The maximum radiographic diameter ranged from 2 to $15.4 \mathrm{~cm}$ and actual tumour volume ranged from 2 
to $747 \mathrm{ml}$ (median $21.5 \mathrm{ml}$ ). The radiographic estimate was an average of $2.8 \mathrm{ml}$ smaller (SD of difference $9 \mathrm{ml}$ ) than the actual volume and the difference was not statistically significant (paired $\mathrm{t}$ test). The error (ml) was not a function of tumour size. Simple volume measurements from plain standard chest radiographs allow measurement of tumour volume with a mean error (ignoring sign) of $10.5 \mathrm{ml}$ or $26 \%$.

\section{Long term consequence of inhaling a foreign body}

H DAVIES, I GORDON, D HEAF, P HELMS, D MATTHEW, V NOVELLI Hospital for Sick Children, London Although the acute effects of inhaling a foreign body (FB) have been studied in detail, little is known about the long term consequence for the growing lung. Over the period January 1980 to December 198426 children were discharged from this hospital with a bronchoscopically proved diagnosis of foreign body inhalation. Twenty-one children, 14 boys and seven girls, mean age 2.16 years (range 1 to 5.75 ), were recalled for clinical assessment, chest radiography and $81 \mathrm{~m} K r$ ventilation/ $99 \mathrm{~m}$ Tc perfusion lung scan ( $\dot{V} / Q$ scan). All except one had inhaled a peanut; in 8 cases the FB lodged in the right lung, in 11 it lodged in the left, in one it lodged in the carina, and in one case an FB lodged in both lungs. In 11 cases removal was delayed beyond 7 days. Nine children needed more than one bronchoscopy $(\max 4)$. Mean follow-up was 2.05 years $(0.38$ to 4.8$)$. Fourteen were asymptomatic, 13 had a normal chest radiograph but only five had a normal $\dot{V} / Q \dot{Q}$ scan. Foreign bodies in the left lung carried a significantly worse prognosis, as did the appearances of collapse/consolidation on the initial chest radiograph. Only one of 11 children had a normal lung scan when removal had been delayed beyond seven days. We conclude that pulmonary sequelae after FB inhalation are not uncommon. Persisting abnormalities of regional ventilation are more likely if it lodges in the left lung, if there is collapse/consolidation on the initial chest $\mathrm{X}$-ray or if removal is delayed beyond seven days.

\section{A new rigid bronchoscope for bronchoscopic laser therapy}

K MOGHISSI, A JESSOP, M DENCH Humberside CardioThoracic Surgical Centre, Hull Bronchoscopic laser therapy using a flexible fibreoptic bronchscope has been used for clearance of the major airways affected by obstructive lesions. The flexible instrument however has major shortcomings. We have designed a rigid laser bronchoscope (made by G.U. Company, London). The instrument consists of two parts:

1) A Negus type bronchoscope with two Venturis.

2) A cylindrical rod which fits into the bronchoscope and has three peripheral and one central opening (channel). The peripheral openings are for:

a) Suction.

b) Washout.

c) Laser fibre.

The central opening accomodates the G.U. bronchoscopic telescope. The channel for the laser fibre has a movable tip which guides and can alter the "firing" angle of the laser. The instrument has been used in 10 patients with satisfaction. Blood gas monitoring during the procedure (under general anaesthesia) has shown a satifactory level of ventilation through the Venturi channels in all cases.

A new approach in the treatment of inoperable malignant tumours in the trachea and main bronchi, using iridium 192 and Neodym-YAG laser

HN MACHA, K KOCH, M STADLER, W SCHUMACHER, D KRUMHAAR Department of Chest Diseases, Krankenhaus Spandau, West Berlin, Germany (sponsored by I Gregg) Forty-five patients with stenosis or occlusion of the trachea or main bronchi due to inoperable malignant tumours were treated by intrabronchial high dose iridium 192, using a computer controlled afterloading technique. The afterloading device was introduced under local anaesthesia and positioned with a flexible bronchoscope under fluoroscopic control. In cases where a bronchus had been completely occluded by the tumour, the Neodym-YAG laser was used to form a channel for the afterloading device. Owing to the high activity of the iridium source, an irradiation time of only one to five minutes was required. A rapid reduction of the stenosis with consequent relief of symptoms was observed in $67 \%$ of the patients and was confirmed by improvement in their chest radiographs, perfusion scans and pulmonary function tests. No deleterious effects of the treatment occurred.

Intraoperative assessment of nodal staging in carcinoma of the bronchus

J GAER, P GOLDSTRAW Brompton Hospital, London One aspect in the preoperative assessment of lung cancer is the identification of patients with N2 disease who will not benefit from pulmonary resection. It is increasingly recognised that careful sampling of apparently normal mediastinal glands at thoracotomy will disclose occult N2 disease in a number of patients. Such dissection is necessary if we are a) to obtain a true assessment of our preoperative evaluation, b) to predict prognosis accurately, and c) to use adjuvant therapy intelligently in future studies. In North America such intraoperative staging is checked on frozen section. This is difficult in the UK, and most surgeons will rely upon naked eye assessment. We have attempted to assess the accuracy of this approach by retrospectively reviewing 100 thoracotomies performed in our Unit from 1983 to 1985 . Preoperatively all patients were assessed not to have N2 disease. A total of 287 mediastinal nodes were examined by both naked eye and formal histological examination. False positive naked eye assessment occurred in 13 patients $(4.5 \%)$, false negative assessments in 9 $(3.1 \%)$. Thirty-five of the 287 nodes examined $(12.2 \%)$ contained metastatic disease. pTNM N2 disease was established in $21(21 \%)$ of patients. 
The influence of tumour size and positive lymph nodal invasion on five year survival after surgery for oat cell carcinoma

K JEYASINGHAM, E ANDRIANOPOULOS, N IBRAHIM Frenchay Hospital, Bristol Of 191 consecutive patients who underwent surgical resection of oat cell carcinoma of the lung between January 1969 and December 1978, 31 patients died postoperatively. Seven patients were lost to follow-up. The remaining 153 were followed up regularly. Twenty-two of these patients survived five years or more. In those patients where a lobectomy was deemed feasible, the five year survival was $30.9 \%$ (or after exclusion of early deaths, $39.4 \%(12 / 33))$, whereas if pneumonectomy was required for tumour clearance, the five year survival was only $7.5 \%$ (corrected 8.9\% (10/112)). Analysis of the tumour load at the time of surgery, based on the TNM status, revealed that tumour size played no significant role in determining the chances of five year survival. Invasion of the mediastinal lymph nodes (N2), however, showed statistically significant difference in survival when compared with no nodal invasion at all $(p=0.01)$. Stage I (T1 NO MO) oat cell carcinoma resectable at lobectomy produced a corrected five year survival of $\mathbf{4 5 . 8 \%}$. It is concluded that despite the current fashion of not resecting oat cell carcinomas, surgery has a role to play as the definitive treatment (with or without chemotherapy as an adjunct, in N2 disease).

\section{Measurement of abdominal wall compliance}

JM GOLDMAN, MDL MORGAN, DM DENISON Lung Function Unit, Brompton Hospital, Fulham Road, London. The intraabdominal pressure generated when the diaphragm descends on inspiration depends on the compliance of the anterior abdominal wall; it determines the extent to which the diaphragm lifts the rib cage on breathing in (De Troyer et al, J Appl Physiol 1982;53:30-39). We have estimated abdominal wall compliance by measuring gastric pressure and relating it to abdominal wall displacement. The latter was assessed using optical contour mapping, which can partition ventilation between rib cage and abdomen (Morgan et al, Thorax 1984;39:101-106). We studied pressure volume displacement curves in six relaxed normal subjects and six tetraplegic patients (all lying supine). Normal subjects partitioned a mean of $31 \%$ (SD $7.2 \%$ ) of expired volume to the abdomen and their abdominal wall compliance decreased at high lung volume as suggested previously by Konno and Mead (J Appl Physiol 1968;24:544-8). Tetraplegic patients partitioned greater volumes to the abdomen (77\% (SD 34\%)). Their abdominal walls were more compliant, especially at high lung volume. The increased compliance has a detrimental effect on lower rib cage expansion and may be worth correcting.

\section{Diaphragmatic weakness and orthopnoea}

A MIER, J MILLER, C BROPHY, J MOXHAM, M GREEN Brompton Hospital, Fulham Road, London Complete paralysis of the diaphragm is known to cause dyspnoea, orthopnoea and a supine fall in vital capacity $(\Delta V C)$ of $>25 \%$.
However the clinical features of partial weakness of the diaphragm are less pronounced. We studied twelve patients aged 15-72 years with diaphragm weakness as judged by low transdiaphragmatic pressures (range 6-60 $\mathrm{cmH}_{2} \mathrm{O}$ ) during a sharp maximal sniff (Sniff Pdi: normal $>82$ $\mathrm{cmH}_{2} \mathrm{O}$, Miller et al, Clin Sci, in press). All patients complained of dyspnoea on exertion but only those five with the lowest sniff Pdi values $\left(<26 \mathrm{cmH}_{2} \mathrm{O}\right)$ complained of orthopnoea. Their $\triangle \mathrm{VCs}$ were $>25 \%$. The remaining seven patients with sniff Pdi over $30 \mathrm{cmH}_{2} \mathrm{O}$ were not breathless when supine, had no abdominal paradox and $\Delta \mathrm{VC}$ was $<25 \%$. The specific gravity of the abdominal contents is about $1 \mathrm{cmH}_{2} \mathrm{O}$ per $\mathrm{cm}$ distance; when supine the five weakest patients were unable to generate the Pdi required during inspiration to prevent the weight of the abdominal contents from displacing the diaphragm cephalad. The other seven patients, with moderate weakness, could counteract the weight of their abdominal contents. Thus, the patients with severe diaphragm weakness complained of orthopnoea. There was a further group of patients with moderate weakness who complained only of shortness of breath on exertion.

\section{Cardiorespiratory consequence of idiopathic scoliosis}

EH SAWICKA, RA PARKER, MA BRANTHWAITE Brompton Hospital, London The cardiorespiratory consequences of unfused idiopathic scoliosis have been assessed in a retrospective survey of 54 patients seen at or beyond $\mathbf{3 0}$ years of age. Disabling breathlessness for which there was no other cause was present in $\mathbf{1 6}$ patients, scoliosis having been noticed first before five years in all. Patients with a vital capacity at presentation of less than $50 \%$ predicted (based on span) tended to deteriorate with time, and the lowest values for vital capacity were associated with scoliosis of early onset. 10 of 15 patients with scoliosis first noticed before five years of age have developed cardiorespiratory failure before the age of 60 ; whereas among 28 patients with scoliosis first noticed at or after 11 years, there is only one with disabling dyspnoea attributable solely to scoliosis. Four patients developing cardiac failure after 60 years all have associated cardiorespiratory disease and none had scoliosis of early onset. 19 patients with unfused idiopathic scoliosis have died, 11 from cardiorespiratory failure, in 10 of whom the curve had first been noticed at less than five years. It is concluded that idiopathic scoliosis of adolescent onset is unlikely to lead to serious cardiorespiratory complications in the absence of associated disease.

Cuirass assisted ventilation in chest wall and neuromuscular disease

WJM KINNEAR, JM SHNEERSON, GD SHAW, T HIGENBOTTAM Newmarket General Hospital and Papworth Hospital We have investigated the value of resting the respiratory muscles by the use of cuirass respirators in six patients with generalised neuromuscular disease, five patients with non-paralytic scoliosis and three with thoracoplasty. Reduction in inspiratory muscle activity during assisted ventilation was demonstrated by a 
$27 \%$ decrease in surface diaphragmatic EMG $(p<0.05)$. There was a decrease in oxygen consumption during assisted ventilation of $7 \%$, which was not statistically significant. Maximal inspiratory pressure (MIP) and maximal expiratory pressure (MEP) were measured at the mouth using an occluded mouthpiece with a standard leak before and after a period of nocturnal cuirass assisted ventilation, mean 7 months (range 2-18). MIP increased by $50 \%(\mathrm{p}<0.05)$ and MEP by $15 \%(\mathrm{p}<0.05)$. The increase in MIP was greater in the scoliotic and thoracoplasty patients $(59 \%)$ than neuromuscular patients $(38 \%)$ whereas the increase in MEP was greater in the neuromuscular patients (21\% and $10 \%$ respectively). There was no significant correlation between the changes in MIP or MEP and $\mathrm{PaO}_{2}$ (0.32), in MIP and RV (0.03), or in MEP and TLC (0.24). We suggest that cuirass assisted ventilation is a useful way of improving respiratory muscle function in neuromuscular and chest wall disease, perhaps by relieving muscle fatigue.

Protriptyline for nocturnal hypoventilation in restrictive chest wall disease

AK SIMONDS, RA PARKER, EH SAWICKA, MA BRANTHWAITE Brompton Hospital, Fulham Road, London $\mathrm{SW3}$ Episodes of hypoventilation during REM sleep occur in patients with restrictive chest wall disease and probably contribute to the development of respiratory and ultimately cardiac failure. The effects of protriptyline, 10-20 mg nocte, have been evaluated in eight patients with chest wall disease (7F, 1M; age 26-68 years) who presented in cardiac or respiratory failure (VC $21-43 \%$ predicted; $\mathrm{PaCO}_{2}$ at presentation 5.5-7.9 kPa). Polysomnography was carried out before and after 4-6 weeks' treatment with protriptyline. Five patients with cardiac failure had previously required one or more periods of negative pressure ventilation. Cardiac failure did not recur in any patient once protriptyline was started. Median arterial oxygen tension while awake increased from $8.0(6.1-9.9)$ to $9.0 \mathrm{kPa}(6.8-9.8)(\mathrm{p}=0.05)$ but the median carbon dioxide tension was unchanged. Total sleep time was unaltered but the proportion of REM sleep fell from $22 \%$ to $12 \%$ $(p=0.05)$. Total time spent with an arterial oxygen saturation of less than $80 \%$ decreased $(p=0.01)$ and this correlated with the reduction in REM time $(r=0.67$, $\mathrm{p}<0.05$ ). Anticholinergic side-effects were noted in most patients but did not limit treatment.

Allergy to isphaghula in workers manufacturing a bulk laxative

K MCCONNOCHIE, J EDWARDS, R FIFIELD, G COLLINS, D TROTMAN MRC Pneumoconiosis Unit, Llandough Hospital, Penarth, Wales, and Supraregional Protein Reference Unit, Cardiff Royal Infirmary, Cardiff Husks of Plantago ovata, also known as psyllium or ispaghula, are hydrophilic, a property which makes them useful bulk laxatives. Asthma, conjunctivitis, skin irritation and nasal congestion are known to occur in individuals handling the substance, but these case reports can give no indication of prevalence. We have studied 92 people engaged in the manufacture of a laxative preparation from ispaghula. The process requires 13 workers for each shift drawn from a pool within the factory. All subjects completed the MRC Questionnaire on Respiratory Symptoms (1976) and were skin prick tested with common allergens and extracts of ispaghula husk. Blood was examined for total IgE and for specific IgE antibodies to ispaghula by radioallergosorbent assay (RAST). Peak flow readings were recorded on all subjects exposed to ispaghula at the time of the study. Forty-eight employees gave a history of work related symptoms. In 31 cases these symptoms were of a trivial nature, but 17 employees complained of chest tightness and wheeze. Four of these were considered to have occupational asthma. The remaining 13 subjects showed no evidence of sensitisation to ispaghula but as a group contained more cigarette smokers and had more respiratory morbidity than their workmates.

Effect of welding fumes on the lungs of young shipyard welders

FM EL-GAMAL, DJ CHINN, JJ WELLER, JE COTES Respiration and Exercise Laboratory, University Department of Occupational Health, Medical School, Newcastle upon Tyne Studies of shipyard welders have usually included older men whose fume exposure is now only of historical interest. The present subjects were young men (18-47 years old), comprising 180 welders, 152 caulker burners, and 181 other tradesmen from one yard. Anthropometry, respiratory symptom and occupational questionnaires, forced spirometry, single breath nitrogen and transfer factor tests, and an exercise test were performed. The results were submitted to principal component regression analysis. This was used instead of multiple regression analysis to allow for collinearity among the independent variables. Welders and caulker burners who regularly worked in confined spaces were found to have significantly raised values for closing volume (CV\% and $\mathrm{CC} \%$ ), residual volume $(R V \%)$ and exercise ventilation $\left(\dot{V} E_{45}\right)$. They had significantly reduced ventilatory capacity $\left(\mathrm{FEV}_{1} \%, \dot{\mathrm{V}} \max _{50}\right.$ and $\left.\dot{V} \max _{25}\right)$ and a reduced transfer factor. Being older and being a smoker exerted additional adverse effects. Amongst the youngest men (ages 18-25 years) CV\%, CC\% and RV\% were significantly increased and the men had more chronic bronchitis than other tradesmen of the same age and smoking habits. Thus, independently of age and smoking, welding fumes exerted a direct adverse effect which was exposure related. The effect was present in very young workers.

A computerised interactive questionnaire in the epidemiology of occupational asthma

AD Blainey, S Ollier, RJ DAVIES Academic Unit of Respiratory Medicine, St Bartholomew's Hospital, London Occupational asthma is increasingly recognised but its epidemiological investigation is hampered by the lack of a bias free questionnaire designed to record histories of asthma and allergic disease. We have developed a questionnaire using a microcomputer program (Interact 3) 
which interacts directly with the interviewee. It contains 122 questions relating to asthma, rhinitis and their allergic precipitants, and occupational respiratory symptoms. It has been adminstered to 133 employees of a grain terminal at the workplace. Seventy-nine percent said they enjoyed completing it, and only $13 \%$ found it hard to understand. One percent of answers were mutually incompatible with others. It took from 12 to 35 minutes to complete (mean 21.3 mins). Symptoms of current asthma derived from the questionnaire correlated well with $\mathrm{FEV}_{1}$ and bronchial reactivity. Reproducibility was assessed in 75 subjects who completed the questionnaire again 7 months later. On this occasion smoking histories recorded by computer were compared with those recorded by a physician interviewer. Concordance for individual symptoms was good, ranging from $73 \%$ for cough to $80 \%$ for wheeze attacks, and there was no difference in symptom prevalence on the two occasions. For only $8 \%$ of interviewees answers differed between computer and physician derived smoking histories. We conclude that administering respiratory questionnaries by interactive microcomputer program is an acceptable, reproducible and bias free method of obtaining a respiratory history in the workplace.

The temporal relationship between airway reactivity and late asthmatic reactions induced by occupational agents

SR DURHAM, BJ GRANEEK, R HAWKINS, AJ NEWMANTAYLOR Brompton Hospital, London We have investigated the temporal relationship between airway reactivity and the development of the late asthmatic reaction in seven patients with occupational asthma. Six patients who developed late asthmatic reactions after inhalation testing (toluene di-isocyanate (1), carmine (1), maleic anhydride (2), and colophony (2)) had significant increases in bronchial responsiveness to inhaled histamine $(p<0.05)$ at 2 to 3 hours after the test. The increase in histamine responsiveness preceded the development of the late reaction in four of the six patients and was independent of changes in airway calibre $\left(\mathrm{FEV}_{1}>\mathbf{9 0 \%}\right.$ pre-test values). The magnitude and time of onset of the late reaction appeared to be related to the intensity of the provoking stimulus and the increase in histamine responsiveness. The one patient who developed an isolated early asthmatic reaction had no increase in histamine responsiveness. We conclude that an early increase in airway reactivity may be necessary for, rather than, as previously suggested, consequent upon, the development of a late asthmatic reaction and could have importance in the diagnosis of occupational asthma.

\section{Immunoglobulin measurements in humidifier fever (HF)}

K ANDERSON, CP MCSHARRY, G BOYD Department of Respiratory Medicine, Glasgow Royal Infirmary, Glasgow

Symptomatic individuals from an outbreak of humidifier fever in a Glasgow electronics factory agreed to answer a doctor administered questionnaire and to provide a blood sample before and eight months after the humidifier system was rectified. Precipitins to HF antigens (including Naegleria gruberi and an unidentified antigen) were detected in nine of 20 symptomatic individuals, none of whom smoked. Total serum IgG was reduced in every case whether or not precipitins were detected (initial sample mean $15.6 \mathrm{~g} / 1$, second sample mean $11.7 \mathrm{~g} / 1$; $\mathrm{p}<0.001$ ), implying increased immune response in all individuals, including those partially protected by cigarette smoke. The major symptoms disappeared in the group after rectification except in one case where the total IgG remained high and precipitins remained strongly positive despite the return of abnormal gas transfer and lung volumes to normal. The chest radiograph, initially abnormal, quickly resolved after a short holiday. Disease activity may be monitored by total IgG levels without more complicated serological investigations or pulmonary function assessment. The chest radiograph may be abnormal in acute disease but is not a sensitive indicator of disease activity.

Advanced squamous carcinoma of the lung: trials of etoposide $v$ no treatment and etoposide $v$ etoposide + cyclophosphamide

G ANDERSON, ET PEEL from the Lung Cancer Treatment Study Group

TRIAL 1 ETOPOSIDE $V$ NO TREATMENT

In a multicentre trial 155 patients with advanced squamous carcinoma of the lung were randomised to receive either no treatment or six cycles of oral etoposide. There were no significant survival differences between the groups but there was a significant difference in survival $(p=0.05)$ for patients with metastatic (M1) disease receiving etoposide. Toxicity of etoposide was not marked.

TRIAL 2 ETOPOSIDE V ETOPOSIDE + CYCLOPHOSPHAMIDE

In a multicentre trial 155 patients with advanced squamous carcinoma of the lung were randomised to receive six cycles of either the same dose of oral etoposide as in Trial 1 or that dose of oral etoposide plus intravenous cyclophosphamide. There were no significant survival differences between treatments but two drugs caused more side effects than one.

Management of pulmonary disease in the acquired immune deficiency syndrome (AIDS)

JB WARREN, J WEBER, S THOM, EE KEAL, AJ PINCHING $S t$ Mary's Hospital, London Between August 1983 and February 1985, 24 bronchoscopies were performed on 21 patients with AIDS at St Mary's Hospital. All were homosexual men aged $22-52$ years (mean 38 ). Bronchoscopy was performed for a clinical suspicion of opportunistic lung infection. The mean $\mathrm{Po}_{2}$ while they were breathing air was $67 \mathrm{~mm} \mathrm{Hg}$ (range 49-100). Pneumocystis carinii pneumonia (PCP) was diagnosed in 12 patients by transbronchial biopsy and 6 of these also showed pneumocysts on bronchoalveolar lavage. Other findings were: endobronchial Kaposi's sarcoma in 3; Candida albicans in 2; Streptococcus pneumoniae in 1; cytomegalovirus in 1. Two patients had PCP with normal chest radiographs . Of the 12 cases of PCP, 11 resolved clinically on trimethoprim/sulphamethoxazole (T/S) and 1 patient died only three days after starting treatment. Four 
others have since died of other opportunistic infections at four weeks, seven weeks, four months and six months after successful treatment of PCP. The remaining seven are alive, one six months after bronchoscopy (mean 3.9). Our results agree with a recent report from the USA that successful treatment of PCP is to be expected in patients with AIDS (Engleberg et al, Am Rev Resp Dis 1984;130:689). However, this depends on accurate diagnosis and early treatment. Of 15 cases treated with $T / S$, 12 developed a florid rash and in some cases fever and increased leucopenia. The high incidence of side effects suggests that empirical treatment is not justified.

Nasál electrical potential recordings - a new diagnostic test for cystic fibrosis?

EW ALTON, JG HAY, C MUNRO, DM GEDDES Brompton Hospital, London An abnormally high potential across nasal epithelium in cystic fibrosis (CF) was first described in 1981 (Knowles $M$ et al, N Eng J Med 305:1489-95), readings being taken from the undersurface of the inferior turbinate. We have confirmed this (Hay JG, Geddes DM, Thorax $1985 ; 40: 493-6)$, but the technique is difficult, with some overlap of values. We have recorded voltages existing along the floor of the nasal cavity, in a control population and amongst patients with CF, Young's syndrome and bronchiectasis. The technique is rapid, easily performed and well tolerated. The control population $(n=20)$ showed a mean maximum stable voltage of $18 \mathrm{mV}$ lumen negative, and patients with CF $(n=20)$ a mean of $45 \mathrm{mV}(p<0.002$ Mann-Whitney $U$ test), there being no overlap between the two populations. To determine whether this difference was related to problems with mucus clearance or chronic infection, two further groups were studied; seven patients with Young's syndrome had a mean maximal potential difference (p.d.) of $20 \mathrm{mV}$, and a group with bronchiectasis $(n=12)$ a mean of $17 \mathrm{mV}$. In neither case was there overlap with the CF patients, and neither group was significantly different from controls. In view of the apparent discrimination we conclude that this may be an easily performed diagnostic procedure for $C F$. The increased p.d., suggested by Quinton (Nature 1983;301:421-2) to be due to chloride impermeability, does not appear to be secondary to chronic infection or mucus transport problems.

Nebulised ceftazidime compared with gentamicin and carbenicillin in adults with cystic fibrosis infected with $P S$ aeruginosa

RJ STEAD, ME HODSON, JC BATTEN Cardiothoracic Institute, Brompton Hospital, London Long term nebulised gentamicin and carbenicillin were shown to be effective in cystic fibrosis (CF) patients infected with $P s$ aeruginosa (Hodson et al, Lancet 1981 ;ii:1137). Ceftazidime is a highly active against this organism and we compared nebulised i) ceftazidime, ii) gentamicin and carbenicillin and iii) placebo given for four month periods in a randomised crossover study. Gentamicin and carbenicillin were 'open' to the patients but otherwise the study was blind to patients and investigators. On study entry and monthly thereafter patients attended for assessment including measurement of $\mathrm{FEV}_{1}$ and FVC. Eighteen CF patients (age range 16-40 y) were studied. Five were withdrawn: two deteriorated on placebo and were placed on active therapy, two were noncompliant and one could not tolerate placebo. Mean (SD) $\mathrm{FEV}_{1}$ on gentamicin and carbenicillin, $1.70(0.97) 1$, and on ceftazidime, $1.70(1.02) 1$, were greater than on placebo, $1.48(0.85) 1(\mathrm{p}<0.01$ and $\mathrm{p}<0.02$ respectively). Similarly, mean (SD) FVC on gentamicin and carbenicillin, 2.93 (1.05) 1 , and on ceftazidime, 2.95 (1.12) 1, were greater than on placebo, $2.70(1.04) 1 \quad(p<0.05$ and NS respectively). $\mathrm{FEV}_{1}$ and FVC on gentamicin and carbenicillin and on ceftazidime were not significantly different. This study suggests that long term nebulised ceftazidime provides a useful alternative to gentamicin and carbenicillin in CF.

Treatment of purulent bronchiectasis with nebulised antibiotics

RA STOCKLEY, SL HILL, HM MORRISON, D BURNETT Clinical Teaching Block, General Hospital, Birmingham Since long term antibiotic therapy may be important in the management of chronic purulent bronchiectasis (Medical Research Council, Br Med J 1957;ii:255) we have studied the acute and long term effects of nebulised antibiotics in six such patients. All had radiologically proved bronchiectasis, were non-smokers (aged 37-71 years) and had airflow obstruction $\left(\mathrm{FEV}_{1} / \mathrm{FVC}=53.0 \%\right.$ SD 14.0). Each patient had failed to respond to amoxycillin $3 \mathrm{gram}$ sachets twice daily (14 day course) and was subsequently treated with nebulised amoxycillin twice daily for 4 months. Five hundred $\mathrm{mg}$ was dissolved in $5 \mathrm{ml}$ of sterile water $(\mathrm{pH}$ 8.7-9.0) and delivered using a Bard Inspiron air compressor (7-8 1/min) with an Incenti-Neb nebuliser. Patients kept a diary of their symptoms, sputum colour and volume and PEFR (Wright mini peak flow meter). The nebulised antibiotic had no demonstrable acute effect on lung function (mean $\mathrm{FEV}_{1}=1.34$ (SD 0.58) 1 before nebulisation; $1.29(0.54)$ at the end and $1.32(0.55) 1$ after 1 hour). Over 4 months the patients all showed a significant clearance in their sputum from purulent towards mucoid $(p<0.025)$, reduction in volume $(p<0.05)$ and an increase $(\mathrm{p}<0.05)$ in average PEFR from $230.5 \mathrm{l} / \mathrm{min}$ (SD 79.2) to 255 (SD 90.1). No side effects or emergence of resistant organisms has been observed. The results demonstrate the feasibility, acceptability and benefit of long term nebulised antibiotics in these patients.

Nebuliser therapy and cardiac dysrhythmias in patients with COAD

WOCM COOKSON, S JOHN, G MCCARTHY, S MCCARTHY, DJ LANE The Osler Chest Unit, Churchill Hospital, Headington, Oxford, and Department of Geriatrics, Radcliffe Infirmary, Oxford Twenty-four hour ambulatory cardiac monitoring was carried out on three female and six male patients with COAD who were using nebulisers at home. The mean age was 68 years (SD 7.4) and 
the mean FEV 1 was 0.7 litres (SD 0.26). Beta agonist (B-A) (salbutamol $2.5 \mathrm{mg}$ or terbutaline $5 \mathrm{mg}$ ) was given by nebuliser in seven subjects, three of whom were also receiving $0.125 \mathrm{mg}$ ipratropium (I). Two others received $0.125 \mathrm{mg}$ ipratropium without B-A. Nebuliser use (N) was marked and the hour before $\mathrm{N}$ compared with the hour after, for three events. Ectopic activity after $\mathbf{N}$ increased in four patients receiving B-A: one developed atrial flutter and ventricular trigeminy, and another developed ventricular bigeminy and nodal tachycardia. The mean heart rate for the patients receiving B-A was 81 per minute (SD 10).before $\mathrm{N}$ and 84 (SD 12) after $(\mathrm{p}=\mathbf{0 . 0 6 3 )}$. The incidence of wide premature beats was 0.82 per minute (SD 2.56) before $\mathrm{N}$ and 3.91 (SD 8.46) after $\mathrm{N}(\mathrm{p}=0.0001)$, and the incidence of beats showing $R$ on $T$ phenomena was 0.06 (SD 0.15)

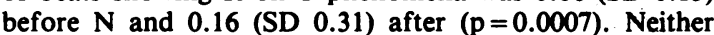
patient receiving ipratropium alone showed any change. Self-administration of nebulised beta agonists by patients with COAD may carry risk.

\section{Nebuliser therapy:- patient compliance and problems}

DC CURRIE, PJ COLE Host Defence Unit, Department of Medicine, Cardiothoracic Institute, Brompton Hospital, London Thirty-nine consecutive out-patients (median age 53 years, range $14-77 ; 25$ female, 14 male; asthma (21), bronchiectasis (16), allergic bronchopulmonary aspergillosis (11), chronic obstructive airways disease (10)) using Inspiron mini-nebulisers with various compressors (on loan) completed a questionnaire to assess compliance and problems with this therapy. Thirty of the 39 patients had been keen to start using a nebuliser. Eleven nebulised two drugs (bronchodilator and antimicrobial), 21 only bronchodilators and eleven antimicrobials alone. Median time taking nebulised drugs was nine months (range three weeks to six years). Thirty-two had received their instruction from Brompton Physiotherapy Department. The median time for each treatment, including preparation, was 15 minutes (range 3-45 minutes); the total time spent daily was 60 minutes (range 12-200 minutes). 2/4 swabs from nebulisers that were not subject to routine sterilisation grew Staphylococcus aureus (in one case this organism was also present in the sputum). There was no growth on 20 swabs from routinely sterilised nebulisers. Thirty-five patients found the treatment helpful; 28 had used the equipment away from home and only two missed sessions frequently. Only nine recorded more than two problems (11 problems with drug or diluent supplies). Thirty-four patients wished to remain on the treatment. In summary, this group of well motivated patients were compliant and experienced no significant problems with taking treatment by nebuliser despite its time consuming nature and the complexity of the equipment.

\section{Measurement of urine salbutamol to monitor the compliance of asthmatics}

CR hORn, E ESSEX, GM COChrane Chest Clinic, New Cross Hospital, London The persisting mortality and morbidity from asthma may be a consequence of under-use of therapy by asthmatic patients. Assessment of compliance by questionnaire alone is unreliable, over-estimating by up to $30 \%$. Verification by drug assay in biological fluids is therefore mandatory. We have employed a high performance thinlayer chromatographic assay for salbutamol in urine (Colthup PV, 3rd UK symposium on HPLC, 1985) to study compliance in patients in general practice. The accuracy of the assay was confirmed in a double blind study on timed urine samples from hospital inpatients following nebulised salbutamol. There were no false positives or false negatives and no cross reaction with other $\beta_{2}$ agonists, antibiotics or methyl xanthines. A second study in 10 normal volunteers established a predicted range of levels following $200 \mu \mathrm{g}$ from a pressurised aerosol. At 2 hours the urine levels were 20-165 $\mu \mathrm{g} / \mathrm{l}$ (mean 103). Assay of timed urine samples from 52 asthmatic patients in general practice revealed $38 \%$ in the expected range but $16 \%$ had levels lower than expected for their declared dose and time. In addition $45 \%$ had levels greater than predicted. These results confirm the necessity of bioassay to verify compliance with inhaled $\beta_{2}$ agonist and support the usefulness of the current method. Management of patients requires an accurate knowledge of their current therapy and this study reveals both significant under-use and significant over-use of inhaled salbutamol.

Local fat necrosis secondary to a continuous subcutaneous infusion of terbutaline in unstable asthmatics

LD LEWIS, R O'DRISCOLL, CR HORN, GM COCHRANE Chest Clinic, New Cross Hospital, London We have four brittle asthmatic patients whose asthma remains well controlled by a continuous low dose subcutaneous infusion of terbutaline as maintenance therapy (Ayres et al, Br Med J 1984;288:1715-1716). Two of these patients have developed unexpected skin reactions to this treatment. Both patients developed tender, indurated subcutaneous swellings around the infusion site. This reaction developed after four weeks (patient 2) and three months (patient 1) of terbutaline treatment. The swellings appear at each new infusion site within six-36 hours of resiting the infusion needle. Microscopy revealed these lesions to consist of areas of fat necrosis. Patient 1 had an associated intense eosinophilic infiltrate. This patient was changed to a continuous subcutaneous infusion of salbutamol; within 24 hours a similar lesion appeared which was histologically identical to that produced by terbutaline. However, he was able to tolerate regular daily subcutaneous injections of terbutaline or salbutamol or a continuous subcutaneous infusion of saline without any adverse local effects. Skin prick tests with these solutions produced no response, suggesting that this is not an allergic phenomenom. Further investigation of the causative mechanisms - drug solution osmolality, $\mathrm{pH}$, or impurities - suggest that undetermined impurities are the most likely cause.

Treatment of nocturnal asthma with an inhaled anticholinergic

CI COE, PJ BARNES Department of Medicine, Hammersmith Hospital, London The mechanism of nocturnal asthma is 
still uncertain; increased vagal cholinergic tone at night may be a contributory factor. If so, anticholinergic drugs should have some effect in preventing nocturnal asthma. We have investigated the effect of an inhaled anticholinergic agent, oxitropium bromide (oxi), given as a single dose at night on nocturnal asthma. Thirteen patients (22-75 y) with documented nocturnal asthma were studied in a double blind randomised, crossover study in which they received either oxi 200 or $400 \mu \mathrm{g}$ or placebo by inhalation given as a single dose at night for 2 weeks. On placebo the mean (SEM) fall in early morning peak flow (PF), as \% evening PF, was $18.5(2.2 \%)$ for placebo, $17.9(2.7 \%)$ for oxi $200 \mu \mathrm{g}$ (NS) and $12.3(3.0 \%)$ for oxi $400 \mu \mathrm{g}(\mathrm{p}<0.05)$. There was no difference in inhaled salbutamol use during the night or symptom scores between treatment periods. Closer analysis revealed that $6 / 13$ subjects had responded in a dose dependent manner, but the remaining subjects showed no response to either dose. In "responders" mean $\%$ fall for placebo, oxi $200 \mu \mathrm{g}$ and oxi $400 \mu \mathrm{g}$ were $20.6(3.6), 13.2(4.0)$ $(\mathrm{p}<0.01)$ and $8.4(3.3)(\mathrm{p}<0.01)$ respectively. There were no obvious clinical differences between "responders" and "non-responders". No significant side effects from oxitropium bromide were reported. We conclude that anticholinergic drugs may have some preventive effect against nocturnal asthma in some patients, indicating involvement of vagal cholinergic mechanisms.

Metabolic and cardiac effects of nebulised salbutamol in normal volunteers

A POZNIAK, D BIHARI, A KURTZ, D FREEDMAN, N MCI JOHNSON The Middlesex Hospital, London Factors contributing to sudden death in asthma may be related to the effects of $\beta_{2}$ agonist therapy. We have studied cardiac rhythm and the metabolic response of nebulised salbutamol in six fasting non-asthmatic healthy volunteers. They attended on four separate days and on each occasion one of four treatments was randomly given eight hourly, over 24 hours. These were: 1 , placebo ( $4 \mathrm{ml} 0.9 \%$ saline); $2,5 \mathrm{mg}$ salbutamol; 3, $10 \mathrm{mg}$ salbutamol; 4, $10 \mathrm{mg}$ salbutamol one hour after oral $\beta_{2}$ blockade (ICI $11855140 \mathrm{mg}$ ). Blood glucouse, serum C-peptide, potassium, free fatty acid, catecholamines, cAMP and lactate concentrations were measured 15 minutes before and immediately prior to nebulisation and then at 15 minute intervals for 1 hour. A 24 hours ambulatory monitor recorded cardiac rhythm over each study day. The blood glucose rose: mean (SD) vs placebo after 2: $0.43(0.34) \mathrm{mmol} / 1(\mathrm{p}<0.05)$ and after 3 : $1.22(0.9) \mathrm{mmol} / \mathrm{l}(\mathrm{p}<0.02)$. C-peptide rose, vs placebo after 2: $118(63) \mathrm{pmol} / 1(\mathrm{p}<0.01)$ and after 3: $396(270)$ $\mathrm{pmol} / 1(\mathrm{p}<0.01)$. Serum potassium fell vs placebo after 2 : $0.36(0.16) \mathrm{mmol} / 1(\mathrm{p}<0.005)$ and after 3: $0.69(0.19)$ $\mathrm{mmol} / 1(\mathrm{p}<0.001)$. Serum cAMP rose vs placebo after 3 (but not after 2): 26.4 (15.2) $\mathrm{pmol} / \mathrm{ml}$. There were no significant changes in any of the above parameters after 4 . There were no significant changes in plasma catecholamines, free fatty acids or lactate after any treatment. No cardiac arrhythmias were recorded with any of the treatments. Nebulised salbutamol caused significant metabolic changes unassociated with changes in cardiac rhythm in normal volunteers. These changes were not seen after $\beta_{2}$ blockade.
Adrenaline induced changes in plasma $\mathrm{K}^{+}$as an index of beta $a_{2}$ receptor responsiveness in normal and asthmatic subjects

KE BERKIN, CC INGLIS, SG BALL, NC THOMSON Department of Respiratory Medicine and MRC Blood Pressure Unit, Western Infirmary, Glasgow Atopic asthmatics may have generalised $\beta$-adrenergic hyporesponsiveness (Shelhamer et al, J Allerg Clin Immunol 1980;66:52). Comparison of airway responsiveness to $\beta$-agonists in normal and asthmatic subjects is difficult because of different baseline airway calibre, and studies of $\beta$-mediated metabolic responses are conflicting. The decrease in plasma $\mathrm{K}^{+}$with adrenaline is a $\beta_{2}$-mediated effect, but this has not been used previously to compare $\beta_{2}$-responsiveness in normal and asthmatic subjects. Six non-atopic normal and six atopic asthmatic subjects who had not taken $\beta$-agonists during the preceeding $\mathbf{1 0}$ days were infused with saline as control or adrenaline at four incremental rates $(4,10,25$ and $62.5 \mathrm{ng} / \mathrm{kg} / \mathrm{min} ; 20 \mathrm{~min}$ each rate). Blood for $\mathrm{K}^{+}$was taken at the end of each infusion period. In normal subjects mean (SEM) plasma $K^{+}$decreased from $4.19(0.13)$ to 3.86 $(0.10) \mathrm{mmol} / \mathrm{l}(\mathrm{p}<0.05)$ at the highest infusion rate; in asthmatic subjects $K^{+}$decreased from $4.14(0.08)$ to 3.72 (0.15) $\mathrm{mmol} / 1(\mathrm{p}<0.05)$. Baseline plasma $\mathrm{K}^{+}$was not significantly different and the $\beta_{2}$-mediated decrease in plasma $\mathrm{K}^{+}$with adrenaline infusion was not diminished in asthmatic subjects. This study does not suggest a generalised $\beta_{2}$-receptor abnormality in atopic asthmatic subjects.

Dose-duration effect of sodium cromoglycate aerosol in exercise asthma (EIA)

KR PATEL, WN TULLETT, MG NEALE, RT WALL Department of Respiratory Medicine, Western Infirmary, Glasgow; Fisons plc, Loughborough, England The dose-duration effect of 2,10 and $20 \mathrm{mg}$ of sodium cromoglycate (SCG) aerosol using two formulations ( $1 \mathrm{mg}$ and $5 \mathrm{mg}$ per actuation) was compared with placebo in a double blind randomised trial in 9 patients with EIA. Effects were assessed from the mean maximal percentage fall in $\mathrm{FEV}_{1}$ after 6-8 min treadmill exercise at 15,145 and $265 \mathrm{~min}$ after each treatment. The plasma concentrations (Cmax) of SCG were measured using sensitive radioimmunoassay before each exercise challenge. The mean baseline $F_{E V}$ before and after treatment was comparable on four days of testing. SCG inhibited EIA with all doses in the first test at $15 \mathrm{~min}$ after treatment $(p<.01)$ and the protection was dose related. The effect of $2 \mathrm{mg}$ SCG had worn off by 2 hours whereas significant protection was still present with $10 \mathrm{mg}$ and $20 \mathrm{mg} \mathrm{SCG}$ at 2 and $4 \mathrm{~h}$. In addition, the Cmax SCG and the duration of presence of SCG in the plasma was dose related.

\begin{tabular}{|c|c|c|c|c|c|c|c|}
\hline \multirow{3}{*}{$\begin{array}{l}\text { Exercise } \\
\text { Test } \\
\text { 1st }\end{array}$} & \multirow{3}{*}{$\begin{array}{c}\text { Placebo } \\
33 \\
\text { (4) }\end{array}$} & \multicolumn{3}{|c|}{$\begin{array}{c}\text { \% change in } F E V_{l} \\
\text { SCG }\end{array}$} & \multicolumn{3}{|c|}{$\begin{array}{c}S C G \\
C \max (n g / m l)\end{array}$} \\
\hline & & $2 \mathrm{mg}$ & $10 \mathrm{mg}$ & $20 \mathrm{mg}$ & $2 \mathrm{mg}$ & $10 \mathrm{mg}$ & $20 \mathrm{mg}$ \\
\hline & & $\begin{array}{l}18 \\
(3)\end{array}$ & $\begin{array}{l}10 \\
(3)\end{array}$ & $\begin{array}{c}8 \\
(2)\end{array}$ & $\begin{array}{c}1.0 \\
(0.1)\end{array}$ & $\begin{array}{c}2.4 \\
(0.5)\end{array}$ & $\begin{array}{c}3.4 \\
(0.7)\end{array}$ \\
\hline 2nd & $\begin{array}{l}27 \\
(2)\end{array}$ & $\begin{array}{l}25 \\
(6)\end{array}$ & $\begin{array}{l}15 \\
(5)\end{array}$ & $\begin{array}{c}9 \\
(2)\end{array}$ & $\begin{array}{l}<0.5 \\
(0.1)\end{array}$ & $\begin{array}{c}1.0 \\
(0.1)\end{array}$ & $\begin{array}{c}1.6 \\
(0.3)\end{array}$ \\
\hline 3rd & $\begin{array}{l}29 \\
(5)\end{array}$ & $\begin{array}{l}22 \\
(4)\end{array}$ & $\begin{array}{l}17 \\
(5)\end{array}$ & $\begin{array}{l}10 \\
(3)\end{array}$ & $\begin{array}{l}<0.5 \\
(0.04)\end{array}$ & $\begin{array}{c}0.5 \\
(0.1)\end{array}$ & $\begin{array}{c}0.8 \\
(0.1)\end{array}$ \\
\hline
\end{tabular}


Therapeutic bronchial lavage in asthma

IJ GORDON, J COAKLEY, P SMITH, AR LUKSZA, ST ATHERTON Whiston Hospital, Prescot, Merseyside A retrospective analysis was made of 34 ventilated asthmatic patients treated over a 10 year period. In addition to conventional management, therapeutic bronchial lavage was performed 21 times in 19 patients. The indication for lavage was reduced compliance resulting in high upper airway pressure and hence difficulty in maintaining an adequate tidal volume. Patients were hand ventilated using $100 \%$ oxygen, and ether was given prior to lavage to produce bronchodilatation and bronchorrhoea. Aliquots of $10-20 \mathrm{ml}$ of $1.26 \%$ sodium bicarbonate were warmed to body temperature and injected down the endotracheal tube using an aseptic technique. The solution was dispersed by manual IPPV and removed either by postural drainage and suction or by fibreoptic bronchoscopy. In all instances there was an improvement in effective static compliance from a mean of $17 \mathrm{ml} / \mathrm{cm} \mathrm{H}_{2} \mathrm{O}$ (SD 6) to $20 \mathrm{ml} / \mathrm{cm} \mathrm{H}_{2} \mathrm{O}$ (SD 6) on completion and $24 \mathrm{ml} / \mathrm{cm} \mathrm{H}_{2} \mathrm{O}$ (SD9) at four hours. Eleven out of 19 patients receiving lavage developed respiratory infections compared with one of 13 patients who received IPPV alone. No other complications were observed in excess during bronchial lavage. Enthusiasm for therapeutic lavage should be tempered by the consideration of infection.

Systemic administration of a beta 2 adrenoceptor agonist during chronic hypoxia augments the polycythaemic response and increases right ventricular hypertrophy

RJD WINTER, PE RUDDOCK, RM RUDD London Chest Hospital, London We studied the effects of treatment with a $\beta_{2}$ agonist on the development of polycythaemia, pulmonary hypertension and right ventricular hypertrophy in response to chronic hypoxia. In rats $(n=>9$ in every group), subcutaneous salbutamol $2.5 \mathrm{mg} / \mathrm{kg}$ body weight twice daily during 28 days' continuous hypoxia $\left(\mathrm{F}_{\mathrm{I}} \mathrm{O}_{2}=10 \%\right)$ increased haematocrit (hypoxic treated 63.4 SEM 1.7, hypoxic untreated 57.7 SEM 1.9, p <0.05; both greater than 47.3 SEM 0.9 for normoxic controls, $\mathrm{p}<0.001)$. Salbutamol also increased right ventricular hypertrophy (mean right ventricular weight/final body weight $\times 10^{-4}$ : hypoxic treated 10.69 SEM 0.45 , hypoxic untreated 9.51 SEM 0.33, p $<0.001$; both greater than 5.05 SEM 0.19 for normoxic controls, $\mathrm{p}<.0 .001)$. Mean right ventricular systolic pressure, measured in anaesthetised animals following hypoxia, was not influenced by treatment (hypoxic treated 41.3 SEM 2.4, hypoxic untreated 41.2 SEM $3.8 \mathrm{~mm} \mathrm{Hg}$; both greater than 24.0 SEM $1.3 \mathrm{~mm} \mathrm{Hg}$ for normoxic controls, $\mathrm{p}<0.001)$. At lower doses of salbutamol $(0.05 \mathrm{mg} / \mathrm{kg}, 0.1 \mathrm{mg} / \mathrm{kg}$ and 0.5 $\mathrm{mg} / \mathrm{kg}$ s.c. twice daily during exposure to 10 hours' hypoxia/day) there was a trend towards an increase in haematocrit and greater right ventricular hypertrophy in all treated groups. Again treatment did not affect mean right ventricular systolic pressure. These results indicate that systemic $\beta_{2}$ agonist therapy during hypoxia enhances the development of polycythaemia and right ventricular hypertrophy in the rat.
Does long term therapy with oral beta 2 agonist improve pulmonary haemodynamics in hypoxic chronic bronchitis?

JB NEILLY, R CARTER, A TWEDDEL, B MARTIN, SW BANHAM, RD STEVENSON Department of Respiratory Medicine and Cardiology, Royal Infirmary, Glasgow A group of 11 patients with hypoxic chronic bronchitis were studied prior to and following six months' therapy with oral pirbuterol. Resting and maximum exercise haemodynamics were obtained using a thermodilution catheter and intra-arterial line. Ventricular function was evaluated by radionuclides. At six months heart rate (HR) (80 (13), mean (SD)), 80 (16)bpm), systolic pulmonary artery pressure (PAP) (34.3 (11), 34.8 (10.1) $\mathrm{mm} \mathrm{Hg}$ ) and mean PAP (24.2 (7.5) mm $\mathrm{Hg})$ were unchanged. Cardiac output (CO) (5.16 (0.78), $4.97(0.73) \mathrm{l} / \mathrm{min}$ ) and pulmonary vascular resistance (PVC) (245 (99), 230 (104) dynes $\mathrm{s} \mathrm{cm}^{-5}$ ) were unaltered, but systemic arterial pressure fell (114 (18), 105 (17) $\mathrm{mm} \mathrm{Hg}$; $\mathrm{p}<0.05)$. Right ventricular ejection fraction (RVEF) (32 $(8), 33(12) \%)$ and LVEF (35.5 (14), $39 \%(11 \%))$ were unchanged. No haemodynamic differences were noted on exercise at six months. Arterial $\mathrm{Po}_{2}$ (58.6 (10), 55.0 (7.8) $\mathrm{mm} \mathrm{Hg}$ ), $\mathrm{PCO}_{2}$ (50.7 (6.8), 48.6 (6.5) $\mathrm{mm} \mathrm{Hg}$ ), $\mathrm{FEV}_{1}$ (0.62 $(0.17), 0.72(0.18) \mathrm{l})$ and 12 minute walking distance (484 (237), 412 (234) $\mathrm{m}$ ) remained unaltered. A single dose of 20 mg oral pirbuterol at 6 months produced no change in PAP or PVR at rest and after exercise. In conclusion long term treatment with oral $\beta_{2}$ agonist produced no pulmonary haemodynamic changes in patients with hypoxic chronic bronchitis. In addition no changes were observed acutely after six months' therapy.

Three weeks' versus six weeks' anticoagulation in the treatment of deep vein thrombosis and pulmonary embolus

AG FENNERTY, J DOLBEN, IA CAMPBELL, PA ROUTLEDGE Department of Chest Medicine, Llandough Hospital, Cardiff; Department of Clinical Pharmacology, University Hospital of Wales, Cardiff In patients with venous thromboembolic disease, anticoagulation for 6 weeks has been shown to be as effective as six months in the prevention of recurrence. In a study to assess a shorter period of treatment, 101 hospital in-patients with deep vein thrombosis or pulmonary emboli were randomly allocated to receive three or six weeks anticoagulation and followed up for one year. Forty-nine patients were treated for three weeks and 52 for six weeks, each receiving a five day heparin infusion and warfarin thereafter. Patients with persisting risk factors, malignancy or a past history of venous thrombosis or pulmonary emboli were excluded from the study. A definitive diagnosis using a $\dot{V} / \dot{Q}$ scan or venogram was made in 54 patients; in 40 patients the diagnosis was made on the basis of clinical findings and a recognised risk factor, and in seven on the basis of clinical findings only. Six patients died during follow-up, five in the six week group, of causes unrelated to thromboembolism. There were 11 recurrences, five in the group treated for 3 weeks. A definitive diagnosis of recurrence was made in four of the 11 patients. These results suggest that for patients without persisting risk factors three weeks' anticoagulation is as effective as 6 weeks'. 
Pharmacokinetics of prednisolone in adults with cystic fibrosis

RJ STEAD, CFA PANTIN, J ENGLISH, ME HODSON, JC BATTEN Cardiothoracic Institute, Brompton Hospital, London; Department of Biochemistry, University of Surrey Many patients with cystic fibrosis (CF) receive prednisolone, but we recently demonstrated no improvement in pulmonary function in CF patients with severe, stable airflow obstruction (Stead et al, Thorax 1985;40:211). As drug malabsorption is a possible explanation, the pharmacokinetics of prednisolone were studied in six adult CF patients (median age 25.5 years) and six age and sex matched controls. No subjects were receiving corticosteroids or had significant hepatic or renal disease. After an overnight fast, subjects received prednisolone $0.2 \mathrm{mg} / \mathrm{kg}$ body weight orally or intravenously (order randomised). Serial blood samples were drawn between 0 and 9 hours later and plasma prednisolone concentrations measured by radioimmunoassay. The study was later repeated using the alternative route of administration. Comparing patients with controls: (i) peak plasma concentration (Cmax) after oral prednisolone was reduced, mean (SD): $171(28) \mathrm{ng} / \mathrm{ml}$ versus 262 (17) $\mathrm{ng} / \mathrm{ml}(\mathrm{p}<0.001)$, (ii) Cmax occurred later, median (range): $3(11 / 2-5) h$ versus $1(0.5-1) h(p<0.01)$, (iii) the 'area under the curve' after oral prednisolone was not reduced, (iv) half-life, mean (SD): $2.9(0.3) \mathrm{h}$ versus 3.8 $(0.6) \mathrm{h}$ was less $(\mathrm{p}<0.01)$. This study suggests that overall absorption of prednisolone is not reduced in CF but delayed, resulting in a reduced Cmax.

The effect of inhaled codeine on the cough response to citric acid in normal humans

JC POUNSFORD, KB SAUNDERS Department of Medicine $1, S t$ George's Hospital Medical School, London Oral codeine has been shown to be effective in diminishing the cough response to inhaled citric acid. Opiate receptors have been identified in smooth muscle cells of some mammalian species and we wondered whether inhaled codeine would have any effect on citric acid induced cough. Ten healthy, non-smoking volunteers received either nebulised codeine phosphate $(30 \mathrm{mg})$ or nebulised normal saline in a double blind crossover study. Each study was performed on a separate day. The subjects then received incremental concentrations of nebulised citric acid at four minute intervals. The number of coughs and the latency of the cough response were measured at each concentration. The citric acid was started at a concentration of $0.25 \%$ and increased to $32 \%$ logarithmically. The concentration of citric acid at which coughing first occurred, the cough threshold, was also noted. By dividing the number of coughs induced by the latency we obtained a further measurement of the cough response which we termed the cough index. We were unable to induce coughing in one subject on either of the two days. We compared the three variables of the cough response (cough number, cough index and cough threshold) on the two days and there was no significant difference on the two days (Wilcoxon signed rank test). We conclude that inhaled codeine has no effect on the cough response to citric acid in normal man.

\section{Laboratory assessment of oxygen concentrators}

W SCOTT, GA GOULD, MD HAYHURST, DC FLENLEY Department of Respiratory Medicine, Rayne Laboratory, University of Edinburgh, City Hospital, Edinburgh Long term oxygen therapy prolongs life in hypoxic chronic bronchitis and emphysema (NOTT Group, Ann Intern Med 1980;93:391-8; MRC Working Party, Lancet 1981;1:681-6). Concentrators are the cheapest way to supply oxygen (DHSS Report No. 4/9/176. December 1983). We studied three molecular sieve (MS) concentrators (Cryogenics/Planer Products Roomate III; DeVilbiss Mini $\mathrm{DeVO}_{2}$; Mountain Medical $\mathrm{ECONO}_{2}$ ) and a membrane oxygen enricher (Oxygen Enrichment Company OE-4E). The MS concentrators, notably the Roomate, were simple to operate. The $\mathrm{DeVO}_{2}$ weighed $20 \mathrm{~kg}$ and the Roomate 25 kg. During 14 days constant operation at $21 / \mathrm{min}(61 / \mathrm{min}$ OE-4E) each device delivered gas of consistent composition (Table: (mean (SD)).

\begin{tabular}{l|c|c|c|c}
\hline & Roomate III & $\mathrm{DeVO}_{2}$ & ECONO & OE-4E \\
\hline $\mathrm{O}_{2} \%$ & $91.9(1.6)$ & $93.8(0.7)$ & $93.3(1.0)$ & $37.9(0.6)$ \\
$\mathrm{Humidity}^{*} \%$ & $50.7(7.6)$ & $51.7(7.0)$ & $57.4(5.0)$ & $90.9(3.8)$ \\
Temp $^{\circ} \mathrm{C}$ & $27.7(2.4)$ & $24.0(2.5)$ & $24.6(2.8)$ & $19.3(3.9)$ \\
\hline
\end{tabular}

$\mathrm{O}_{2}$ levels over $92 \%$ were delivered by all MS concentrators at settings up to $2 \mathrm{l} / \mathrm{min}$, and at $31 / \mathrm{min}$ by Roomate and $\mathrm{DeVO}_{2}$. The $\mathrm{ECONO}_{2}$ gave $86.4 \%$ at $31 / \mathrm{min}$. $\mathrm{O}_{2}$ levels fell below $85 \%$ with all MS concentrators at flows over $31 / \mathrm{min}$. In eight hypoxic patients $\left(\mathrm{PaO}_{2} 4.9-9.0 \mathrm{kPa}\right)$ at $21 / \mathrm{min}(6$ $1 /$ min OE-4E) by nasal prongs, the oxygen saturation achieved was Roomate $91.8 \%$ (4.2)\%; $\mathrm{DeVO}_{2} 91.4 \%$ (4.0)\%; ECONO$_{2} 91.8 \%$ (4.5)\%; OE-4E 89.8\% (5.3)\%. These MS concentrators can achieve adequate oxygenation for long term domiciliary use. The OE-4E, owing to limited flow rates, may not do so in severe hypoxaemia.

\section{Accuracy of Biox IIA ear oximeter}

PM TWEEDALE, NJ DOUglas Respiratory Function Laboratory and Rayne Laboratory, City Hospital, Edinburgh The measurement of arterial oxygenation by ear oximetry has proved extremely useful but the ear oximeter hitherto most widely used, the Hewlett Packard 47201A, is no longer available. We have evaluated an available alternative, the Biox IIA, which is smaller and more convenient but which operates on two wave bands compared with the eight wave bands used by the 47201A. We have compared the ear oximeter readings $\left(\mathrm{SeO}_{2}\right)$ with the oxygen saturation $\left(\mathrm{SaO}_{2}\right)$ measured from 
simultaneously sampled arterial blood on 311 occasions. Overall the regression relationship was $\mathrm{SeO}_{2}=0.87\left(\mathrm{SaO}_{2}\right)$ +13.49 where $r=0.89$ and $p<0.001$. The confidence limits were not significantly different from those previously obtained (Douglas et al, Am Rev Respir Dis 1979;119:311-313) for the HP 47201A ear oximeter and, for example, at $90 \% \mathrm{SaO}_{2}$ the Biox oximeter read 91.4 with $95 \%$ confidence limits of $\pm 5.9 \%$. However on four occasions (1\% of readings) there was a greater than $10 \%$ error between the oximeter and directly measured arterial oxygen saturation. We suspect that these errors may result from inadequate ear perfusion, although none of the readings was taken when warning lights indicated inadequate perfusion. Overall we found the oximeter accurate, comfortable and easy to use but very occassionally errors may occur which might be misleading if a single reading from this instrument is used as the only measure of a patient's oxygenation.

Tracheal concentrations of oxygen with Hudson and MC masks

WFS SELLERS, CMB HiggS Department of Anaesthetics and Chest Unit, Royal United Hospital, Bath Tracheal concentrations of oxygen were measured in 17 patients, aged 27-79 years, undergoing bronchoscopy. After bronchscopy a $12 \mathrm{~F}$ gauge rolled tip suction catheter was left $5 \mathrm{~cm}$ above the carina, coming out through a nostril. Patients were randomly allocated to a Hudson (9) or an MC mask (8). They breathed air then oxygen at $2,4,7$ and 10 $1 /$ min delivered from a Boyle machine for 3 minutes at each flow rate. After 1 minute, during regular breathing, peak inspired $\mathrm{O}_{2}$ concentration was measured by a MS2 mass spectrometer. Respiratory rate was recorded. Medication included intramuscular omnopon and atropine, intravenous diazemuls and lignocaine local anaesthesia. Informed consent was given. Results are tabulated as means (SD).

\begin{tabular}{lcccccc}
\hline & Air & 2 & 4 & 7 & 10 & $1 / \min \mathrm{O}_{2}$ \\
\hline Hudson & $18(0.5)$ & $32(7)$ & $46(6)$ & $58(8)$ & $65(7)$ & $\% \mathrm{O}_{2}$ \\
MC & $18(0.5)$ & $38(6)$ & $57(11)$ & $70(8)$ & $76(12)$ & $\% \mathrm{O}_{2}$ \\
\hline
\end{tabular}

These are peak $\mathrm{O}_{2}$ concentrations and mean $\mathrm{O}_{2}$ concentrations will be less. They suggest higher $\mathrm{O}_{2}$ concentrations than expected from manufacturers' figures at low flow rates, and higher concentrations with MC mask at higher flow rates. There was wide variation in $\mathrm{O}_{2}$ delivery. With the Hudson particularly, $\mathrm{O}_{2}$ concentrations were affected by respiratory rate, falling with increased rate. This is a useful technique for measuring $\mathrm{O}_{2}$ delivery.
Transtracheal oxygen via a micro-catheter in chronic obstructive airways disease

NR BANNER, JR GOVAN Harefield Hospital, Harefield, Middlesex A study was carried out to determine the efficacy and acceptability of administering continuous oxygen via a micro-catheter inserted percutaneously into the trachea as described by Heimlich (Ann Otol Rhinol Laryngol 1982;91:643-7). Eight patients with resting hypoxaemia (mean $\mathrm{PaO}_{2} 6.2 \mathrm{kPa}$ ) due to chronic obstructive airways disease were studied. In each patient a Teflon catheter, diameter $1.7 \mathrm{~mm}$, length $13 \mathrm{~cm}$, was inserted percutaneously under local anaesthesia into the trachea between the second and third rings. Patients were supplied with portable cylinders and a domestic source of oxygen. The catheters were used continuously for periods of up to eight months with only minor complications. Arterial blood gas results indicated that using this system hypoxaemia could be relieved with $50 \%$ less oxygen than was required using nasal cannulas. The majority of patients preferred transtracheal oxygen to face masks or nasal cannulas. It permits lower flow rates by avoiding wastage at the face and by bypassing the dead space. This facilitates portable oxygen therapy by extending the life of the cylinders. By being both more comfortable and cosmetically more acceptable than face masks or nasal cannulas transtracheal oxygen via a micro-catheter may lead to improved compliance with therapy when continuous oxygen is prescribed.

Effects of correcting arterial hypoxaemia on respiratory resistance in patients with chronic airflow obstruction

CI COE, NB PRIDE Department of Medicine, Hammersmith Hospital, London We have re-examined the effects of arterial hypoxaemia on airway calibre, measuring total respiratory resistance (Rrs) by imposing forced oscillations over the range 6-26 Hz during tidal breathing and oxygen saturation $\left(\mathrm{SaO}_{2}\right)$ with an ear oximeter. Six normal subjects (mean age 27.3 years, FEV $_{1} 3.82$ litres) and 13 patients with severe chronic airflow obstruction and hypoxaemia (mean age 66.2 years, $\mathrm{FEV}_{1} 0.61$ litres, $\mathrm{SaO}_{2}$ breathing air $86.9 \%$ ) were examined in the sitting position breathing air and $100 \%$ oxygen before and after treatment with nebulized 2.5 mg salbutamol. In normal subjects Rrs at $8 \mathrm{~Hz}$ breathing air was $2.35(0.16 \mathrm{SEM}) \mathrm{cmH}_{2} \mathrm{O} .1^{-1}$.s and breathing oxygen was $2.38(0.10)$. Rrs showed little frequency dependence. 
Rrs after bronchodilators fell to $1.99(0.12)$ breathing air and $2.05(0.14)$ breathing $100 \%$ oxygen. In the patients Rrs was frequency dependent; at $8 \mathrm{~Hz}$ mean values were 4.29 (0.47) breathing air and $3.64(0.38)$ breathing $100 \% \mathrm{O}_{2}$. After salbutamol Rrs at $8 \mathrm{~Hz}$ was unchanged (mean 4.19 (0.37)) breathing air, but again fell to $3.64(0.33)$ breathing $100 \%$ oxygen. Patients with the highest Rrs breathing air tended to show the largest decrease in Rrs; frequency dependence of Rrs was not changed. These studies confirm that hypoxaemia can contribute to increased resistance.

\section{A computerised low cost respiratory testing machine}

P CHOWIENCZYK, C LAWSON, D PARRY, PJ REES, GM COCHRANE Respiratory Function Unit, Guy's Hospital, London A computerised, portable low cost respiratory testing machine has been constructed. This links together a device for measuring total lung capacity from chest radiographs with a turbine based system which measures respiratory variables from the subjects flow volume loop. The total lung capacity measurement is performed on normal diagnostic Postero anterior and lateral radiographs, which are divided into slices and measured by a computer in a similar method to that of Pierce et al (Thorax 1979;34:726-34). A simple potentiometer based tracker is used to outline the lung, which takes around five minutes. The results are analysed on a microcomputer and stored on floppy disc. The turbine is adapted from that described by Chowienczyk and Lawson ( $\mathrm{Br} \mathrm{Med} J$ 1982;285:15-17). The results obtained are assessed on a VDU and can be stored or presented on paper with up to six flow volume loops. The system is relatively portable and easy to use; it provides a flow volume loop displayed at absolute volume outside a respiratory function laboratory.

\section{External quality assessment of lung function laboratories}

DJ CHINN, Y NARUSE, JE COTES Respiration and Exercise Laboratory, University Department of Occupational Health, Medical School, Newcastle upon Tyne As a sequel to an earlier study (Cotes JE, Thorax 1963;18:151) test gas mixtures of carbon monoxide, helium and oxygen in nitrogen, and carbon dioxide and oxygen in nitrogen were analysed in 50 hospital lung function laboratories. The recommended standard of $1 \%$ accuracy (Quanjer and Bull, Eur Physiopath Resp 1983;19:Suppl 5) was achieved in only a minority of laboratories (for $\mathrm{O}_{2} 48 \%$ of laboratories, $\mathrm{He}$ $37 \%, \mathrm{CO}_{2} 28 \%$ and $\mathrm{CO} 14 \%$ ). Ratios of concentrations of $\mathrm{CO}$ and $\mathrm{He}$ were analysed more accurately than single samples. Values for $\mathrm{KCO}$ and respiratory exchange ratio calculated using these results showed between-laboratory variations respectively of $7 \%$ and $10 \%$. Faults included alinear CO meters, large zero errors in oxygen meter (both in five laboratories) and reliance on what may have been inaccurate calibration mixtures for $\mathrm{CO}_{2}$. These results demonstrate that despite previous prompting (Saunders KB, Proc $R$ Soc Med 1977;70:162) quality control is still inadequate. For oxygen and $\mathrm{CO}_{2}$ the position is worse than in 1962 .
A portable, oral high frequency oscillator (POHFO) for relieving breathlessness and improving exercise tolerance

RJD GEORGE, AJ STEARN, DM GEDDES The London Chest Hospital OHFO increases endurance and reduced breathlessness in patients with chronic lung disease (Thorax $1985 ; 40: 213)$ and has potential as a portable aid. To test the effectiveness of a portable, pocket sized OHFO device, 10 patients with severe CAO were studied. All were using oxygen at home. Exercise tolerance was assessed by the distance covered in 6 minutes (6MD) and breathlessness was measured at each minute by visual analogue scale. Comparisons were made between portable $\mathrm{O}_{2}(4 \mathrm{l} / \mathrm{min})$, POHFO and control, when the patient carried nothing. Six walks were done in random order, 2 for each limb of the study. Mean control 6MD was $230 \mathrm{~m}$ (range: $80 \mathrm{~m}-470 \mathrm{~m}$ ). Compared with control, subjects were able to walk $20 \%$ further with oxygen (range 76\%-180\%: $\mathrm{p}<0.05$ ) and $21 \%$ further with POHFO (range $80 \%-161 \%$ : $\mathrm{p}<0.05$ ). Patients were also less breathless during the first three minutes of exercise with both oxygen and POHFO $(p<0.05)$. Recovery time (time to return to baseline breathlessness) was reduced from $1 \mathrm{~min} 37 \mathrm{sec}$ (range $45 \mathrm{sec}-2 \mathrm{~min} 30 \mathrm{sec}$ ) to $1 \mathrm{~min}$ with oxygen (range $21 \mathrm{sec}-2 \mathrm{~min} 30 \mathrm{sec} ; \mathrm{p}<0.01$ ) and to $42 \mathrm{sec}$ with POHFO (range $0-1 \mathrm{~min} 30 ; \mathrm{p}<0.01$ ). In these patients, all dependent upon domiciliary oxygen, POHFO conferred as much benefit during exercise as portable oxygen.

\section{Structure and function in bullous lung disease}

PJM OPENSHAW, JMB HUGHES, D CARR, S VALIND, JP LAVENDER, NB PRIDE Departments of Medicine and Radiology and MRC Cyclotron Unit, Hammersmith Hospital, London Bullous lung disease has been classified pathologically as paraseptal (without generalised emphysema) or deep (in emphysematous lung). We studied 16 patients with bullae $(>1 \mathrm{~cm})$ proved on CT scan. All patients had multiple bullae, including those with a single bulla or emphysema without bullae on chest radiography. In patients without emphysema on CT (type $I, n=6$ ) small bullae were mainly apical and on the cardiac surface of the lung; subpleural or paraseptal bullae were frequent. In patients with emphysema on CT (type II, $n=10$ ) small bullae were distributed within areas of emphysematous lung. The extent of bullous disease on CT scan was similar in the two groups, and both had similarly increased plethysmographic TLC. KCO was normal or slightly low in type I ( $81 \%$ pred), but low in patients with type II scans (46\% pred; p <0.0001). $\mathrm{FEV}_{1} / \mathrm{VC}$ was low in type I $(0.59)$ and very low in type II $(0.33 ; \mathrm{p}<0.02)$. Ventilation was low or absent in all bullae studied by positron emission tomography using inhaled ${ }^{19} \mathrm{Ne}$. We conclude that paraseptal bullous disease may be distinct from bullous emphysema, but that airflow obstruction (rather than restrictive changes) may be associated with either type of disease.

Smoking pattern in middle aged men with normal and accelerated rate of decline in $\mathrm{FEV}_{1}$

A WATSON, H JOYCE, MD GOLDMAN, NB PRIDE Department of Medicine, Hammersmith Hospital, London We examined 
the relation between intensity of smoking and decline in lung function in 10 pairs of middle aged men who had similar smoking histories (49.6 vs 52.0 pack-years), currently smoked similar numbers of cigarettes each day (21.0 vs 23.4) and were of similar age ( 54.9 vs 56.7$)$. One man of each pair (group C) had shown nearly normal decline in height corrected $\mathrm{FEV}_{1}$ over the preceding 10 years (mean 6.06 (SEM 0.95) $\mathrm{ml} \mathrm{y}^{-1} \mathrm{~m}^{-3}$ ), the other (group F) accelerated $\Delta \mathrm{FEV}_{1} / \mathrm{ht}^{3}$ (mean 18.74 (1.77)). Each man smoked two of his usual brand of cigarettes through an orifice-holder (to obtain puff characteristics) while ventilation was continuously measured by magnetometers. The two cigarettes smoked in the laboratory were smoked similarly but more intensely than those smoked in the preceding 24 hours. Puff volume, inhalation volume, breath holding time and number of puffs per cigarette were similar in the normal and fast decliners; the only trends were that all men in group $C$ showed some mouth 'spill' of smoke before inhalation and more smoked lower-yield cigarettes. Nevertheless plasma cotinine (C 299 (48) vs F 316 (48) $\mathrm{ng} / \mathrm{ml}$ ) and fractional expired CO (C 14.3 (2.1) vs F $14.2(1.8) \mathrm{ppm}$ ) were similar in the two groups. The study showed no systematic differences in smoking pattern but suggested a slower $\triangle F E V_{1}$ in smokers of lower yield cigarettes.

Long-term oxygen for hypoxic cor pulmonale - eight year follow up and prognostic factors

PMA CALVERLEY, DC FLENLEY Rayne Laboratory, Department of Respiratory Medicine, University of Edinburgh, City Hospital, Edinburgh Long term domiciliary oxygen therapy improves survival in hypoxic chronic bronchitis and emphysema, but its long term effects and optimal selection of patients remain unclear. We have studied 48 patients who had sustained one or more episodes of cor pulmonale $\left(\mathrm{PaO}_{2} 6.99\right.$ (SD 1.04) kPa, $\mathrm{PaCO}_{2} 7.1$ (SD 0.9) $\mathrm{kPa}, \mathrm{FEV}_{1} 0.55$ (SD 0.17) 1, FVC 1.5 (SD 0.4) 1. Of these 20 (13M 7F), mean (SD) age 59 (7.2)y), were not given oxygen, whereas 28 (19M 9F), mean (SD) age 58 (7.9)y), received 2 litres $\mathrm{O}_{2}$ for more than $15 \mathrm{~h} /$ day. All were followed either until death or until 8 years had elapsed. Half ( $50 \%$ mortality) of those without oxygen died in $\mathbf{4 0 0}$ days, whereas half of those receiving oxygen survived over 1700 days. All controls were dead by 2300 days, but $25 \%$ of oxygen treated patients were then still alive. Survival was unrelated to age, $\mathrm{PO}_{2} \mathrm{PCO}_{2}$, before entry to the study. In $21 / 28 \mathrm{O}_{2}$ patients total pulmonary vascular resistance (TPVR) was measured; $5 / 6$ of those with TPVR $<400$ dyne.s.cm ${ }^{-5}$ were alive at eight years, while all those with TPVR $>\mathbf{4 0 0}$ were dead by six years. Progressive bicycle exercise tests, with measurement of ventilation $\left(\dot{\mathrm{V}}_{\mathrm{E}}\right)$ to $\mathrm{CO}_{2}$ output $\left(\dot{\mathrm{V}} \mathrm{CO}_{2}\right)$ ratio when receiving air could predict survival in control patients $(r=-0.75, p<0.001)$ whereas $\dot{\mathrm{V}}_{\mathrm{E}} / \dot{\mathrm{V}}_{\mathrm{CO}}$ values when breathing oxygen predicted survival in treated patients $(\mathrm{r}=-0.77, \mathrm{p}<0.001)$. Thus domiciliary long term oxygen therapy improves long term survival in hypoxic chronic bronchitis and emphysema, particularly in those with lower pulmonary, vascular resistance, and produces more normal ventilatory responses to exercise.
Correlation between pulmonary capillary blood flow and oxygen delivery to the tissues in ventilated patients

DF TREACHER, TK COWELL, NT BATEMEN, RD BRADLEY Intensive Care Unit, Medical Unit and Bioengineering Department, St Thomas' Hospital, London An inert gas rebreathing method has been developed to measure pulmonary capillary blood flow (Q்c) in ventilated patients. This method has been validated by comparison with predicted values for Q́c derived from simultaneous measurements of cardiac output and shunt fraction in 16 patients following cardiac surgery (Treacher et al, Clin Sci 1985;68:6p). This measurement may be valuable in assessing oxygen delivery to the tissues (OD) since $\dot{Q} \mathrm{c}=\mathrm{OD} \times(1$-shunt fraction $) / \mathrm{CaO}_{2}$. Measurements were made in twelve patients (mean age 54 (7) y; 6 males) ventilated using a Siemens Servo Ventilator with $\mathrm{FiO}_{2}$ 0.4 , resulting in mean $\mathrm{SaO}_{2}=93.8 \%$ 4.5\%). Nine patients had undergone uncomplicated cardiac surgery, two were admitted after myocardial infarction and one following abdominal surgery. Q́c was measured by the inert gas method and OD calculated from measurements of cardiac output (thermodilution), haemoglobin concentration and arterial oxygen content (IL 282, Instrumentation Labs). Analysis of the results showed significant correlation between $O D$ and Q́c: $O D=15.0$ Q́c $+8.0 \mathrm{r}=0.86$ $(p<0.001)$. In five patients, change in treatment produced significant changes in OD and provided a further 5 results. Analysis of all 17 results showed no significant change in the correlation: $O D=16.7 \dot{Q} c+1.9 \mathrm{r}=0.85(\mathrm{p}<0.001)$. We conclude that measurement of $\dot{Q} c$ by this method satisfactorily reflects oxygen delivery to the tissues.

Right ventricular function in acute and chronic cor pulmonale - the acute effects of oxygen

W MACNEE, KF WHYTE, CG WATHEN, AL MUIR, DC FLENLEY Departments of Medicine and Respiratory Medicine, Royal Infirmary and City Hospital, Edinburgh Right ventricular ejection fraction (RVEF) is relatively well preserved in patients with chronic bronchitis and emphysema (CB and E) except in those with oedema consequent on "cor pulmonale" (MacNee et al, Thorax 1983;38:494). We have measured RVEF, cardiac index and right ventricular (RV) pressures to determine the RV pressure/volume (P/V) relationships in an assessment of $R V$ contractility in 14 patients with $\mathrm{CB}$ and $\mathrm{E}\left(\mathrm{PaO}_{1} 6.1\right.$ (SD 1.5) $\mathrm{kPa}, \mathrm{PaCO}_{2}$ 7.1 (SD 1.6) kPa) and "cor pulmonale". Eight were studied when stable without oedema (mean PAP 30 (SD 3) $\mathrm{mmHg}$ ) and six when they presented acutely with oedema (mean PAP 33 (SD 3) mmHg. RV systolic (RVPs) and diastolic pressures, stroke volume index and total pulmonary vascular resistance were similar in the two groups. However, those with oedema had a lower RVEF (0.23 (SD 0.05)) than those without oedema (0.47 (SD 0.04), $\mathrm{p}<0.01)$, and a higher RV end-diastolic volume index $(218$ (SD 68) $\mathrm{ml} \mathrm{m}^{-2}$ vs 69 (SD 9) $\mathrm{ml} \mathrm{m}^{-2}$ respectively, $\mathrm{p}<0.05$ ). The endsystolic pressure/volume ratio (P/V) was lower in those patients with oedema $(0.27(0.11)$ vs 1.61 (SD 0.36), $\mathrm{p}<0.02)$. As RVPs was similar, this indicates normal $R V$ contractility in those patients without oedema, but depressed RV contractility in those with oedema. Oxygen 
(2l/min, nasal prongs, $30 \mathrm{~min}$ ) reduced RVPs in both groups, but $R V E F$ and the $P / V$ ratio were unchanged. These results suggest that $R V$ function is depressed in patients with "acute cor pulmonale" by some mechanism other than an acute increase in PAP, or hypoxaemia.

Comparison of right ventricular size at necropsy in interstitial pulmonary fibrosis and in chronic bronchitis and emphysema

GE PACKE, RM CAYTON, CW EDWARDS Departments of Thoracic Medicine and Histopathology, East Birmingham Hospital It is generally accepted that cor pulmonale is less common in patients with interstitial pulmonary fibrosis (IPF) than in those with chronic bronchitis and emphysema. It has been shown that an increased right ventricular weight at necropsy indicates pulmonary artery hypertension during life (Heath et al, in: The Human Pulmonary Circulation. London: Churchill Livingstone, $1977 ; 511)$. We therefore compared the ventricular weights in 43 patients with IPF ( 32 males, mean age 65 years) with the ventricular weights in 172 emphysematous subjects who had chronic bronchitis (146 males, mean age 70 years). Ventricular weights were measured by the method of Fulton et al (Br Heart J 1952;14:413). 36 patients (84\%) with IPF had a right ventricular weight of over $65 \mathrm{~g}$ compared with $124(72 \%)$ of those with emphysema. The mean right ventricular weight for those with IPF was $85.5 \mathrm{~g}$ (SD 23.2) and $88.8 \mathrm{~g} \mathrm{(34.3)}$ for those with emphysema. The mean ratios of left to right ventricular weights in the two groups were $2.13(0.63)$ and $2.35(0.77)$ respectively. Differences between the two groups were not statistically significant. Our results indicate that the incidence of pulmonary hypertension at the time of death in patients with IPF is similar to that found in chronic bronchitis and emphysema.

Effect of $\beta_{1}$ receptor blockade on pulmonary capillary blood volume (Vc) and transit time

HG KENNEDY, PW IND, HA JONES, JMB HUGHES Department of Medicine, Royal Postgraduate Medical School, Hammersmith Hospital, London We have studied the effects of isoprenaline and $\beta_{1}$ blockade on TLCO and the haemodynamic variables that influence it. We used a rebreathing technique, a mass spectrometer and a $\beta+$ counter with simultaneous measurement of freon 22 and CO 11 uptake rates to measure cardiac output $(\dot{Q})$ and TLCO. This was repeated after preoxygenation to partition TLCO into its components Dm and Vc (Roughton and Forster, J Appl Physiol 1957;11:290-302). On two separate days, five normal volunteers received randomised and double blind atenolol $100 \mathrm{mg}$ or placebo. Two hours later saline infusion was commenced and after 15 minutes TLCO, $\dot{Q}, \mathrm{Dm}$ and $\mathrm{Vc}$ were measured seated. The infusion was then changed to isoprenaline, increasing to $0.02 \mu \mathrm{g} / \mathrm{kg} / \mathrm{min}$ for 10 minutes, and the measurements were repeated. TLCO and Kco did not vary with $\dot{Q}$ under these conditions nor did Dm. Vc was correlated with $\dot{Q}(r=0.57, p<0.01)$ and stroke volume $(r=0.58, p<0.01)$ but not heart rate. Atenolol did not alter these relationships but $\mathrm{Vc} / \mathrm{Q}$, the notional transit time, was significantly longer (placebo 0.80 sec (SD 0.16), atenolol $1.12 \mathrm{sec}$ (SD 0.34), $\mathrm{p}<0.001$ ). Transit time was related to stroke volume $(r=-0.81$, $\mathrm{p}<0.01$ ) after atenolol but not placebo.

Ethnic variation in respiratory symptoms and lung function in London primary school children

IDA JOHNSTON, HR ANDERSON, S PATEL, JM BLAND The Middlesex Hospital and St George's Hospital Medical Schools Studies showing ethnic differences in childhood lung function have infrequently provided statistical comparisons between ethnic groups and few data are available from the UK. A respiratory questionnaire was completed by parents of 5806 primary school children, who were classified by appearance into white (5287), Asian (204), black (198) and other/mixed (117). The prevalence of most past chest illnesses and current respiratory symptoms did not differ significantly between white, Asian and black children: for example, the 12 month period prevalence of an attack of asthma or wheeze was $9 \%$ (whites), $5 \%$ (Asians) and $11 \%$ (blacks). A sub-sample of 973 white, 40 Asian and 47 black children performed spirometry (Vitalograph). There was significant ethnic variation (analysis of covariance) in FEV $0.75, \mathrm{FEV}_{1}$ and FVC. White children had the highest and black children the lowest values: for example, the mean $\mathrm{FEV}_{1}$ adjusted to height 128 $\mathrm{cm}$ was $1.74,1.57$ and 1.511 (SD for whole sample $0.18 \mathrm{l}$ ) for white, Asian and black children respectively. $\mathrm{FEF}_{25-75 \%}, \mathrm{FEV}_{1} / \mathrm{FVC}$ and mean transit time showed no significant ethnic variation. These findings have important implications for lung function testing in childhood and population studies are needed in this country to develop prediction equations that take account of ethnicity.

Studies of the electrophysiological and mechanical behaviour of isolated airways smooth muscle

SL ALLEN, RW FOSTER, GP MORGAN, RC SMALL (Sponsored by PJ Barnes) Department of Pharmacology, Materia Medica and Therapeutics, University of Manchester Using a tissue holder permitting adjustment of the degree of tissue stretch (Dixon and Small, Br J Pharmac 1983;79:75-83) we have been able to record simultaneously the membrane potential and tension changes evoked by both bronchoconstrictor and bronchodilator drugs acting on isolated airways smooth muscle. Guinea pig isolated trachealis muscle exhibits spontaneous mechanical tone and its spontaneous electrical activity comprises oscillations of membrane potential known as slow waves. The bronchodilators isoprenaline and nicorandil suppress mechanical tone and slow wave activity. These effects are associated with hyperpolarisation of the muscle cells. Organic inhibitors of calcium influx (eg verapamil and nifedipine) suppress slow waves but cause little or no change in mechanical tone or resting membrane potential. Bronchoconstrictors such as acetylcholine and histamine initially increase slow wave frequency. This effect is accompanied by increased mechanical tone. The bronchoconstrictors also cause depolarisation and when the membrane potential falls sufficiently slow waves are abolished. 
Does thromboxane $A_{2}$ mediate the indirect contractile effect of leucotriene $\mathrm{D}_{4}$ in guinea pig lung parenchyma?

MA GIEMBYCZ, IW RODGER (sponsored by NC Thomson) Department of Physiology and Pharmacology, University of Strathclyde, Glasgow In 1982 Piper and Samhoun $(B r$ $J$ Pharmac 77;267) suggested that the contraction of guinea pig lung strips (GPLS) induced by leucotriene (LT) $\mathrm{D}_{4}$ was mediated, in part, by the synthesis and subsequent release of thromboxane (TX) $A_{2}$. Since then several conflicting reports have appeared in the literature which both confirm and deny this original proposal. We report here the results from a detailed study in which we have re-examined the putative role for $\mathrm{TXA}_{2}$ in the genesis of this $\mathrm{LTD}_{4}$-induced response. $\mathrm{LTD}_{4}(200 \mathrm{nM})$ produced a biphasic contraction of GPLS: an initial fast response followed by a slow (tonic) phase. Such contractions were paralleled by significant increases in $\mathrm{TXB}_{2}$ release from the lung. Pre-treatment of GPLS with flurbiprofen abolished the initial fast response and the release of $\mathrm{TXB}_{2}$ without affecting the tonic phase of the contraction. In contrast, neither dazmegrel nor the TX-receptor blocking drugs EP 092 and AH 23848 affected the $\mathrm{LTD}_{4}$ induced contractile response. The $\mathrm{LTD}_{4}$ induced release of $\mathrm{TXB}_{2}$ from GPLS was unaffected by either of these antagonists of TX. Dazmegrel, on the other hand, abolished the production of $\mathrm{TXB}_{2}$. Since flurbiprofen abolished the initial fast phase of the contraction induced by LTD $_{4}$ but neither dazmegrel, EP 092 nor AH 23848 affected this response these results suggest that a cyclooxygenase product other than TXA 2 mediates the indirect contractile effect of $\mathrm{LTD}_{4}$ in GPLS.

Effects of leucotriene $D_{4}$ and other agonists on ${ }^{45} \mathrm{Ca}$ efflux from airway smooth muscle

SE BRYSON, D RAEBURN, IW RODGER (sponsored by NC Thomson) Department of Physiology and Pharmacology, University of Strathclyde, Glasgow It has been suggested that leucotriene (LT) $\mathrm{D}_{4}$ utilises principally an intracellular source of $\mathrm{Ca}^{2}+$ to initiate contraction of airway smooth muscle (Raeburn and Rodger, $B r J$ Pharmac 1984;83:499-504). In this study, therefore, we have examined both the pattern of ${ }^{45} \mathrm{Ca}$ efflux from the guinea pig isolated trachealis and the effect of certain agonists on the rate of ${ }^{45} \mathrm{Ca}$ efflux. ${ }^{45} \mathrm{Ca}$ efflux from unstimulated trachealis consisted of three exponential components, two fast components $\left(t_{1 / 2}=0.13 \pm 0.03\right.$ and $\left.4.0 \pm 0.06 \mathrm{~min}\right)$ and one slower component $\left(t_{1 / 2}=33 \pm 7 \mathrm{~min}\right) . \mathrm{KCl}(90$ mmol $\left.1^{-1}\right), \operatorname{LTD}_{4}\left(50 \mathrm{nmol} 1^{-1}\right)$ and tetraethylammonium (TEA; $25 \mathrm{mmol}^{-1}$ ) all produced significant $(\mathrm{p}<0.05)$, but transient, increase in the rates of ${ }^{45} \mathrm{Ca}$ efflux when applied during the slowest efflux period. The effects of both $\mathrm{KCl}$ and TEA, but not $\mathrm{LTD}_{4}$, were abolished by treating the trachealis with $\mathrm{La}^{3}+\left(10 \mathrm{mmol}^{-1}\right)$ for $10 \mathrm{~min}$ prior to their addition. These data clearly illustrate that superfusion of isolated trachealis with a $\mathrm{Ca}^{2+}$ free medium alone is insufficient to remove all extracellularly located $\mathrm{Ca}^{2+}$. The finding that $\mathrm{LTD}_{4}$, after removal of extracellular $\mathrm{Ca}^{2}+$ with $\mathrm{La}^{3+}$ significantly accelerated ${ }^{45} \mathrm{Ca}$ loss from the tissue lends support to the suggestion that this agonist may mobilise $\mathrm{Ca}^{2}+$ from an intracellular store.
Muscarinic receptors and phosphatidylinositol turnover in airway smooth muscle

B GRANDORDY, FM CUSS, JB PALMER, A SAMPSON, PJ BARNES Department of Medicine, Royal Postgraduate Medical School, Hammersmith Hospital, London The coupling mechanism by which stimulation of receptors leads to contraction of airway smooth muscle is uncertain. Recently cholinergic agents have been shown to stimulate membrane phospolipid breakdown, which is associated with release of intracellular stores of calcium. We have investigated the relationship between carbachol induced contraction, phosphatidylinositol (PI) breakdown and muscarinic receptor binding in bovine tracheal smooth muscle. Carbachol produced concentration dependent contractile responses $\left(\mathrm{EC}_{50}=7.4 \times 10^{-8} \mathrm{M}\right)$ which were competitively antagonised by atropine. Muscarinic receptors were identified using ${ }^{3} \mathrm{H}$-quinuclidinyl benzylate (a muscarinic antagonist), and specific binding was inhibited by carbachol $\left(\mathrm{IC}_{50}=3.6 \times 10^{-5}\right)$. At concentrations causing maximal contractile responses there was $40 \%$ receptor occupancy. Phosphatidylinositol turnover, which was measured by the method of Berridge $e t$ al (Biochem $J$ 1982;206:587), also showed a concentration dependent increase $\left(\mathrm{EC}_{50}=8.7 \times 10^{-6} \mathrm{M}\right)$ which was blocked by atropine. In contrast to the difference in agonist potency between the three measurements the potency of atropine was similar in the receptor binding, PI turnover and contractile responses. We conclude that cholinergic contraction of airway smooth muscle is related to PI turnover and therefore release of intracellular calcium. This molecular mechanism may be important in understanding exaggerated contactile responses of airway smooth muscle in disease.

Calcitonin gene related peptide is a potent constrictor of human airway smooth muscle

JBD PALMER, FMC CUSS, PK MULDERRY, MA GHATEI, SR BLOOM, PJ BARNES Department of Medicine, Royal Postgraduate Medical School, Hammersmith Hospital, London Calcitonin gene related peptide (CGRP) is a recently discovered 37 amino acid peptide that is formed by alternative processing of mRNA from the calcitonin gene in neural tissue. In vitro and in vivo it is a potent vasodilator. In the lung CGRP coexists with substance $P(S P)$ in afferent nerves; thus it is likely that the two peptides are closely related. We have studied the effect of CGRP on human airway smooth muscle in vitro and compared it with SP and carbachol (carb). Cartilaginous bronchi (3-4 mm diameter) were obtained from patients undergoing thoracotomy for bronchial carcinoma and studied in an organ bath containing oxygenated Krebs solution. CGRP, SP and carb all caused dose dependent contraction of human bronchi, the order of potency being CGRP $>$ SP $>$ carb (EC values were $2 \times 10^{-8} \mathrm{M}, 2 \times 10^{-7} \mathrm{M}$ and $9 \times 10^{-7} \mathrm{M}$ respectively). CGRP contractions were unaffected by histamine, leucotriene, $\beta$-adrenergic or muscarinic antagonists, cyclooxygenase inhibitors or nerve blockers, indicating a direct effect of this peptide. CGRP is therefore a potent bronchoconstrictor neuropeptide in human airways which may be important in regulating airway tone. 
Effect of inhaled and intravenous substance $P$ on human airway function

RW FULLER, CMS DIXON, D MAXWELL, PJ BARNES Department of Clinical Pharmacology and Medicine, Royal Postgraduate Medical School, London Substance P (SP) is present in nerve endings in human airway and is a potent constrictor of human airway smooth muscle in vitro; however, its effects in man are unknown. SP inhaled in doses up to $0.65 \mu \mathrm{mol}$ by asthmatic subjects $\left(\mathrm{PD}_{35}\right.$ histamine $0.85 \mu \mathrm{mol}$ ) had little effect on specific airway conductance (mean (SD) maximum fall $16 \%$ (12\%). In 6 subjects (2 asthmatics) SP infused at rates of 0.2-3.2 $\mathrm{pmol} / \mathrm{kg} / \mathrm{min}$ caused dose dependent vasodilatation and tachycardia: mean (SD) maximum change in diastolic BP -11.7 (7.1) $\mathrm{mm} \mathrm{Hg}$, systolic BP -3.8 (6.4) $\mathrm{mm} \mathrm{Hg}$ and heart rate 17 (11) beats $/ \mathrm{min}$. The flow at $30 \% \mathrm{VC}$ of a partial flow volume curve initially fell by $15 \%(9 \%)$ $(p<0.05)$ and then rose by $38 \%(50 \%)$. Minute ventilation tended to increase with increasing concentrations of SP (maximum change $+13 \%$ ). This study demonstrates that inhaled SP is a weak bronchoconstrictor in man, probably owing to local degradation or diffusion difficulties. However, infused SP causes bronchoconstriction at low infusion rates, before causing bronchodilatation at higher infusion rates, possibly owing to reflex withdrawal of vagal tone following vasodilatation. SP also appears to cause a small increase in respiratory drive as in animals.

Effect of infused vasoactive intestinal peptide in normal subjects

JBD PALMER, FMC CUSS, JB WARREN, PJ BARNES Department of Medicine, Royal Postgraduate Medical School, Hammersmith Hospital, London There is accumulating evidence that vasoactive intestinal peptide (VIP) is the neurotransmitter in non-adrenergic inhibitory nerves in human airways. VIP potently relaxes human airways in vitro; however previous in vivo studies of infused VIP in asthmatics showed a very small bronchodilator effect, which may have been secondary to the cardiovascular effects of the peptide. We have now studied the effect of infused VIP on airway function in normal subjects. Six normal male subjects received in a double blind randomised fashion on two separate days either VIP or vehicle (Haemaccel) by infusion. Incremental doses of 1, 3, and 6 $\mathrm{pmol} / \mathrm{kg} / \mathrm{min}$ of VIP were infused for 15 minutes. At 6 $\mathrm{pmol} / \mathrm{kg} / \mathrm{min}$ VIP caused a mean (SEM) fall in systolic blood pressure (108 (4) to $88(5) \mathrm{mm} \mathrm{Hg}$ ) and rise in heart rate $(71$ (4) to 95 (4) beats $/ \mathrm{min}$, both $\mathrm{p}<0.01)$, but there was no significant rise in specific airways conductance (sGaw) at any dose of VIP. No significant change was seen with placebo. Isoprenaline $(400 \mu \mathrm{g})$ given by inhalation at the end of the infusion produced a $50 \%(4 \%)$ rise from baseline sGaw. Despite producing marked cardiovascular effects infused VIP does not alter airway tone in subjects who readily bronchodilate with a $\beta$-agonist. Its lack of effect in vivo may be due to rapid enzymatic breakdown or failure to reach airway receptor sites owing to its high molecular weight.
The effect of intravenous VIP following cholinergic blockade

AH MORICE, PS SEVER Department of Clinical Pharmacology, St Mary's Hospital Medical School, London Vasoactive intestinal peptide (VIP) causes slight but significant bronchodilatation when given intravenously. To determine whether this effect is due to reflex cholinergic inhibition we have given seven inpatient volunteers with asthma (mean age 48, range 28-78) nebulised ipratropium bromide $500 \mu \mathrm{g}$. Observations were made at 15 minute intervals of peak expiratory flow (PEF) best of two readings) and pulse until maximum bronchodilatation was achieved. An intravenous infusion of placebo for 15 minutes followed by VIP $\left(6 \mathrm{pmol} \mathrm{kg}^{-1}\right.$ $\min ^{-1}$ ) for 30 minutes was then commenced and recordings made every 5 minutes. Ipratropium caused bronchodilatation in all subjects with a mean increase in PEF of $1341 \mathrm{~min}^{-1}$ after a mean of 69 minutes. Placebo infusion did not cause further bronchodilatation whereas VIP infusion caused a significant $(p=0.05$, Wilcoxon rank sum test) increase in PEF of $271 \mathrm{~min}^{-1}$ after a 30 minute infusion. VIP infusion was associated with a tachycardia of 7 beats per minute when compared with placebo. We have previously shown that VIP infusion is not associated with a significant rise in plasma adrenaline in asthmatic subjects (AH Morice et al, Lancet 1984;1:457-458) and we therefore feel that the action of intravenous VIP cannot be ascribed to reflex mechanisms.

Effect of verapamil on leucotriene $D_{4}$ induced bronchoconstriction in asthmatic patients

JA ROBERTS, IW RODGER, NC THOMSON Department of Respiratory Medicine, Western Infirmary, Glasgow, and Department of Physiology and Pharmacology, Strathclyde University, Glasgow We have previously shown that verapamil inhibits the bronchoconstriction produced by inhaled leucotriene $\mathrm{D}_{4}\left(\mathrm{LTD}_{4}\right)$ in normal subjects (Roberts et al, Thorax 1985;40:216-217). We have repeated this study in asthmatic patients using a similar protocol. The effect of inhaled verapamil on the bronchoconstriction produced by $\mathrm{LTD}_{4}$ was examined in six atopic asthmatic patients (age 22-49, FEV $183-139 \%$ predicted). On separate days, after pretreatment with placebo or verapamil $(2.5 \mathrm{mg} / \mathrm{ml})$ administered on a double blind basis, LTD $_{4}$ was inhaled to a maximum of $10 \mu \mathrm{g} / \mathrm{ml}$. Aerosols of the drug were generated by a Wright nebuliser $\left(50 \mathrm{lb} / \mathrm{in}^{2}, 8 \mathrm{l} / \mathrm{min}\right)$. Results were expressed as the provocation concentration (PC) producing a $35 \%$ fall in specific airways conductance (PC 35 SGaw) and a 30\% fall in flow rate at 30\% of vital capacity, determined from partial expiratory flow-volume curves $\left(\mathrm{PC}_{30} \dot{\mathrm{V}} 30(\mathrm{p})\right)$. Verapamil did not alter baseline sGaw or $\dot{V} 30(\mathrm{p})$. Geometric mean (SEM) PC $_{35}$ sGaw was 1.38 (0.55) after saline and $0.71(0.39)$ after verapamil (NS). The $\mathrm{PC}_{30} \dot{\mathrm{V}} 30(\mathrm{p})$ was $0.5(0.13)$ after saline and $0.49(0.15)$ after verapamil (NS). Thus, in contrast to our findings in normal subjects, verapamil has no effect on $\mathrm{LTD}_{4}$ induced bronchoconstriction in asthmatic patients. This may be due to verapamil inhibiting the bronchial response only to higher concentrations of $\mathrm{LTD}_{4}$ as inhaled by the normal subjects, or may represent a fundamental difference in the 
airway response to $\mathrm{LTD}_{4}$ between normal and asthmatic subjects.

\section{Airway adrenoceptor responsiveness in asthma}

JR BRITTON, RM AGIUS, AE tATTERSFIELd City Hospital, Nottingham, and General Hospital, Southampton Increased alpha and decreased beta receptor responsiveness has been postulated in asthma on the basis of receptor binding studies and functional studies in nonpulmonary tissues. Studies of asthmatic airways have been less conclusive. We have investigated the functional balance of airway adrenoceptors in asthma by comparing the doseresponse relationships of five adrenoceptor agonists given by inhalation to ten asthmatic and ten normal subjects, measuring response as \% maximum change in sGaw for any drug in each subject. Salbutamol, isoprenaline, noradrenaline, phenylephrine and methoxamine were selected to represent a different rank order of potency for alpha and beta adrenoceptors. Mean (SD) baseline sGaw was slightly lower in asthmatic $\left(0.18(0.04) \mathrm{s}^{-1} \mathrm{kPa}^{-1}\right)$ than normal subjects $(0.21(0.07))$ and increased after salbutamol by a mean of $106 \%$ and $56 \%$ respectively. Salbutamol and isoprenaline caused dose dependent bronchodilatation in both groups. The area under the isoprenaline dose-response curve was greater in asthmatic than normal subjects. Phenylephrine caused bronchodilatation in asthmatic subjects only. There was no response to noradrenaline or methoxamine in either group. Heart rate and blood pressure showed no consistent change with any drug. Subjects with mild asthma have no evidence of increased alpha nor decreased beta responsiveness in the airways.

Does circulating adrenaline protect against exercise induced bronchoconstriction?

AH MORICE, C KENNEDY, P SEVER Department of Clinical Pharmacology and Metabolic Unit, St Mary's Hospital Medical School, London Exogenous adrenaline is a potent bronchodilator, but the role of circulating adrenaline in the control of airways tone has not been fully evaluated. We have investigated airways reactivity in bilaterally adrenalectomised subjects in response to exercise and adrenaline infusions. Six subjects, five female, one with chronic airways obstruction and one with asthma, performed exercise on a bicycle for a mean of 5.25 minutes. Mean post-exercise pulse was 123 beats/minute. Subjects did not bronchoconstrict after exercise (mean baseline PEF 315 compared with $3281 \mathrm{~min}^{-1} 10$ minutes post-exercise). There was no post-exercise bronchoconstriction in the asthmatic subject (mean baseline PEF 337.5 compared with $3301 \mathrm{~min}^{-1} 10$ minutes post-exercise) despite a diurnal variation of $30-40 \%$. Adrenaline infusion was associated with progressive bronchodilatation at the rate of $0.025 \mu \mathrm{g}$ $\mathrm{kg}^{-1} \min ^{-1}$ for 20 minutes (mean increase in PEF 351 $\min ^{-1}$ ) and at the rate of $0.05 \mu \mathrm{g} \mathrm{kg}^{-1} \mathrm{~min}^{-1}$ (mean increase in PEF $731 \mathrm{~min}^{-1}$ ). Adrenaline infusion also produced a significant and dose related increase in blood glucose of 1 and $2 \mathrm{mmol} \mathrm{1}^{-1}$ and a fall in plasma potassium of 0.2 and $0.5 \mathrm{mmol}^{-1}$. Despite bilateral adrenalectomy one subject had a normal plasma adrenaline $(0.24 \mathrm{nmol}$ $\left.1^{-1}\right)$, which rose on exercise. Two further subjects had detectable plasma adrenaline after exercise (lower limit of assay $0.1 \mathrm{nmol}^{-1}$ ) but not at rest. The source of this adrenaline is unknown. Lack of circulating adrenaline does not appear to predispose to exercise induced bronchoconstriction.

Evidence of endothelial cell dependent relaxation of pulmonary artery in man

B GReEnberg, K RHODEN, PJ BARNes Royal Postgraduate Medical School, Hammersmith Hospital, London The effects of many vasodilators require the presence of endothelial cells to work. However, the substance released from the endothelium is unknown. Also, the existence of endothelial dependent relaxation in human pulmonary artery (PA) has not yet been shown. We evaluated the effects of acetylcholine (ACh) and adenosine triphosphate (ATP) in segments of PA obtained from patients undergoing lung resection. PA rings of 3-5 $\mathrm{mm}$ diameter were pre-contracted to $3 \mathrm{~g}$ of tension in an oxygenated muscle bath. In half of the 20 segments endothelial cells were removed by gentle abrasion. Maximal (max) relaxation and the dose needed to relax by $50 \%\left(\mathrm{EC}_{50}\right)$ were obtained from dose-response curves for the agents. In the presence of endothelium max relaxation to Ach was $74 \%$ $(21 \%)$ and the $\mathrm{EC}_{50}$ was $1.5 \times 10^{-8} \mathrm{M}$. In rings without endothelial cells ACh failed to produce relaxation. Similar findings were seen with ATP, which caused max relaxation of $91 \%(6 \%)$ with an $\mathrm{EC}_{50}$ of $1.3 \times 10^{-5} \mathrm{M}$ only in the presence of endothelial cells. Relaxation was not blocked by $10^{-6} \mathrm{M}$ propranolol or $10^{-5} \mathrm{M}$ indomethacin. It was inhibited by quinacrine $30 \mu \mathrm{M}$ and nordihydroguauretic acid $10^{-4} \mathrm{M}$, suggesting that the relaxant is a lipoxygenase breakdown product of endothelial cell phospholipid. Endothelial dependent relaxation occurs in vitro in human PA. These data raise the possibility that endothelial damage may inhibit vasodilation and thus play a role in causing PA hypertension.

\section{Characteristics of VIP and PHI relaxation of bovine and} human pulmonary artery

B GREENBERG, K RHODEN, PJ BARNES Department of Medicine, Royal Postgraduate Medical School, London Both vasoactive intestinal peptide (VIP) and peptide histidine isoleucine (PHI) are present in nerve endings in pulmonary artery (PA). Although these peptides are known to cause vascular relaxation many characteristics of this response are uncertain. Also, their effects in man have not been reported. Segments of bovine $(n=21)$ and human $(n=12)$ PA which were precontracted to $6 \mathrm{~g}$ and $3 \mathrm{~g}$ respectively were suspended in an oxygenated muscle bath. Endothelium was removed from half the specimens by gentle abrasion. Maximal $(\max )$ relaxation and the dose required to relax by $50 \%\left(\mathrm{EC}_{50}\right)$ were determined for the peptides. Removal of endothelial cells from bovine and human PA did not significantly alter relaxation to VIP or 
PHI. Neither atropine, propranalol, nor phentolamine (all $10^{-6} \mathrm{M}$ ) blocked relaxation. In bovine PA the mean SD maximal relaxation $(73 \%(21 \%)$ vs $63 \%(22 \%))$ and $\mathrm{EC}_{50}$ (4.3 (0.3) $\times 10^{-9} \mathrm{M}$ vs $\left.8.7(0.9) \times 10^{-9} \mathrm{M}\right)$ for VIP and PHI were not significantly different. VIP relaxed human PA by $72 \%(10 \%)$ with an $\mathrm{EC}_{50}$ of $3.3 \times 10^{-9} \mathrm{M}$. Both VIP and PHI are potent PA relaxants whose effects are independent of the endothelium. Neither adrenergic nor cholinergic pathways are involved in peptide induced relaxation. These peptides may be important determinants of PA tone in man.

Comparison of the effects of oxygen and prostacyclin as pulmonary vasodilators

A BUSH, C BUSST, EA SHINEBOURNE, DM DENISON Departments of Respiratory Physiology and Paediatric Cardiology, Brompton Hospital, London Prostacyclin $\left(\mathrm{PGI}_{2}\right)$ has been shown to be a powerful pulmonary vasodilator in adult patients with primary pulmonary hypertension (Thorax $1985 ; 40: 232-233)$. We have studied its effects in a group of 20 children with pulmonary hypertension complicating congenital heart disease. $\mathrm{PGI}_{2}$ was infused at 5-20 $\mathrm{ng} / \mathrm{kg} / \mathrm{min}$ to obtain dose-response curves for the drug. Results were analysed using Williams test (Biometrics 1972;28:519-531). When the children breathed air their pulmonary vascular resistance (PVR) fell from a mean of 11.9 units to a mean of 9.6 units (standard error of the difference $=0.5, \mathrm{p}<0.01$ ). This was similar to the PVR found when the patients breathed $100 \%$ oxygen with no drug. When $\mathrm{PGI}_{2}$ was added to $100 \%$ oxygen PVR fell by a further 1.7 units $(\mathrm{SE}=0.5, \mathrm{p}<0.01)$. At these doses $\mathrm{PGI}_{2}$ also caused tachycardia and systemic hypotension. The results suggest that, in this group of patients at least, oxygen does not cause maximal vasodilatation of the pulmonary vascular tree and further vasodilatation can be obtained with a blood borne agent. This may need to be kept in mind when using oxygen for diagnostic or therapeutic purposes in patients with pulmonary hypertension.

IgG mediated release of leucotriene $C_{4}$ from human eosinophils: relevance to asthma and other diseases associated with hypereosinophilia

RJ SHAW, GM WALSH, O CROMWELL, R MOQBEL, CJF SPRY, AB KAY Cardiothoracic Institute, Brompton Hospital, and Royal Postgraduate Medical School, Hammersmith Hospital, London Eosinophils are known to generate sulphidopeptide leucotrienes (SRS-A), when incubated with an artificial secretagogue, calcium ionophore. A physiological trigger needs to be identified before this property of eosinophils can be considered relevant to asthma. In this study we show that IgG, when presented to eosinophils on a non-phagocytosable surface, produces sulphidopeptide leucotriene production in amounts similar to that found in body fluids during allergic reactions. IgG (but not albumin) coated Sepharose particles, when incubated with human eosinophils, leads to the generation of leucotriene $\mathrm{C}_{4}$ in a dose and time dependent manner (as measured by specific radioimmunoassay and confirmed by RP-HPLC). This was enhanced by prior incubation of the cells with fMLP, an agent known to increase expression of IgG (Fc) receptors. Low density, partially degranulated eosinophils, collected from patients with hypereosinophilia, which are thought to have been activated in vivo, generated a four fold increase in the amount of $\mathrm{LTC}_{4}\left(20\right.$ pmoles $/ 10^{6}$ cells). These results suggest a potential mechanism by which eosinophils may be stimulated during, and contribute to, the allergic reactions.

IgE dependent release of leucotriene $C_{4}$ and prostaglandin $D_{2}$ from human bronchoalveolar cells

KC FLINT, BN HUDSPITH, KBP LEUNG, FL PEARCE, K SIEGER, MDG HAMMOND, J BROSTOFF, N MCI JOHNSON The Middlesex Hospital, University College London and Miles Laboratories UK Leucotrienes (LT) are putative major mediators of human asthma, nanogram quantities leading to bronchoconstriction of human airways in vivo (MD Griffin et al, $N$ Engl J Med 1983;301:436). Prostaglandin $\mathrm{D}_{2}\left(\mathrm{PGD}_{2}\right)$ is the major cyclooxygenase product of rat connective tissue and human dispersed lung mast cells. However rodent bone marrow derived mucosal type mast cells fail to generate this prostanoid after activation but generate large quantities of leucotrienes (Razin et al, $J$ Exp Med 1983;157:189). We have now determined the IgE dependent generation of $\mathrm{LTC}_{4}$ and $\mathrm{PGD}_{2}$ from human lung cells recovered by bronchoalveolar lavage. $\mathrm{LTC}_{4}$ and $\mathrm{PGD}_{2}$ were measured in cell free supernatants by radioimmunoassay. Dose dependent generation of prostaglandin $D_{2}$ and histamine occurred in parallel (antihuman IgE $1 / 3000-1 / 100)$. Optimum $\mathrm{PGD}_{2}$ release occurred at a dilution of $1 / 100$ (mean $283 \mathrm{ngPGD}_{2} / 10^{6}$ mast cells $78(\mathrm{SE}))$. Generation of $\mathrm{PGD}_{2}$ was significantly correlated with the percentage release of histamine $(r=0.783, n=33)$ suggesting generation by a single cell type. Spontaneous generation of $\mathrm{LTC}_{4}$ was variable ( $<10-380 \mathrm{pg} / 10^{6}$ cells) but increased generation after IgE dependent challenge was seen in all experiments (6.6-350 $\mathrm{pg} / 10^{6}$ cells). Mean optimum $\mathrm{LTC}_{4}$ release of 51 (37) $\mathrm{pg} / 10^{6}$ cells occurred at an anti-IgE dilution of $1 / 100$. No correlation was seen between the percentage release of histamine and generation of $\mathrm{LTC}_{4}\left(\mathrm{pg} / 10^{6}\right.$ cells or $\mathrm{pg} / 10^{6}$ mast cells).

Mediators released from human alveolar macrophages by IgE/anti-IgE complexes

RW FULLER, DM KEMENY, ST HOLGATE, PK MORRIS, CT DOLLERY, J MACDERMOT Royal Postgraduate Medical School, London; Guy's Hospital Medical School, London; University of Southampton Alveolar macrophages (AM) are the most numerous cells within the lumen of human airways and are believed therefore to come into close contact with inhaled antigen. We have shown that mediator release from $\mathbf{A M}$ is stimulated by opsonised zymosan. These studies have now been extended to establish whether AM can be stimulated by an IgE dependent mechanism. AM harvested from 31 patients at bronchoscopy were separated from other cells by culture at $37^{\circ} \mathrm{C}$ for $1 \mathrm{~h}$. The 
AM were then incubated with 10000 IU human myeloma $\mathrm{IgE}$ for $1 \mathrm{~h}$ at $4^{\circ} \mathrm{C}$. AM were subsequently incubated with selected concentrations of either mouse monoclonal antiIgE or one of three rabbit anti-IgE (immunoglobulins) (2 affinity purified) for $30 \mathrm{~min}$ at $4^{\circ} \mathrm{C}$ then $1 \mathrm{~h}$ at $37^{\circ} \mathrm{C}$. Thromboxane $\mathrm{B}_{2}\left(\mathrm{TXB}_{2}\right)$ release was measured by RIA. The release of $\mathrm{TXB}_{2}$ was increased from a mean basal production of 2.1 (SE 1.7) ng/mg protein by the addition of anti-IgE to give a maximum increase of $81 \%(25 \%)$ for the mouse monoclonal anti-IgE; $37 \%(17 \%)$ for the rabbit antiIgE; and $313 \%(235 \%)$ and $20 \%(19.9 \%)$ for the two affinity purified anti-IgE immunoglobulins. Increases in the release of prostaglandin $\mathrm{F}_{2} \alpha$ and $\mathrm{N}$-acetyl- $\beta$-Dglucosaminidase were also measured. This study demonstrates activation of human AM by an IgE dependent mechanism.

Bronchoalveolar lavage mast cells in asthma and other respiratory diseases

AJ WARDLAW, O CROMWELL, D CELESTINO, P FITZHARRIS, JV COLLINS, AB KAY Cardiothoracic Institute and Brompton Hospital, London We have studied the functional and morphological characteristics of mast cells obtained in bronchoalveolar lavage from 50 patients with a variety of lung diseases. The percentage of mast cells ranged from $0.04 \%$ to $0.6 \%$ (bronchial carcinoma), $0.05 \%$ to $0.3 \%$ (sarcoidosis), $0.06 \%$ to $0.25 \%$ (asthma), $0.04 \%$ to $1.8 \%$ (miscellaneous) and $0.02 \%$ to $0.04 \%$ (normals). These mast cells exhibited heterogeneity of size, shape and intensity of staining. Cells from 31 subjects were further studied for histamine content and the effect of incubation with various releasing agents. Histamine was measured using a single isotope radioenzymatic assay. There was a significant correlation $(p<0.001)$ between histamine content of the total lavage cell population and mast cell counts. The mean mast cell histamine content was 6.3 picograms (range 2.2 to 10.8 picograms). Histamine was released in a dose dependent fashion after stimulation with anti-IgE, calcium ionophore and phorbol myristate acetate, with a time course of histamine release characteristic of the mast cell. No release was observed following incubation with the synthetic bacterial analogue f-met-leu-phe or compound $48 / 80$. Inhibition of histamine release following anti-IgE stimulation was obtained following pre-incubation with salbutamol. These studies indicate that bronchoalveolar lavage fluid is a suitable model for the study of human lung mast cells.

The hyperosmolar release of histamine from bronchoalveolar mast cells and its inhibition by sodium cromoglycate

KC FLINT, BN HUDSPITH, KBP LEUNG, FL PEARCE, J BROSTOFF, N MCI JOHNSON University College London and The Middlesex Hospital, London Hyperosmolar release of histamine has been demonstrated from human basophils and mast cells dispersed enzymatically from human lung. Lying superficially, bronchoalveolar mast cells are exposed to lung secretions that are hyperosmolar (Potter et al, Am
Rev Resp Dis, 1967;96:83) and estimates of water flux during hyperventilation suggest that this osmolarity would increase. In seven experiments we have investigated the osmotic release of histmine from bronchoalveolar cells. Osmolarity was varied from 280 to $1270 \mathrm{mOsm} / \mathrm{kg}$ using increasing concentrations of mannitol (0.1-1.0 M) (PA Eggleston et al, Am Rev Resp Dis, 1984;130:86). Histamine release occured in a dose dependent manner reaching a mean (SE) optimum of $12.5 \%(1.7 \%)$ at $1020 \mathrm{mOsm} / \mathrm{kg}$. Significant release was seen at osmolarities as low as $\mathbf{4 6 0}$ $\mathrm{mOsm} / \mathrm{kg}$. Sodium cromoglycate (SCG) is an effective prophylactic in vivo against a variety of non-immunologic stimuli, casting doubt on its proposed mode of action as a mast cell stabiliser. However, SCG significantly inhibited the hyperosmolar release of histamine from bronchoalveolar cells. Inhibition occurred over a similar dose range to the inhibition of IgE dependent histamine release $\left(10^{-3}-10^{-7} \mathrm{M}\right)$, the mean maximum inhibition being $33.5 \%(6 \%)$ at $10^{-5} \mathrm{M}$.

\section{Bronchoalveolar lavage in asthma}

DR GRAHAM, AR LUKSZA, CC EVANS Bronchoalveolar lavage (BAL) was performed in five patients with stable asthma and five patients with acute severe asthma. None of the patients were smokers. Although the total cell count was comparable in the two groups there were changes in the differential cell patterns. Thus, patients with stable asthma demonstrated a significant lymphocytosis $(p<0.05)$ while the patients with acute severe asthma showed an elevation in eosinophils $(p<0.05)$ and neutrophils $(p<0.05)$. Simultaneous blood eosinophil counts were performed in all patients. Eosinophil numbers showed parallel changes in the two media in eight patients. Two patients with acute severe asthma had received high doses of systemic steroids for 24 hours prior to bronchoscopy and venesection. Both displayed blood eosinopenia but demonstrated large numbers of eosinophils in BAL fluid. Cell patterns in BAL fluid in asthma have not been previously described. The lymphocytosis in stable asthma is an unexplained finding. The persistence of high numbers of eosinophils in BAL fluid after 24 hours of systemic steroids may explain the apparent delay in response to therapy in acute severe asthma.

Relative potency of inhaled leucotrienes $C_{4}$ and $D_{4}$ compared with methacholine in asthmatics and normals

PM O'BYRNE, E ADELROTH, M MORRIS, FE HARGREAVE Firestone Regional Chest and Allergy Unit and McMaster University, 50 Charlton Avenue East, Hamiton, Ontario, Canada L8N4A6 Inhaled leucotrienes $\mathrm{C}_{4}$ and $\mathrm{D}_{4}\left(\mathrm{LTC}_{4}, \mathrm{LTD}_{4}\right)$ are potent bronchoconstrictors in both asthmatic and non-asthmatic subjects. However the range of potency compared with other bronchoconstrictors varies widely between subjects. We examined the relationship between the relative potency of both $\mathrm{LTC}_{4}$ and $\mathrm{LTD}_{4}$ compared with methacholine and the baseline airway responsiveness to methacholine in 18 subjects chosen to cover a range of responsiveness to methacholine; 12 
subjects had current asthma, six had never had asthma. $\mathrm{LTC}_{4}$ and $\mathrm{LTD}_{4}$ and methacholine were inhaled in doubling concentrations and the response to the agonist was expressed as the dose $(\mu \mathrm{M})$ which caused a $40 \%$ fall in flows at $40 \%$ of VC using partial flow volume curves $\left(\mathrm{PD}_{40} \dot{\mathrm{V}}_{40} \mathrm{P}\right)$. The relative potency of the leucotrienes was expressed as the dose-ratio of $\mathrm{PD}_{40} \dot{\mathrm{V}}_{40} \mathrm{P}$ methacholine and $\mathrm{PD}_{40} \dot{\mathrm{V}}_{40} \mathrm{LTC}_{4}$ and $\mathrm{LTD}_{4}$. There was a close linear relationship between the baseline airway responsiveness to methacholine and the relative potency of $\mathrm{LTC}_{4}(r=0.82$, $\mathrm{p}<0.001)$ and $\operatorname{LTD}_{4}(\mathrm{r}=0.76, \mathrm{p}<0.001)$. Thus subjects who are most responsive to methacholine had the lowest relative potency for $\mathrm{LTC}_{4}$ and $\mathrm{LTD}_{4}$. The results indicate that while asthmatic subjects appear to be hyperresponsive to inhaled peptide leucotrienes compared with nonasthmatics, the peptide leucotrienes are less potent bronchoconstrictors than methacholine in asthmatics compared with non-asthmatics.

Do measurements of airway calibre, lung volumes and compliance differentiate preferential sites of action of bronchoconstrictor agents?

I BOTTRILL, C HARDY, GM STERLING, ST HOLGATE Medicine 1, Southampton General Hospital, Southampton It is claimed that different physiological measurements may reflect changes in airway calibre at different levels of the bronchial tree. We have investigated the comparative concentration related effects on airway calibre (sGaw, $\mathrm{FEV}_{1}$, $\dot{\mathrm{V}} \max _{30}$ ), lung volumes (VC, RV) and lung compliance of three bronchoconstrictor agents, prostaglandin $\mathrm{D}_{2}\left(\mathrm{PGD}_{2}\right)$, histamine (hist) and methacholine $(\mathrm{MCh})$ that in vitro are considered to have actions on different sized airways. We studied seven subjects (six $M$, one $F$, age $23 \pm 1$ y) with mild allergic asthma. sGaw and lung volumes were measured by body plethysmography, $\mathrm{FEV}_{1}$ and $\dot{\mathrm{V}} \max _{30}$ by flow dependent spirometry, and compliance by oesophageal manometry. Doubling concentrations of $\mathrm{PGD}_{2}(0.01$ to $3 \mathrm{mg} / \mathrm{ml})$, hist (0.06 to $24 \mathrm{mg} / \mathrm{ml})$ and $\mathrm{MCh}(0.06$ to $60 \mathrm{mg} / \mathrm{ml})$ were aerosolised via an Inspiron nebuliser, and concentrationresponse curves constructed. Geometric mean $\mathrm{PC}_{35}$ sGaw for $\mathrm{PGD}_{2}$, hist; and $\mathrm{MCh}$ were $0.09,1.68,1.50 \mathrm{mg} / \mathrm{ml}$. Mean (\%) maximum falls in $\dot{\mathrm{V}} \max _{30}$ with $\mathrm{PGD}_{2}$, hist, and MCh of 65 (SE 5), 64 (3), 69 (3) respectively were attended by falls in sGaw (\%) of $66,70,66$; in FEV $_{1}(\%)$ of 26,32 , 23 ; in VC of $17,20,23$; in compliance (\%) of $12(12), 3(11)$, $13(4)$ and increases in RV (\%) of $72,63,68$, which were not significantly different between constrictor agents. Thus considerable caution should be exercised in ascribing preferential sites of action to bronchoconstrictor agents, based on these measurements alone.

Blood eosinophil and total white cell counts and bronchial reactivity to histamine in smokers and ex-smokers

RG TAYLOR, E GROSS, H JOYCE, F HOLLAND, NB PRIDE Department of Medicine, Hammersmith Hospital We have examined in non-asthmatic middle aged male smokers and ex-smokers the relation between bronchial reactivity and the peripheral blood eosinophil and total white cell (WBC) counts, both being raised in smokers. Bronchial reactivity was determined as the provocation concentration of inhaled histamine $\left(\mathrm{PC}_{20}\right)$ reducing $F_{E V}$ by $20 \%$ : men were classed as reactors (R) or non-reactors (NR) by $\mathrm{PC}_{20} \leqslant$ or $>16 \mathrm{mg} / \mathrm{ml}$. Twentythree of 87 smokers and 13 of 49 ex-smokers were reactors. The eosinophil count was no higher in reactors among smokers (R geometric mean 0.142 (95\% C.I. 0.099-0.201), NR $0.149(0.125-0.177) \times 109 / 1, p>0.8)$ or ex-smokers $(R$ $0.120(0.075-0.193)$, NR $\left(0.097(0.074-0.127) \times 10^{9} / 1\right.$, $\mathrm{p}>0.4)$, and was not related to $\mathrm{PC}_{20}$ in reactive smokers $(r=0.34, p>0.1)$ or ex-smokers $(r=0.28, p>0.3)$. The WBC was no higher in reactors among smokers ( $R$ 7.51 (6.46-8.73), NR $\left.7.24(6.71-7.82) \times 10^{9} / 1, \mathrm{p}>0.2\right)$ or ex smokers (R 5.74 (4.99-6.60), NR 6.32 (5.70-7.02) $\times 109 / 1$, $\mathrm{p}>0.3$ ), and was not related to $\mathrm{PC}_{20}$ in reactive smokers $(r=0.23)$ or ex-smokers $(r=-0.03)$. Thus, smokers differ from asthmatics, in whom increases in blood eosinophils and reactivity appear related; while smokers' increased reactivity may be associated with neutrophilic infiltration in the airways, this association is not reflected in the peripheral blood.

Airways responsiveness to methacholine during the natural menstrual cycle: effect of oral contraceptives

EF JUNIPER, PA KLINE, EE DANIEL, FE HARGREAVE Firestone Regional Chest and Allergy. Unit, and McMaster University, 50 Charlton Avenue East, Hamilton, Ontario, Canada $L 8 N \quad 4 A 6$ Premenstrual exacerbation of symptoms has been reported in some women with asthma. We examined changes in airway responsiveness to methacholine during two consecutive menstrual cycles in 17 well controlled asthmatics with a wide range of responsiveness. In 10 women, with regular natural cycles, measurements were made one week before and one week after the start of menstruation to coincide with the highest and lowest progesterone levels. The mean concentration of methacholine to cause a fall in $\mathrm{FEV}_{1}$ of $20 \%\left(\mathrm{PC}_{20}\right)$ premenstruation was $1.49 \mathrm{mg} / \mathrm{ml}$, which was not different from the mean postmenstruation $\mathrm{PC}_{20}$ of $1.34 \mathrm{mg} / \mathrm{ml}$. Although there were only 10 subjects, the power was $96 \%$, indicating little likelihood of any difference between the two phases. In seven women on oral contraceptives, the mean $\mathrm{PC}_{20}$, measured within one week of completing a 21 day course, was $1.19 \mathrm{mg} / \mathrm{ml}$, which was not different from the mean $\mathrm{PC}_{20}$ of $0.97 \mathrm{mg} / \mathrm{ml}$ measured after the beginning of menstruation but before restarting medication $(p=0.17)$. The power was $98 \%$. Changes in $\mathrm{PC}_{20}$ were not related to the severity of the airway hyperresponsiveness. The results suggests that changes in responsiveness, during the natural cycle and on oral contraceptives, are small and are not clinically or statistically significant.

Cough induced by ultrasonically nebulised water is related to aerosol particle charge

RA LEWIS, CJ Ellis, A BAILEY, A HASHISH, W BALACHANDRAN Southampton General Hospital, and Applied Electrostatics Group, University of Southampton Cough and bronchoconstriction induced by 
water is markedly less if delivered from a Mini-Neb jet nebuliser (JN) than from a Pulmosonic ultrasonic nebuliser (UN) which delivers a similar volume of solution to the subject (Lewis et al, Thorax 1984;39:712). The water particles from the JN carry a steady net negative current of $5 \times 10^{-11} \mathrm{~A}$, but from the UN they carry a fluctuating current of $\pm 1 \times 10^{-11} \mathrm{~A}$. In a single blind study eight normal and eight asthmatic subjects inhaled water from two unmodified UNs and a UN modified so that droplets were charged by ions from a corona discharge delivering either $+5 n A$ or $-4 n A$, depending on electrode polarity. In normal subjects, inhaling from control and charged UN on the same day, cough was reduced from 9.8 (SD 8.8)/min to 1.1 (SD 2.9)/ $\mathrm{min}$ with $+5 \mathrm{nA}(\mathrm{p}<0.05)$ and from 12.1 (SD $7.5) / \mathrm{min}$ to 1.1 (SD 2.2)/min with $-4 \mathrm{nA}(\mathrm{p}<0.001)$. In asthmatics who inhaled from each UN on separate days, cough was reduced from 36.7 (SD 27.3)/min to 12.4 (SD $8.05) / \mathrm{min}$ with $-4 \mathrm{nA}(\mathrm{p}<0.05)$ and to 15.7 (SD 9.1) with $+5 n A$ (NS). The effect on bronchoconstriction was less consistent. We conclude that the charge carried by UN water particles is important in determining the cough response.

Human lymphocyte derived neutrophil chemotactic activity - partial characterisation and inhibition of release

DR CUNDELL, RJ DAVIES St Bartholomew's Hospital, London High molecular weight neutrophil chemotactic activity (NCA) has been detected in the sera of asthmatic patients, and, although it has been suggested to come from mast cells, (Kay AB and Lee TH, J Allergy Clin Immunol 70:317-20), its origin remains speculative. Many investigators have used circulating white cells to probe for pathogenic mechanisms in asthma and we set out to identify a cellular source for NCA using peripheral white cells. Leucocytes obtained from five asthmatic patients were separated, and incubated with either allergen, anti-IgE, or concanavalin A. NCA (NCA ${ }^{w}$ ) was found to be released only by fractions containing lymphocytes, release being maximal 30 minutes after addition of the releasing agent. The lymphocytes from non-atopic, non-asthmatic subjects released significantly lower levels of NCA ${ }^{w}$ than those obtained from asthmatic patients $(p<0.001)$. Comparison of the physicochemical characteristics of $\mathrm{NCA}^{\mathrm{w}}$ with those of NCA obtained from the sera of asthmatic patients (NCA $\left.{ }^{A}\right)$ demonstrated that the two mediators had similar molecular weights and isoelectric points. Both $\mathrm{NCA}^{\mathrm{w}}$ and $\mathrm{NCA}^{\mathrm{A}}$ consisted of four proteins corresponding to $1 \times 10^{6}$, $600 \times 10^{3}, 400 \times 10^{3}$ and $40 \times 10^{3}$ daltons with isoelectric points of 7.9-8.3, 6.0-6.5, 5.2-5.8 and 6.2-6.8 respectively. A significant $(p<0.05)$ inhibition of NCA release occurred following pre-treatment of the cells with salbutamol but not with sodium cromoglycate. These results suggest that $\mathrm{NCA}^{\mathrm{W}}$ may be released by cells other than mast cells, that the mediator is present in greater amounts in allergic individuals and that salbutamol may be effective in asthma by means other than bronchodilatation.
Allergen induced release of high molecular weight neutrophil chemotactic activity in nasal secretions from patients with allergic rhinitis

JA MACKAY, O CROMWELL, AB KAY Cardiothoracic Institute, Brompton Hospital, London Six subjects with perennial rhinitis underwent nasal challenge with an extract of the house dust mite (Dermato phagoides pteronyssinus). Postchallenge, but not pre-challenge, nasal washings contained neutrophil chemotactic activity (NCA), which was released in a time dependent fashion with maximal activity 10-15 minutes after allergen administration. In contrast, when the same patients were challenged with methacholine on a control day negligible quantities of NCA were detected. Secretions obtained by allergen or methacholine challenge were reduced in $6 \mathrm{M}$ urea, standardized for their mucus glycoprotein content and subjected to cation exchange chromatography (SP-Sephadex), gel filtration (Sephacryl S-400) and chromatofocusing (Mono-P gel). The allergen induced NCA was associated with molecules of 600000 daltons molecular weight and neutral isoelectric point. These studies suggest that HMW-NCA is a mediator of rhinitis and, as with asthma, appears to be associated with mast cell activation.

The role of histamine as mediator of nasal hypersecretion and blockage in atopic and non-atopic perennial rhinitis

D SYKES, R WILSON, P STANLEY, PJ COLE Host Defence Unit, Department of Medicine, Cardiothoracic Institute, Brompton Hospital, London Histamine has been considered of less importance as a mediator of nasal obstruction than of nasal hypersecretion. We performed nasal histamine provocation tests in $\mathbf{4 0}$ patients with atopic and non-atopic perennial rhinitis presenting with predominant nasal "running"' or "blocking". Nasal airway resistance (NAR) was measured by active anterior rhinomanometry and histamine was administered in doubling increments $(12.5 \mu \mathrm{g}-400 \mu \mathrm{g})$ at 5 minute intervals. The number of patients developing NAR $>1.0$ Pascal $/ \mathrm{cm}^{3} / \mathrm{sec}$ is shown in the table with the number of patients developing sneezing, itching or running nose prior to obstruction in parenthesis:

\begin{tabular}{|c|c|c|c|c|}
\hline \multirow{2}{*}{$\begin{array}{l}\text { Conc histamine } \\
\text { provoking } \\
\text { obstruction ( } \mu g \text { ) }\end{array}$} & \multicolumn{2}{|c|}{ Atopic } & \multicolumn{2}{|c|}{ Non-atopic } \\
\hline & "Blockers" & "Runners" & "Blockers" & “Runners \\
\hline $\begin{array}{l}12.5,25,50 \\
100,200 \\
400\end{array}$ & $\begin{array}{l}8(4) \\
1(0) \\
0(0)\end{array}$ & $\begin{array}{l}8(7) \\
1(0) \\
1(0)\end{array}$ & $\begin{array}{l}6(3) \\
1(0) \\
0(1)\end{array}$ & $\begin{array}{l}1(0) \\
0(2) \\
3(0)\end{array}$ \\
\hline No response & $1(0)$ & $0(0)$ & $3(0)$ & $6(0)$ \\
\hline
\end{tabular}

Patients with nasal blockage were sensitive to histamine provocation irrespective of atopic status. There was a marked lack of histamine sensitivity in non-atopic patients with predominantly nasal "running". We conclude that histamine may be more important in mediating nasal blockage than has been suggested, and that non-atopic nasal "running" is likely to be mediated by non-histamine mechanisms. 
Histamine induced changes in pulmonary epithelial permeability via $\mathrm{H}_{1}$-receptors

TB CHAN, DM SHELTON, PJ REES, NM EISER Guy's and Lewisham Hospitals, London Histamine induced bronchoconstriction is associated with increased permeability of respiratory mucosa. This study investigates whether this increase is mediated via $\mathrm{H}_{1}$ or $\mathrm{H}_{2}$-receptors. In seven normal subjects and five asthmatics, the permeability of pulmonary epithelium was determined by measuring the half-time clearance from lung to blood of $99 \mathrm{mTc}$-labelled diethylene triamine pentaacetate $\left(\mathrm{T}^{1} 1 / 2 \mathrm{LB}\right)$, on separate days, both before and after inhaled aerosols of histamine, betahistine (specific $\mathrm{H}_{1}$-receptor agonist) and impromidine (specific $\mathrm{H}_{2}$-receptor agonist). Doses were: $16 \%$ impromidine for all subjects $1-15 \%$ betahistine and $0.2-10 \%$ histamine, depending on predetermined bronchial responsiveness. In general, asthmatics had four times greater responsiveness to histamine when compared with normals and histamine was 2-10 times more potent than betahistine. For normal subjects and asthmatics respectively, there were mean histamine induced falls in PEF of $44 \%$ and $28 \%$ and decreases in T $1 / 2 \mathrm{LB}$ of $44 \%$ and $43 \%$. Following betahistine, mean PEF fell by $43 \%$ and $25 \%$ and $T 1 / 2 \mathrm{LB}$ by $51 \%$ and $51 \%$ for normal subjects and asthmatics respectively. Impromidine changed neither PEF nor $T^{1} 1 / 2$ LB. In four normal subjects, histamine induced changes in PEF and $T^{1 / 2} \mathrm{LB}$ were prevented by oral pretreatment with terfenadine $120 \mathrm{mg}$ but not by cimetidine $400 \mathrm{mg}$. In normal and asthmatic man, histamine induced increases in pulmonary epithelial permeability are mediated via $\mathrm{H}_{1}$-receptors only.

Chronic aminophylline therapy in normocapnic obstructive airways disease

CB COOPER, AC DAVIDSON, IR CAMERON Department of Medicine, United Medical and Dental Schools, St Thomas's Hospital, London We have previously studied respiratory muscle strength and exercise tolerance in patients with chronic obstructive airways disease following acute administration of aminophylline (Bull Eur Physiopathol Respir 1984;20(5):23A). We found bronchodilatation and a small increase in six minute walking distance without evidence of an increase in respiratory muscle strength. In this study we recruited 14 subjects, aged 61.7 (2.3) y (mean (SEM)), with airflow obstruction which did not improve $>15 \%$ after inhalation of salbutamol $400 \mu \mathrm{g} ; \mathrm{FEV}_{1} 0.87$ (0.12)1, FRC 6.1 (0.46)l, Kco $0.71(0.12) \mathrm{mmol} / \mathrm{min} / \mathrm{kPa} / 1$, $\mathrm{PaO}_{2} 10.0(0.4) \mathrm{kPa}, \mathrm{PaCO}_{2} 5.4(0.2) \mathrm{kPa}$. They were given slow release aminophylline or placebo tablets, each for two weeks, in a double blind crossover fashion with an intermediate washout period. Satisfactory plasma theophylline levels were obtained on active study days (15.0 (1.1) $\mathrm{mg} / \mathrm{l}$ ). Spirometry, lung volumes, six minute walking distance, with breathlessness scores, and maximal static inspiratory and expiratory mouth pressures were recorded during a control period and at the end of both aminophylline and placebo treatment periods. There was significant bronchodilatation following aminophylline $\left(\mathrm{FEV}_{1} 0.93(0.12) / \mathrm{l}\right)$ when compared with the placebo treatment period $(0.81(0.10) / 1)$ but not compared with the control assessment $(0.87(0.12) / 1)$. There were no differences in any of the other measured variables. With chronic administration of aminophylline we have been unable to demonstrate improvement in walking distance, breathlessness during exercise or respiratory muscle strength.

The effect of aminophylline on fatigue of the sternomastoid muscle in man

J EFTHIMIOU, J FLEMING, RHT EDWARDS, SG SPIRO Department of Thoracic Medicine, University College Hospital, London Respiratory muscle fatigue may contribute significantly to dyspnoea and respiratory failure, and part of the therapeutic benefit of aminophylline could be related to an improvement in respiratory muscle contractility. This may explain the discrepancy that sometimes exists between the poor bronchodilator effect of aminophylline and clinical improvement. Aubier et al (N Engl J Med 1981;305:249-52) demonstrated that therapeutic concentrations of aminophylline improved the diaphragm's contractility and rendered it less susceptible to fatigue in normal subjects. The potential importance of this controversial finding led us to investigate the effect of aminophylline on fatigue in the sternomastoid muscle, where force production can be measured more directly than in the diaphragm. We studied the effect of intravenous aminophylline on the contractility of the sternomastoid muscle in the fresh state and after the induction of significant fatigue in five normal subjects. Aminophylline did not influence the frequency/force relationships, relaxation rate, or maximum voluntary contractile force (MVC) in the fresh muscle. Furthermore, aminophylline given prior to or immediately after fatiguing exercise did not influence the recovery of either fatigue or the MVC. The therapeutic benefit of aminophylline in patients with respiratory disease is unlikely to be due to an effect on respiratory muscle contractility.

\section{Aminophylline and skeletal muscle}

C BROPHY, A MIER, C LANIGAN, J MOXHAM, M GREEN Brompton Hospital, Fulham Road, London The effect of aminophylline on respiratory muscle strength and on the strength and endurance of the quadriceps muscle was studied in five normal subjects. Four male and one female (28-32 years) performed baseline measurements to establish reproducibility. Aminophylline was taken for several days to determine therapeutic dosage. Subjects then, in random order and double blind, took aminophylline or placebo for 3-5 days. A period on aminophylline followed, with double blind crossover to placebo or active drug for 3-5 days. At the end of each treatment period measurements were made and blood taken for aminophylline assay. Respiratory muscle strength was assessed from the best three of each of two sets of maximal static inspiratory and expiratory mouth pressures at residual volume and total lung capacity respectively, and from transdiaphragmatic pressure during 10 maximal sniffs. The best three maximal voluntary contractions (MVC) for each leg were measured, as was the 
time to fatigue for each quadriceps when contracting intermittently to 60\% MVC. Quadriceps strength increased with aminophylline but this was significant for the right leg only. No effect was seen on quadriceps endurance. There was a mean increase of $4.5 \%$ in respiratory muscle strength with aminophylline. Although small, this effect was statistically significant.

Exercise and 12 minute distance: their effect on the sternomastoid muscle

GB RHIND, GA GOULD, GJR MCHARDY Department of Respiratory Medicine, City Hospital, Edinburgh In bronchitics a 12 minute walk may fatigue the sternomastoid muscle (SMM), as assessed by the ratio of force produced by a $20 \mathrm{~Hz}$ stimulation to that from $50 \mathrm{~Hz}$ (20:50 ratio) (Wilson SH et al, Am Rev Resp Dis 1984). Theophylline may improve contractility of skeletal muscle. We have studied SMM function in 12 bronchitics (59-72 y; FEV 0.45-1.8 l) before and after (a) a 12 minute corridor walk (12MD) and (b) 50 head raises. One week later 12MD and spirometry were repeated. In a double blind parallel study of 14 days' sustained release choline theophyllinate (Sabidal-SR) or placebo, spirometry, 12MD and SMM tests were reassessed. Initial 20:50 ratio for the SMM was $79 \%$

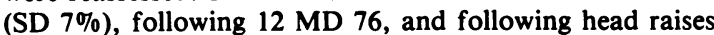
$66 \%(10 \%)$. Two patients after $12 \mathrm{MD}$, and eight after head raises had $>15 \%$ fall in the ratio, indicating fatigue. Six patients on placebo for 14 days showed no difference in either 12MD (924-925 m: NS) or 20:50 ratio after head raises (70-74\%: NS). The increase in $12 \mathrm{MD}(918-980 \mathrm{~m} ; 0.1$ $>p>0.05)$ and $20: 50$ ratio $(63-69 \%$ : NS) for those receiving theophylline was not significant. We conclude that SMM fatigue in bronchitics is unusual after an unencumbered 12 minute walk, and in this small sample there is no evidence that SMM fatigue is affected by theophylline.

Sternomastoid muscle function and fatiguability in patients with severe dyspnoea

J EFTHIMIOU, J FLEMING, RHT EDWARDS, SG SPIRO Department of Thoracic Medicine, University College Hospital, London In patients with severe breathlessness, the work of breathing is increased, and in this situation the respiratory muscles, particularly those of inspiration, may fatigue and result in the development or worsening of ventilatory failure. We studied 25 breathless patients with a variety of respiratory diseases, measuring fatigue and fatiguability in the sternomastoid muscle, using a portable, non-invasive electrical stimulation technique developed in this laboratory (Moxham et al, Clin Sci Mol Med 1980;59:463-68). Sternomastoid muscle fatiguability was assessed by measuring the maximum degree of fatigue and time course of its recovery following the performance of 50 head lifts. The patients were studied on at least two occasions (1) when first admitted to hospital and breathless at rest in bed; and (2) usually when their clinical state had improved, and they were less breathless. Sternomastoid muscle fatiguability was increased in breathless patients and improved in parallel with the patients' clinical course. Three $(12 \%)$ patients with severe respiratory disease had evidence of fatigue in the sternomastoid muscle on admission, and this was associated with a poor outcome. Respiratory muscle fatigue and increased fatiguability may play an important part in the development or worsening of ventilatory failure.

Regular exercise and the relationship of breathlessness to ventilation in cystic fibrosis

PA O'NEILL, M DODDS, J POOLE, B PHILIPS, AK WEBB Monsall Hospital, Manchester The influence of regular exercise on the relationship of breathlessness (B) to ventilation $(\dot{V})$ has not been studied previously. We have examined the effect of a training programme on 12 patients (seven male, five female, mean 17 years, range 8-27) with moderately severe cystic fibrosis. Exercise was undertaken each day for $11 \mathrm{~min}$ according to the Royal Canadian Air force protocol. Diary cards were kept and the programme was supervised. Pulmonary function and the responses to maximal exercise (bicycle ergometer) were determined before and after completion of the training. Breathlessness was assessed using visual analogue scales (VAS) and related to $\dot{v}$ during submaximal exercise on two occasions prior to training and at the end. Apart from a reduced RV (pre $1.5(0.9) 1$, post (1.0) $1(0.4) 1, p<0.05)$ all other indices of pulmonary function and exercise performance were unchanged. The patients' results were highly reproducible, $\dot{V}$ of $31.6 \mathrm{l} / \mathrm{min}$, VAS pre $26.7 \%$, post $12.9 \%, \mathrm{p}<0.01$. The relationship of the variables is therefore not fixed but can be favourably influenced by training with a consequent improvement in exercise tolerance.

Comparison of exercise performance and grading of dyspnoea in pulmonary and cardiac disease

ARH WARLEY, EM NICHOLSON, OC FINNEGAN, G LASZlo Respiratory Department, Bristol Royal Infirmary, Bristol A twelve minute walking test was used to compare the relationship between dyspnoea grade and disability in patients with cardiac disease (valvular or ischaemic; none of the patients was limited by angina pectoris) $(n=30)$, patients with chronic airflow limitation $(n=29)$ and normal subjects $(n=18)$. Patients assigned themselves to one of five grades depending on the severity of their dyspnoea (Fletcher et al, BMJ 1959;2:257-259). Within each grade of dyspnoea there was no significant difference in performance between the cardiac group and the pulmonary group. There was a significant $(p<0.001)$ correlation between vital capacity and performance in the walking test, which was similar in the two groups of patients. There was no correlation between vital capacity and performance in the normal subjects. We conclude that 1. Dyspnoea caused by cardiac disease is associated with comparable reductions in vital capacity to those resulting in similar degrees of disability caused by chronic airflow limitation. 2. Questionnaires about reduction of effort tolerance demonstrate similar degrees of disability in patients with cardiac disease and those with chronic airflow limitation. 
Small airways obstruction in sarcoidosis

P REEVE, NL LAPP, D SEATON, DR HALL, T COADY Ipswich Hospital, Suffolk The data on airways obstruction in sarcoidosis are contradictory. Levinson et al (Am J Med $1977 ; 62: 51)$ found increased upsteam resistance in 16 out of 18 patients with sarcoidosis, whereas DeTroyer (Bull Europ Physiopath Resp 1978;14:299) found normal upstream resistance in 14 patients with recently diagnosed sarcoidosis. However 11 of Levinson's 18 subjects and six of DeTroyer's 14 subjects were smokers. We have studied respiratory function and lung mechanics in 24 non-smokers with sarcoidosis of varying radiographic extent (four Stage I, four Stage II, seven Stage III and five Stage IV chest radiographs). Four further patients whose radiographs had reverted from Stages I or II to normal (0) were included. Radiographic Stage I patients had normal lung volumes and carbon monoxide transfer tests (TLCO, KCO), Stage 0 had normal lung volumes but reduced gas transfer. Stages II, III and IV had reduced lung volumes and gas transfer tests. Three of five patients with Stage IV and one of seven with Stage III had upstream resistance greater than two standard deviations above predicted. Mean upstream resistance was significantly higher in Stage IV $(p<0.05)$ than that found in Stages, I, II, III or 0 . We conclude that in non-smokers with sarcoidosis obstruction in the small airways is uncommon except in radiographic Stage IV.

\section{Reversible airways obstruction in sarcoidosis}

MT NOLAN, MX FITZGERALD Department of Respiratory Medicine, St Vincent's Hospital, Dublin Limitations in previous studies of airways obstruction in sarcoidosis include small or preselected patient populations, variability of definitions of airflow obstruction and lack of information concerning reversibility. We studied 62 consecutive patients with biopsy proved sarcoidosis and a wide spectrum of radiological abnormalities (sixteen stage 0 , nine stage 1 , eleven stage 2 , fourteen stage 3 and twelve stage 4) to determine the prevalence of airways obstruction. All patients were given a combined bronchodilator challenge with terbutaline sulphate and ipratroprium bromide to detect reversible airflow limitation. Airways obstruction, defined by the presence of two of the following: FEV $_{1} \leqslant 80 \%$ of predicted; PEFR $\leqslant 80 \%$ and FEV $_{1} /$ VC $\leqslant 75 \%$ of predicted, was present in 15 patients $(24 \%)$. The most striking findings were (1) the presence of concurrent airways obstruction in 11 of 12 patients with stage 4 fibrobullous disease and (2) a significant reversible component, defined as a $15 \%$ or greater response to bronchodilators in six of the 15 patients with airways obstruction, three of whom were known asthmatics, the other three being newly diagnosed during this study. Analysis of maximum expiratory flow volume curves as an index of small airways disease revealed only 3 additional obstructed patients not previously identified by routine spirometry. Atopic indices (positive skin prick tests and/or elevated serum IgE) were not more common in obstructed (7 of 15) than non-obstructed patients (19 of 47). However, those with obstruction were more likely to be smokers ( 9 of 15) than those without obstruction (15 of 47). Thus airways obstruction present in $24 \%$ of patients with sarcoidosis was most commonly associated with advanced fibro-bullous disease ( 7 of 15), asthma ( 2 of 15$)$, or both (4 of 15). The high prevalence of coincidental asthma and sarcoidosis has clear therapeutic implications.

Clearance of ${ }^{99} \mathrm{mTc}$ DTPA in sarcoidosis with and without pulmonary involvement

DK JONES, TW HIGENBOTTAM, J BAYLISS, R BARBER, P WRAIGHT, CDR FLOWER Department of Chest Medicine, Papworth Hospital, and Department of Nuclear Medicine, Addenbrooke's Hospital, Cambridge The half-time clearance from lung to blood (T1/2LB) of technetium $99 \mathrm{~m}$ labelled diethylene triamine pentacetate ( $99 \mathrm{mTc}$ DTPA) is accelerated in sarcoid induced interstitial lung disease (Rinderknecht et al, Am Rev Resp Dis 1980;121:105-117). T $1 / 2$ LB may correlate with the presence of inflammation in patients with asbestosis (Gellert et al, Thorax 1984;39:709) and is decreased in asbestos exposed subjects even when there is no radiological evidence of lung disease (Gellert $e t$ al, $\mathrm{Br} J$ Dis Chest 1985;79:37-42). We have studied 20 nonsmoking patients with sarcoidosis. Twelve (Group 1) had radiographic changes of interstitial lung disease while eight (Group 2) had hilar and/or mediastinal lymphadenopathy without pulmonary involvement. Overall T $1 / 2 \mathrm{LB}$, measured with a gamma camera, total lung capacity (TLC) and transfer factor (TLCO) were compared between the 2 groups using the $t$ test for unpaired data.

\begin{tabular}{lccc}
\hline & Group 1 & Group 2 & \\
\hline Mean T1/2LB (min, range) & $53(24-102)$ & $83(25-149)$ & $\mathrm{p}<0.05$ \\
\% predicted TLC (range) & $92(72-115)$ & $107(91-117)$ & $\mathrm{p}<0.01$ \\
\% predicted TLCO & $84(51-114)$ & $93(73-125)$ & $\mathrm{p}>0.2$ \\
\hline
\end{tabular}

These results show that T $1 / 2 \mathrm{LB}$ is decreased in sarcoidosis with interstitial lung disease and suggest that this test may be of more value than TLCO in detecting pulmonary involvement with sarcoidosis when the chest radiograph is normal.

\section{Lung permeability in adult obliterative bronchiolitis}

M SWEATMAN, R LAWRENCE, CFA PANTIN, M TURNERWARWICK Cardiothoracic Institute, London The clearance of technetium $99 \mathrm{~m}$ labelled diethylene triamine penta-acetate $(99 \mathrm{~m}$ Tc DTPA) with time from the lungs to the blood is described by mono-exponential curves with comparable half-times in normal subjects and patients with chronic generalised airways obstruction (Huchon et al, Am Rev Resp Dis 1984;130:457-460), and by a multiexponential curve with a fast initial clearance in patients with diseases with known involvement of the alveolarcapillary membrane (adult respiratory distress syndrome, cryptogenic fibrosing alveolitis (Pantin et al, Thorax 1984;39:709)). We measured $99 \mathrm{~m}$ Tc DTPA clearance from the lungs of 9 adults with obliterative bronchiolitis characterised by severe, irreversible airflow obstruction, minimal hyperinflation and substantial gas trapping. The chest radiographs were normal or showed typical vascular 
attenuation and mild hyperinflation. Eight patients had a mono-exponential clearance, with a range of half-time clearance (over 15 minutes) from lung ( $\left.T^{1} 1 / 2\right)$ of 35-103 minutes (normal range 30.5-109). One patient had increased clearance ( $T^{1 / 2} 26$ minutes). Adult obliterative bronchiolitis is characterised histologically by patchy bronchiolar stenosis or occlusion, without alveolar involvement, mucous gland hypertrophy or emphysema (Geddes et al, $Q$ J Med 1977;46:427-44). Normal clearance of $99 \mathrm{~m}$ Tc DTPA from the lungs of our patients supports the idea that there is no alveolar-capillary membrane involvement in this disease.

\section{Changes in pulmonary epithelial permeability in haemodialysis}

NG BELCHER, PJ REES Department of Respiratory Medicine, Guy's Hospital, London In early haemodialysis there is profound leucopenia. This is thought to be due to temporary sequestration of neutrophils. This appears to be caused at least partially by complement activation by the dialysis membrane. A similar mechanism of pulmonary sequestration of neutrophils by the activation of complement may also be involved in the pathophysiology of the adult respiratory distress syndrome (ARDS). In ARDS the permeability of the respiratory epithelium is markedly increased. We studied 12 patients to see if pulmonary sequestration of neutrophils during early haemodialysis was associated with changes in epithelial permeability. Alveolar capillary permeability was assessed by the half-time clearance from lung to blood of an aerosol of technetium $99 \mathrm{~m}$ labelled diethylene triamine pentacetic acid ( $\mathrm{T}^{1} / 2 \mathrm{LB},{ }^{99 \mathrm{~m} T c-D T P A) . ~ P r e d i a l y s i s ~ c l e a r a n c e ~ i n ~ n o n-~}$ smokers was significantly faster than non-smoking controls. There was no significant change in $\mathrm{T}^{1 / 2} \mathrm{LB} 99 \mathrm{~m} \mathrm{Tc}$ DTPA in early haemodialysis when the neutrophil count was lowest, but significantly longer $T^{1} 1 / 2 \mathrm{LB}$ values were found in the last hour of haemodialysis. This suggests: 1) In chronic renal failure removal of dialysable molecules is associated with a decrease in epithelial permeability. 2) Pulmonary sequestration of neutrophils on thier own does not affect epithelial permeability.

\section{Do cannabinoids depress respiration?}

S AHMEDZAI, R CARTER, RJ MILLS, F MORAN Department of Respiratory Medicine, Royal Infirmary, Glasgow Drugs derived from cannabis (cannabinoids) have been shown to exert depressant effects on respiration in most human and animal studies. We studied the ventilatory responsiveness to progressive hypercapnoea in seven normal non-smoking, cannabis naive volunteers, and arterial blood gases in eight patients with COAD and lung cancer, for six hours after a single oral $2 \mathrm{mg}$ dose of nabilone, a synthetic cannabinoid. Nabilone caused drowsiness, postural hypotension and reflex tachycardia in all subjects. In the normals, the slope of the $\dot{\mathrm{V}}_{\mathrm{E}} / \mathrm{P}_{\mathrm{ET}} \mathrm{CO}_{2}$ curves increased from baseline (mean (SEM) $1.87(0.18) 1 / \mathrm{mmHg}$ to $3.01(0.51)(\mathrm{p}<0.002)$, at four hours. The $\dot{\mathrm{V}}_{E} / \mathrm{P}_{\mathrm{ET}} \mathrm{CO}_{2}$ curves were shifted to the left at 3-4 hours. No changes were seen in control runs without nabilone. Baseline arterial blood gases in the patients were normal. At four hours, when most subjects were lightly sleeping, there was a significant reduction in $\mathrm{PaO}_{2}$ and a rise in $\mathrm{PaCO}_{2}$ measured in the supine position. However, all values remained in the normal range and on raising the patients these changes were abolished. In conclusion nabilone causes sedation without respiratory depression.

Exercise performance and carbon monoxide transfer factor in patients with carcinoma of the bronchus before and after lobectomy

PA CORRIS, AH KENDRICK, GJ GIBSON Department of Respiratory Medicine, Freeman Hospital, Newcastle upon Tyne Although lobectomy is commonly performed for carcinoma of the bronchus there is little information on the effect it has on exercise performance or CO transfer factor (TLCO) and transfer coefficient (KCO). We have studied 44 patients (36 men, eight women; mean age $56 \mathrm{y}$; mean preoperative $\mathrm{FEV}_{1} 76 \%$ predicted) using spirometry, single breath TLCO and a symptom limited progressive exercise test on a bicycle ergometer before and four months after lobectomy. Mean values of lung function at rest and maximum ventilation $\left(\dot{\mathrm{V}}_{\mathrm{E}} \mathrm{max}\right)$ and maximum oxygen consumption $\left(\mathrm{V}_{2}\right.$ max $)$ on exercise pre and post lobectomy were:

\begin{tabular}{|c|c|c|c|c|c|}
\hline & $\begin{array}{c}F E V_{I} \\
\text { \%predicted }\end{array}$ & $\begin{array}{c}T L C O \\
\text { \%predicted }\end{array}$ & $\begin{array}{c}\text { KCO } \\
\text { \%predicted }\end{array}$ & $\begin{array}{l}\dot{V} E \max \\
l \min ^{-1}\end{array}$ & $\begin{array}{l}\mathrm{VO}_{2} \max \\
1 \min ^{-1}\end{array}$ \\
\hline $\begin{array}{l}\text { PRE } \\
\text { POST }\end{array}$ & $\begin{array}{r}76.0 \\
* 64.0\end{array}$ & $\begin{array}{r}76.7 \\
.68 .7\end{array}$ & $\begin{array}{r}89.0 \\
* 94.5\end{array}$ & $\begin{array}{r}48.4 \\
-42.4\end{array}$ & $\begin{array}{r}1.54 \\
-1.29\end{array}$ \\
\hline
\end{tabular}

$* p<0.001$ (paired $t$ test)

Twenty-nine of the 44 patients had successful bronchoscopic assessments of lobar function using the single breath argon freon test (Thorax 1985;40:236). There were significant correlations between $\%$ preoperative function of the resected lobe and (1) decrease in $\mathrm{VO}_{2} \max$ $(r=0.76)$ (2) decrease in $\dot{V}_{E} \max (r=0.82)$ (3) decrease in TLCo $(r=0.8)$. We conclude that there are small but significant changes in both exercise performance and TLCO after lobectomy and the changes observed in an individual correlate well with the preoperative function of the resected lobe assessed at bronchoscopy.

Functional effects of laser therapy in malignant narrowing of the central airway

JJ GILMARTIN, D VEALE, BG COOPER, PM KEAVEY, GJ GIBSON, GN MORRITT Regional Cardiothoracic Centre, Freeman Hospital, Newcastle upon Tyne We have evaluated the functional effects of $\mathrm{CO}_{2}$ laser therapy in seven patients with tumours in the central airway. We used spirometry, maximum inspiratory and expiratory flow volume curves and a visual analogue scale of breathlessness (VAS, $0-100 \mathrm{~mm}$ ) to assess function before, at one day and 10 days after treatment. In four patients with tumour in right or left main bronchus, we estimated the change in the contribution of the affected lung to total ventilation and perfusion using ${ }^{131} \mathrm{Xe}$ and $99 \mathrm{~m} \mathrm{Tc}$ respectively. Five patients showed an improvement in their breathlessness and airway function at 
one day, whereas the other two patients deteriorated. By day 10 , however, all seven patients had improved from the pre-treatment level. Mean changes at 10 days were as follows:

\begin{tabular}{lccccc}
\hline & $\begin{array}{c}\text { FEV } \\
\text { \%predicted }\end{array}$ & $\begin{array}{c}\text { VEmax } 50 \\
\text { \%predicted }\end{array}$ & $\begin{array}{c}\text { VImax } \\
\text { \%opredicted }\end{array}$ & $\begin{array}{c}\text { PEF } \\
\text { \%predicted }\end{array}$ & $\begin{array}{c}\text { VAS } \\
\text { mm }\end{array}$ \\
\hline p (paired & +14.9 & +8.6 & +19.4 & +16.2 & -23.7 \\
$\mathrm{t}$ test) & $\mathrm{NS}$ & $<.05$ & $<.02$ & $<.05$ & $<.02$ \\
\hline
\end{tabular}

In all four patients with growth in either main bronchus the relative perfusion of the affected lung increased but only from a mean of $8 \%$ to $15 \%$ of total perfusion. We conclude that laser treatment improves airway function in tracheal and main bronchus tumours and in the latter there is an increase in both ventilation and perfusion of the diseased lung.

A comparison of nasal and tracheobronchial clearance using similar techniques in normal subjects

AB MILLAR, JE AGNEW, SP NEWMAN, MT LOPEZ-VIDRIERO, D PAVIA, SW CLARKE Departments of Thoracic Medicine and Medical Physics, Royal Free Hospital and Medical School, London Several investigators have measured nasal mucociliary clearance and compared it with trancheobronchial mucociliary clearance with varying results (Anderson I et al, Arch Env Health 1974; 29:290-293; Puchelle E et al, Clin Sci 1982;62:13-16). We have studied nasal and tracheobronchial clearance using comparable techniques. Ten healthy subjects were studied (mean (SEM)), age 28 (2) years; \% predicted FEV 121 (5); nine non-smokers, one ex-smoker, 0.6 pack years). $2 \mu \mathrm{m}$ teflon particles labelled with $99 \mathrm{~m}$ Tc were deposited on the inferior nasal turbinate using a pump device. Particle movement was monitored by gamma camera pictures at one minute intervals for $\mathbf{2 0}$ minutes. Comparing the position of the deposited particles to fixed markers, the rate of clearance was calculated, using a superimposed grid technique. Tracheobronchial clerance was measured for six hours after inhalation of $5 \mu \mathrm{m}$ polystyrene particles labelled with $99 \mathrm{~m}$ Tc. We calculated the area under the tracheobronchial clearance curve for each subject, which is inversely proportional to the mean rate of clearance. There is highly significant correlation between the area under the tracheobronchial clearance curve and the rate of nasal clearance $(r=-0.94, p<0.001)$.

Oxidation of $\alpha_{1}$-proteinase inhibitor: the effect of catalase and methionine sulfoxide-peptide reductase in vitro and in vivo

HM MORRISON, RA STOCKLEY The General Hospital, Birmingham Alpha $a_{1}$-proteinase inhibitor $\left(\alpha_{1} \mathbf{P I}\right)$ is present in lung secretions, where it regulates the potentially harmful proteolytic activity of neutrophil elastase (LE). Oxidation of the active site methionine residue renders it inactive against both $\mathrm{LE}$ and porcine pancreatic elastase (PPE). This may occur with exposure to cigarette smoke or various oxidants including hydrogen peroxide $\left(\mathrm{H}_{2} \mathrm{O}_{2}\right)$, but intracellular enzymes such as catalase and methionine sulfoxide-peptide reductase (MSR) may afford protection to $\alpha_{1}$ PI. We have investigated the effect of catalase on oxidation of $\alpha_{1} \mathrm{PI}$ in vitro and also of MSR both in vitro and in lung secretions, by determining PPE inhibitory capacity. Oxidative inactivation of $\alpha_{1} \mathrm{PI}$ by $\mathrm{H}_{2} \mathrm{O}_{2}(52.9 \%$ activity of native $\alpha_{1} \mathrm{PI}$ ) could not be reversed by addition of catalase, but pre-incubation of $\mathrm{H}_{2} \mathrm{O}_{2}$ with catalase protected $\alpha_{1}$ PI from oxidation $(94.9 \%$ activity of nantive $\alpha_{1}$ PI). In contrast, the addition of increasing amounts of MSR resulted in progressive reactivation of $\alpha_{1} \mathrm{PI}$ (from $5 \%$ to $99 \%$ activity of native $\left.\alpha_{1} \mathrm{PI}\right)$. Sputum sol-phase from bronchitic smokers inhibited a mean (SD) of 0.32 (0.27) moles PPE/mole $\alpha_{1}$ PI which increased to 0.58 (0.35) moles PPE/mole $\alpha_{1}$ PI following incubation with MSR. Similar results were obtained for non-smokers $\mathbf{0 . 3 2}$ (0.21) and $0.60(0.36)$ moles PPE/ mole $\alpha_{1} \mathrm{PI}$ without and with MSR respectively). These results show that catalase is effective in protecting $\alpha_{1}$ PI from oxidation in vitro and suggest that sputum from both smokers and non-smokers contains oxidised $\alpha_{1} \mathrm{PI}$ which is capable of reactivation. However, even following this approximately $40 \%$ of $\alpha_{1}$ PI remains inactive.

Cell profile and neutrophil chemotactic factor in lung lavage fluid from patients with chronic bronchitis or

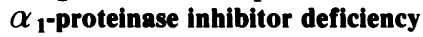

HM MORRISON, D SYKES, PJ COLE, RA STOCKLEY General Hospital, Birmingham and Brompton Hospital,

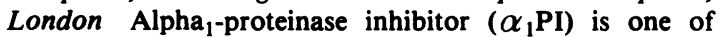
several proteins which protect the lung from attack by proteolytic enzymes. Patients with $\alpha_{1}$ PI deficiency often develop spontaneous emphysema, and also have low levels of serum neutrophil chemotactic factor (NCF) inactivator (Lam et al, Am Rev Resp Dis 1980;121:507-512). Since neutrophils contain a potent elastase and produce oxidants both of which can inactivate $\alpha_{1} \mathrm{PI}$, increased numbers of polymorphs in the lung may disrupt the "enzyme-inhibitor equilibrium" further in these patients. We have therefore compared cell profiles found in bronchoalveolar lavage (BAL) from 12 patients with chronic bronchitis (four current smokers) and five with $\alpha_{1}$ PI deficiency (four smokers and related them to NCF. More white cells were recovered from the $\alpha_{1}$ PI deficiency patients than the bronchitic group (mean (SD) $=1.4(1.3)$ and $0.4(0.24) \times$ $106 / \mathrm{ml}$ BAL respectively $-2 \mathrm{p}<0.01$ ) and of these, neutrophils composed $77.8 \%(18.4)$ of the differential count in the $\alpha_{1}$ PI deficient patients, but only $11.4 \%(22.9)$ in the bronchitic patients $(2 p<0.01)$. Moreover the absolute neutrophil count was greater in the $\alpha_{1}$ PI deficient group $(2 \mathrm{p}<0.01)$. Neutrophil chemotactic factor was identified in three of five bronchitics and four $\alpha_{1}$ PI deficient patients $(p>0.1)$. These results demonstrate that increased numbers of neutrophils can be lavaged from the lungs of $\alpha_{1}$ PI deficient patients compared to the bronchitic group. This may be of importance in the pathogenesis of $\alpha_{1}$ PI deficiency related emphysema. However, this is not clearly related to the presence of NCF in the lavage fluid. 
Inhibition of neutrophil elastase by sputum: variability and relationship to known inhibitors

RA STOCKLEY, HM MORRISON, JA KRAMPS, JH DIJKMAN, D BURNETT The Clinical Research Block, General Hospital, Birmingham and Department of Pulmonology, University of Leiden, Netherlands Neutrophil elastase (NE) has been implicated in the pathogenesis of many acute and chronic lung diseases. Studies of this enzyme and its inhibitors may thus provide an insight into the cause and management of such diseases. We have assessed the daily variability (five consecutive days) of inhibitory capacity of sputum solphase from six patients with chronic obstructive bronchitis using the pure enzyme and a synthetic chromogenic substrate (Succ (Ala) ${ }_{3}$ pNA). The average values for inhibitory capacity ranged from $167.9 \mu \mathrm{g} \mathrm{NE}$ inhibited/ml sputum (SD \pm 87.8) to 207.6 ( \pm 66.9). The between patients variability (coefficient of variation) ranged from $25.58 \%$ to $52.3 \%$ but was less within an individual (7.1-30.2). A similar degree of variability was found for the inhibitors measured: Anti-leucoprotease (ALP), $\alpha_{1}$ proteinase inhibitor $\left(\alpha_{1} \mathrm{PI}\right)$ and $\alpha_{2}$ Macroglobulin $\left(\alpha_{2} \mathrm{M}\right)$. The predominant inhibitor in molar terms was ALP accounting for between $82.4 \%( \pm 11.1)$ and $90.6 \%$ (5.3) of the recognised anti-elastase screen of the individual days. The contribution of $\alpha_{2} \mathrm{M}$ was negligible $(<0.5 \%$ any sample). However even when the molar concentrations of all measured inhibitors were taken into consideration only $50 \%$ of the inhibition of NE could be accounted for. This suggests the presence of further significant NE inhibitors that have yet to be characterised and hence affects our understanding of elastase induced lung disease.

The persistence of alveolar macrophages with smokers' inclusions after stopping cigarette smoking

RM AGIUS, RK KNIGHT, PJ COLE Cardiothoracic Institute and Brompton Hospital Bronchoalveolar lavage (BAL) specimens of cigarette smokers contain macrophages with inclusions (MI) but little is known about their persistence after stopping smoking. We performed BAL on 25 patients who had stopped smoking between five days and 34 years previously, 27 current smokers, and 16 who had never smoked. The BAL cells were stained with May-GrunwaldGiemsa and the \%MI counted (blind). The mean (SEM) \%MI was $11.5(2.5)$ in the ex-smokers, $18.0(2.5)$ in the smokers and $1.5(0.4)$ in the non-smokers. A negative correlation $(r=-0.40, p<0.05)$ existed between $\% \mathrm{MI}$ in the ex-smokers and time since stopping smoking. The correlation was stronger $(r=-0.54, p<0.01)$ when $\% \mathrm{MI}$ was corrected for the original daily cigarette consumption and regressed exponentially. At least 1000 days after stopping smoking had to elapse before the \%MI reached values for the non-smoking controls. These data suggest that MI are present long after stopping smoking and their kinetics warrant further study.

In vivo effects of different spleen suspensions on macrophage distribution and phenotype in the Kveim test

CS MUNRo, DN Mitchell, LW POULTER, PJ COLE Host Defence Unit, Department of Medicine, Cardiothoracic
Institute, and MRC Chest Diseases Unit, Brompton Hospital, and Department of Immunology, Royal Free Hospital School of Medicine, London To explore the mechanism of the Kveim test in sarcoidosis, we examined the effects of different spleen suspensions in vitro. Parallel tests on eight previously Kveim-positive subjects were carried out, using both an acceptable Kveim suspension and an identically prepared non-sarcoid spleen suspension. At two intervals (10-11 and 18-19 days) after injection, both test sites in each of four subjects were biopsied. Cryostat sections were studied, using histochemistry and monoclonal antibodies to characterise the cells of the macrophage lineage present. In all the responses to the non-sarcoid suspension, many activated macrophages, containing the lysosomal enzyme acid phosphatase (ACP), were seen, apparently migrating through the dermis. They were also recognised by anti-macrophage antibodies of broad reactivity (RFD2, Leu-M2) and anti-HLA-DR, and expressed the marker RFD7, which specifically identifies tissue macrophages. In contrast, the macrophage reaction to Kveim suspension remained localised in the dermis, and $\mathrm{ACP}+$ cells were confined to the immediate vicinity of the injection site. Although also RFD2 +, LeuM2 +, and HLA-DR +, they were mainly RFD7 negative. These findings suggest that Kveim suspensions cause inhibition of macrophage migration in vivo, and at the same time modulation of the expression of cell-associated antigens. Since epithelioid cells also have the phenotype RFD2 +, LeuM2 + , HLA-DR + , ACP + , RFD7 - , these effects may be important in the pathogenesis of the epithelioid granuloma.

The Kreim test induces a local cell-mediated response in normal but not Kreim positive subjects

CS MUNRO, DN MITCHELl, LW POULTER, PJ COLE Host Defence Unit, Department of Medicine, Cardiothoracic Institute, and MRC Chest Diseases Unit, Brompton Hospital, and Department of Immunology, Royal Free Hospital School of Medicine, London The Kveim test, which in many cases of sarcoidosis induces epithelioid granulomas structurally similar to lesions of the disease, can be used as a model of granuloma formation in man. We examined biopsies of developing Kveim responses at two, $10-12$, and 17-19 days after injection. At each interval, cryostat sections from eight previously Kveim-positive subjects and four healthy volunteers were studied, using histochemistry and immunohistology to identify mononuclear cells of lymphoid and non-lymphoid lineages, and their subsets. At two days, in all subjects, acidphosphatase-positive $(\mathrm{ACP}+)$ activated macrophages surrounded the injection site. There were also small perivascular mononuclear cell infiltrates, which in the normal subjects at the later stages had become large and dense, tending to surround the areas of ACP + macrophages. The immunohistological appearances of these infiltrates, which were composed of lymphocytes and accessory cells, suggested the development of a cellmediated immune response. In the sarcoid group at 10-12 and 17-19 days, however, perivascular infiltrates were absent or sparse, except in some of the subjects no longer Kveim-positive (3/8 and $4 / 8$ respectively). In these later 
stages, T-cells were seen in Kveim-positive subjects, but were scattered among groups of ACP + cells which may represent maturing epithelioid cells. Despite this presence of T-cells in developing granulomas, our findings suggest a concurrent failure of normal cellular-responses to allergeneic material in Kveim-positive subjects.

\section{Increased production of gamma interferon in sarcoidosis}

KC FLINT, AL POZNIAK, BN HUDSPITH, J BROSTOFF, DG JAMES, N MCI JOHNSON The Middlesex and Royal Northern Hospitals, London Sarcoidosis is characterised by the accumulation of $T$ helper lymphocytes at sites of disease activity with an increased local production of lymphokines. The peripheral anergy seen in this disease has been attributed to sequestration of these cells at such sites. Interferons inhibit the proliferative phase of the immune response in vitro and in vivo (Kadish et al, $J$ Exp Med 1980;151:637) and immune (gamma) interferon (IFN $\mathcal{Y}$ ) is a product of activated lymphocytes (lymphokine). We have therefore investigated the in vitro production of immunoreactive IFN by mitogen stimulated peripheral blood mononuclear cells and bronchoalveolar cells of 10 subjects with sarcoidosis and five controls. Cells were cultured at $5 \times 106 / \mathrm{ml}$ in RPMI 1640 plus $10 \%$ FCS with or without $10 \mu \mathrm{g} / \mathrm{ml}$ ConA for 48 hours. IFN $\mathcal{V}$ in cell culture supernatants was measured by radioimmuno-assay (Boots Celltech Diagnostics Ltd). In control subjects there was no spontaneous production of IFN by peripheral blood mononuclear cells but IFN $\mathcal{V}$ was produced in all cases after ConA stimulation (mean nine $\pm 2.4 \mathrm{iu} / 10^{6}$ cells). In contrast IFN $\mathcal{V}$ was produced spontaneously by peripheral blood mononuclear cells of nine of 10 subjects with sarcoidosis (mean $5 \pm 1.2 \mathrm{iu} / 10^{6}$ cells) and increased in all cases after mitogen stimulation (mean $126.2 \pm 47.2 \mathrm{iu} / 10^{6}$ cells). We found no significant difference in production of IFN $\mathcal{V}$ by bronchoalveolar cells from either group, whether spontaneously or after stimulation. Increased peripheral production of IFN $\mathcal{V}$ may explain the peripheral anergy of sarcoidosis.

Immunocompetent cells in BAL fluids reflect the cell populations in transbronchial biopsies in pulmonary sarcoldosis

DA CAMPBell, LW POULTER, G JANOSSY, RM DU BoIs Departments of Thoracic Medicine and Immunology, Royal Free Hospital, London Immunohistological analysis was performed on both cryostat sections from transbronchial biopsies (TBB) and BAL derived cytospin preparations, to determine whether the BAL reflected the inflammatory cell population identified in-situ in pulmonary sarcoidosis. Five patients underwent BAL and TBB for diagnosis of pulmonary sarcoidosis. Three control subjects underwent BAL. A heterogenous population of macrophages could be identified in both TBB and BAL. However, quantitative analysis revealed that these subpopulations were present in different proportions when BAL and TBB were compared. Analysis of the lymphoid population revealed a direct correlation between BAL and TBB. In both samples the $\mathrm{T} 4+/ \mathrm{T} 8$ + ratio varied from patient to patient, but were concordant between matched BAL and TBB specimens. The T4 + cells predominated in all sarcoid patients, and the level of HLA-DR expression on T-lymphocytes in BAL was significantly elevated in comparison with control subjects. We conclude that immunohistological analysis indicates that BAL accurately reflects the heterogeneity of the mononuclear inflammatory cell infiltrate in TBB from patients with pulmonary sarcoidosis. However, the biopsy also reveals the spatial organisation and interrelationships between macrophage and T-lymphocyte subsets in situ, which of fers insights into the immune response occurring in this condition.

The role of bronchoalveolar lavage in immunological monitoring after lung transplantation

J PEPPER, J KIRBY, J READER, L HUDSON St George's Hospital Medical School, London To distinguish lung rejection from infection in patients after heart-lung transplantation is difficult. At first a close concordance between rejection of heart and lungs was reported but recently rejection of lung has been observed in the absence of cardiac rejection. We used the unilateral canine lung transplant model to develop an assay for allospecific precursors of cytolytic T-lymphocytes (pCTL) in bronchoalveolar lavage (BAL) and peripheral blood (PB). In normal dogs the pCTL count was a mean of $1.4 \times 10^{-6}$ $\mathrm{L}^{-1}$ in $\mathrm{PB}$ and $1.2 \mathrm{ml}^{-1}$ in BAL. After a unilateral autograft these values did not vary significantly from their pre-operative levels. However, the count of donor-sepcific pCTL increased significantly after a unilateral allograft. The pCTL counts were $8 \times 10^{-6} \mathrm{~L}^{-1}$ in BAL recovered from unoperated lung and $116.0 \mathrm{ml}^{-1}$ in BAL from operated lung by post-operative day 12 . These changes preceded clinical evidence of rejection by five days. Estimation of allospecific lymphocyte precursors may be useful in the monitoring of rejection after heart-lung or lung transplantation.

\section{Bronchoalveolar lavage in silicosis}

G BORZONE, M DIAZ, J MENDOZA, J FABA, B GRAY University of Chile School of Medicine and King's College Hospital, London We have investigated the cells obtained by bronchoalveolar lavage (BAL) in 13 patients (mean $57 \pm$ eight years) with chronic exposure to silica-containing dust (mean exposure time: 30 years) and radiological evidence of silicosis. At the time of BAL, nine patients continued to be exposed to silica. BAL fluid showed increased cellularity, with 24 and $46 \times 10^{6}$ cells per $100 \mathrm{ml}$ in seven non-smokers and six smokers respectively (control values per $100 \mathrm{ml}$ : $8 \times 10^{6}$ in smokers). The differential count was normal, with $91 \%$ macrophages, $7 \%$ lymphocytes and $2 \%$ neutrophils. The total and differential cell counts were not significantly related to either radiological stage or exposure time. Particle-containing multi-nucleate macrophages were seen in all samples and quantitated by expressing cells having two or more nuclei as a percentage of 1000 macrophages. As a mean for the group, $8.5 \%$ of 
macrophages were binucleated, $1.7 \%$ had three nuclei, $1.9 \%$ had between four and eight nuclei and $0.3 \%$ had more than eight nuclei. Multinucleate macrophages have been described in BAL of hard metal workers (Davidson et al, Thorax 1983;38:119-128) but there was no evidence of exposure to hard metal in our group. In conclusion, BAL of this group of patients is characterized by: a) an increased cellularity, b) normal differential cell count and c) presence of multinucleate macrophages.

Macrophage like cells in BAL from patients with interstitial lung disease express abnormal phenotype

DA CAMPBELL*, RM DU BOIS, G JANOSSY, LW POULTER Departments of Immunology and Thoracic Medicine, Royal Free Hospital School of Medicine, London Bronchoalveolar lavage (BAL) was performed on six patients with sarcoidosis, five patients with idiopathic pulmonary fibrosis (IPF) and three healthy volunteers. Immunocytological studies of the macrophage tike cells obtained were performed to determine whether distinctive cell surface antigen phenotypes were present in these disorders (Poulter LW. Clin Exp Immunol 1983;53:513). Monoclonal antibodies (McAbs) that recognise antigens common to all macrophage like cells (RFD2, LeuM2) as well as McAbs which appear specific for interdigitating cells (RFD1) and mature macrophages (RFD7) were used, together with the cytochemical reaction for acid phosphatase. These studies revealed that:

1. Phenotypically distinct macrophage subpopulations were observed in BAL from all three groups studied, which are not seen in other normal tissues.

2. The proportion of these phenotypically distinctive cells was higher in the BAL from patients with interstitial lung disease (ILD).

3. No difference in macrophage subpopulations was observed between sarcoidosis and IPF patients.

We conclude that in ILD an increased proportion of macrophage-like cells in BAL express a phenotype not seen in other normal tissues. Cell-surface antigen expression, rather than being cell type-specific may reflect functional capacity or the local envrionmental influences upon the cell.

\section{The importance of iron in bleomycin-induced lung injury}

JG HAY, PL HASLAM, M TURNER-WARWICK, GJ LAURENT Cardiothoracic Institute, London Bleomycin is an important chemotherapeutic agent with serious respiratory adverse effects. To become active bleomycin needs to complex with ferrous iron and then bind oxygen (Burger RM et al, J Biol Chem 1981;256:11636-11644). This active species causes severe cellular injury in the presence of DNA. We have assessed acute lung injury in male Lewis rats 72 hours following intravenous (i.v.) injection of bleomycin by measuring total pulmonary extravascular albumen by a radioisotope technique. One $\mu \mathrm{mol}$ of iron in the form of haemoglobin or ferritin, or saline was placed into the lungs by intubation immediately after an i.v. injection of either bleomycin $5 \mathrm{mg}$ or normal saline. The results expressed as the relative radioactivity of ${ }^{125}$ I albumen in the lungs compared to $1 \mathrm{ml}$ of plasma 24 hours following i.v. injection of ${ }^{125} \mathrm{I}$ albumen are as follows:

\begin{tabular}{lc|c|c|c}
\hline & Control & Saline & Haemoglobin & Ferritin \\
\hline i.v. saline & $0.14(1.5)$ & & $0.15(1.6)$ & $0.16(2.9)$ \\
bleomycin & $0.16(3.8)$ & $0.18(3.8)$ & $0.33^{*}(10)$ & $0.28^{*}(15)$ \\
\hline
\end{tabular}

median values $\left(\mathrm{SD} \times 10^{-2}\right), \mathrm{n}=6$ in each group, $* \mathrm{p}=0.002$

Lung cells are well provided with reducing agents which are able to extract iron in its ferrous form from the carrier proteins. We conclude that iron plays an important role in lung injury. Redistribution of body iron to parenchymal sites as occurs in chronic disease, or bleeding into the lungs, may potentiate lung injury.

The role of oxygen in inducing acute lung injury following intravenous bleomycin

JG HAY, A DEWAR, B ADDIS, M TURNER-WARWICK, GJ LAURENT, PL HASLAM Cardiothoracic Institute, Fulham Road, London Bleomycin is a highly effective anti-neoplastic drug with serious respiratory adverse effects. Patients having surgery following bleomycin therapy have been noted to be at increased risk of developing acute pneumonitis, possibly as a consequence of exposure to oxygen. We have assessed lung injury in male Lewis rats by light and electron microscopic examination of their left lungs and bronchoalveolar cell profiles of their right lungs. Four groups of animals were studied $(n=6)$, the first group received i.v. saline, the second i.v. saline plus $85 \%$ oxygen for $\mathbf{4 8}$ hours, the third i.v. bleomycin $5 \mathrm{mg}$, and the fourth i.v. bleomycin $5 \mathrm{mg}$ plus oxygen as before. All animals were sacrificed at 72 hours. The only animals to develop histological abnormalities were those receiving bleomycin and exposed to oxygen. Patchy areas of alveolar wall oedema with intra-alveolar exudate were seen in all of these animals. Electron microscopy showed areas denuded of alveolar epithelium and necrotic endothelial cells. Lavage profiles were as follows, \% (SD)

\begin{tabular}{l|l|c|c}
\hline & Neutrophils & Lymphocytes & Macrophages \\
\hline saline & $0.2(0.3)$ & $1.1(0.7)$ & $98(1)$ \\
saline + oxygen & $11(6)^{*}$ & $1.1(1)$ & $86(7)$ \\
bleomycin & $0.9(1)^{*}$ & $1.3(2)$ & $97(3)$ \\
bleomycin + oxygen & $30(9)^{*}$ & $5.2(1)^{*}$ & $55(11.2)$ \\
\hline
\end{tabular}

$p=<0.002 *$, compared with saline ${ }^{\circ}$, compared with saline + oxygen.

This study confirms the clinical observation that oxygen exposure can produce acute lung injury following intravenous bleomycin.

\section{How does immunotherapy work in hay fever?}

AG FENNERTY, KP JONES, BH DAVIES Asthma Research Unit, Sully Hospital, Cardiff Immunotherapy, although an effective treatment for hay fever, has an unclear immunological mechanism. We have examined IgG blocking antibodies and an increase in suppressor $T$ cell function as explanations for its action. Seventeen patients underwent pollen immunotherapy for six months using purified Timothy grass antigen. Outcome was assessed 
using both nasal and conjunctival challenge. $T$ cell subsets (monoclonal antibodies) were measured and $\mathrm{T}$ suppressor cell function was assessed by the ability of lymphocytes incubated with histamine or concanavalin A to suppress thymidine uptake by autologous lymphocytes. Specific (S) IgE was measured in RAST units and S.IgG using a ELISA technique. Nine subjects improved objectively with treatment, compared with one out of 13 controls $(p<0.02)$. Pretreatment S.IgE levels did not differ significantly but treatment responders had a significantly higher mean (SD)

\section{Notices}

Conference on Sarcoidosis and Other Granulomatous Disorders

The Fifth European Conference on Sarcoidosis and Other Granulomatous Disorders will be held in Vienna from 27 to 30 August 1986. It will be preceded on 27 August by an international symposium on nuclear medicine in diseases of the lung. Details may be obtained from the Congress Secretariat, PO Box 9, A-1095 Vienna.

\section{Association of Surgeons of India conference}

The All India 46th annual conference of the Association of Surgeons of India will be held in Agra, the city of Taj Mahal, from 27 to 30 December 1986. Besides the general surgery section, there will be large sectional meetings on various specialties, including urology; oncology; and car-
S.IgE level:181 (118) $\mathrm{RU} / \mathrm{ml}$ compared with nonresponders: $56(81) \mathrm{RU} / \mathrm{ml}(\mathrm{p}<0.05)$ following therapy. Responders had a significantly higher pre-treatment S.IgG level:30 (7.3) EU/ml versus $18.4(4.9) \mathrm{EU} / \mathrm{ml}(\mathrm{p}<0.01)$ and post treatment S.IgG level $116(44)$ versus $54(50)(p<0.02)$, there was no significant difference in the S.IgG:S.IgE ratio however. No increase in $T$ suppressor cell numbers or function was found following therapy. Our study does not support a role for IgG blocking antibodies or $\mathrm{T}$ suppressor cells in the mechanism of immunotherapy.

diothoracic, plastic, orthopaedic, and paediatric surgery. Details may be obtained from the organising secretary, Professor BD Sharma, Surgery Department, SN Medical College, Agra 282 002, UP, India.

\section{Correction}

Ceftaxidime compared with gentamicin and carbenicillin in patients with cystic fibrosis, pulmonary pseudomonas infection, and an exacerbation of respiratory symptoms

In the paper by the British Thoracic Society Research Committee (May 1985;40:358-63), in the last paragraph of the first column on page 359 the carbenicillin dose should be $150 \mathrm{mg} / \mathrm{kg}$. In the flow diagram (p 360) we regret that the number with no pseudomonas in the initial specimen was printed as 8 instead of 10 . 